\title{
ÁCAROS EM ARECACEAE DA MATA ATLÂNTICA DO ESTADO DE SÃO PAULO, COM ÊNFASE NA FAMÍLIA STIGMAEIDAE (ACARI: RAPHIGNATHOIDEA)
}

\author{
Geraldo Pereira de Arruda Filho \\ Engenheiro Agrônomo
}

Orientador: Prof. Dr. GILBERTO JOSÉ DE MORAES

\begin{abstract}
Dissertação apresentada à Escola Superior de Agricultura "Luiz de Queiroz", Universidade de São Paulo, para obtenção do título de Mestre em Ciências, Área de Concentração: Entomologiạ.
\end{abstract}

PIRACICABA

Estado de São Paulo - Brasil

Março - 2002 


\title{
Dados Internacionais de Catalogação na Publicação (CIP) DIVISÃO DE BIBLIOTECA E DOCUMENTTAÇÃO - ESALQ/USP
}

\author{
Arruda Filho, Geraldo Pereira de \\ Ácaros em Arecaceae da mata atlântica do Estado de São Paulo, com ênfase na \\ família Stigmaeidae (Acari : Raphignathoidea) / Geraldo Pereira de Arruda Filho. - - \\ Piracicaba, 2002. \\ 89 p. : il. \\ Dissertação (mestrado) - - Escola Superior de Agricultura Luiz de Queiroz, 2002. \\ Bibliografia.
}

1. Acari 2. Biodiversidade 3. Mata Atlântica 4. Palmeiras I. Título

CDD 634.6 
A Deus pela oportunidade que me foi concedida e a toda minha familia, especialmente à minha esposa Carolina Maranhão Fernandes de Arruda e meu filho Geraldo Fernandes de Arruda, pela amizade, companheirismo, amor e dedicação. 


\section{AGRADECIMENTOS}

Ao Prof. Dr. Gilberto José de Moraes, pela orientação, confiança e respeito demonstrado durante nosso convívio.

Aos Profs. do Departamento de Entomologia, Fitopatologia e Zoologia Agrícola (ESALQ/USP), pela ajuda, colaboração no desenvolvimento deste trabalho e nas disciplinas no decorrer do Curso de Pós-Graduação.

Ao Prof. Dr. Carlos H. W. Flechtmann, pela colaboração na realização deste trabalho.

Ao Dr. E. A. Ueckermann pesquisador do Department of Agriculture and Water Supply da África do Sul pela colaboração na identificação dos ácaros da família Stigmaeidae e ao Dr. André Mattioli, pela colaboração na realização deste trabalho.

Ao Dr. Warren Calvin Welbourn do Florida Department of Agriculture and Consumer Services, pela identificação do ácaro Microtrombidiidae e confirmação dos gêneros de Anystidae, Cunaxidae e Eupodidae.

Ao Engenheiro Agrônomo Venésio Felipe dos Santos, estatístico da Empresa Pernambucana de Pesquisas Agropecuárias, pelo auxilio nas análises estatísticas. 
Ao Sr. Lázaro Vanderlei F. Silva e à Renata Angélica Prado Freire pela colaboração na triagem e montagem dos ácaros coletados.

A todos os colegas do curso de pós-graduação, em especial à equipe do Setor de Zoologia (Andréia, Aníbal, Antônio Carlos, Aloyseia, Cláudia, Cristiane, Denise, Edmilson, Jefferson, Gondim Jr., Juarez, Luís, Michele, Tatiane e Zacarias), pela amizade e companheirismo.

Ao Instituto Agronômico de Campinas pelo suporte técnico e logístico.

Ao CNPq (Conselho Nacional de Desenvolvimento Científico e Tecnológico) e PRONEX (Programa de Apoio a Núcleos de Excelência, Ministério da Cultura e Tecnologia) pelo suporte financeiro.

A toda a minha família, em especial aos meus pais, irmã, esposa e filho, que sempre me incentivaram no meu trabalho.

Este trabalho faz parte do Programa BIOTA/FAPESP - O Instituto Virtual da Biodiversidade (www.biotasp.org.br). 


\section{SUMÁRIO}

Página

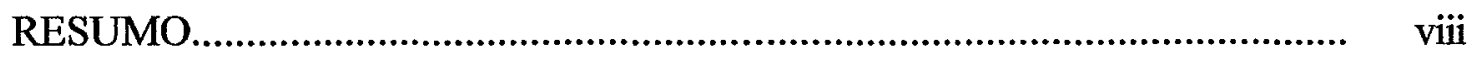

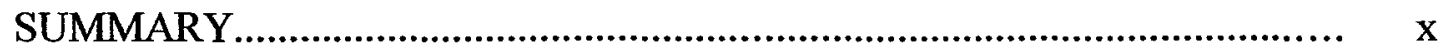

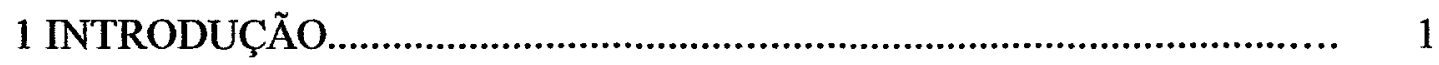

2 REVISÃO DE LITERATURA................................................................

2.1 Estudos de biodiversidade.......................................................................... 3

2.2 Arecaceae no Brasil.................................................................................... 4

2.3 Importância dos ácaros no ecossistema .................................................... 5

2.4 Ácaros em Arecaceae no Brasil.............................................................. 5

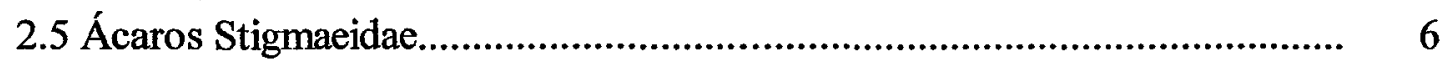

3 GRUPOS DE ÁCAROS (ARTHROPODA, ACARI) ENCONTRADOS

EM ARECACEAE DA MATA ATLÂNTICA DO ESTADO DE SÃO

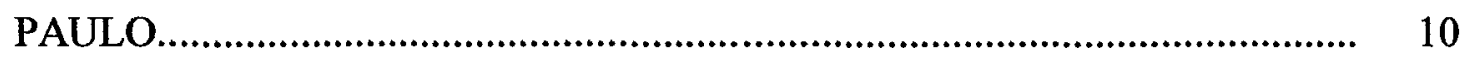

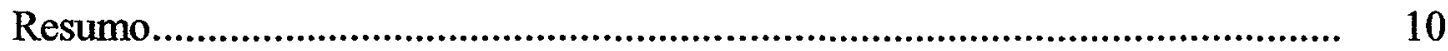

Summary................................................................................................. 11

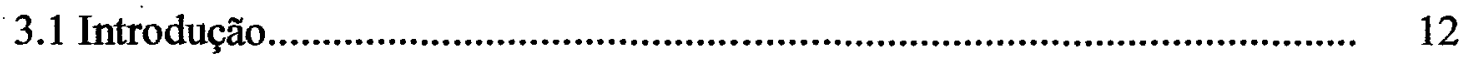

3.2 Material e Métodos............................................................................. 13

3.3 Resultados e Discussão............................................................................ 16

3.3.1 Diversidade de ácaros nas subordens encontradas................................... 18

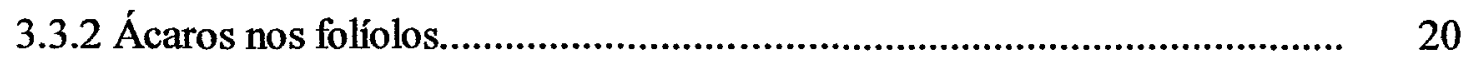

3.3.3Ácaros nas inflorescências.................................................................. 23

3.3.4 Ácaros nos frutos.......................................................................... 25 
3.3.5 Ácaros nos brotos terminais............................................................ 27

3.3.6 Gêneros dos ácaros encontrados.......................................................... 28

3.4 Conclusões............................................................................... 42

4 ÁCAROS STIGMAEIDAE (ACARI : RAPHIGNATHOIDEA) DE ARECACEAE DA MATA ATLÂNTICA DO ESTADO DE SÃO PAULO...... 44

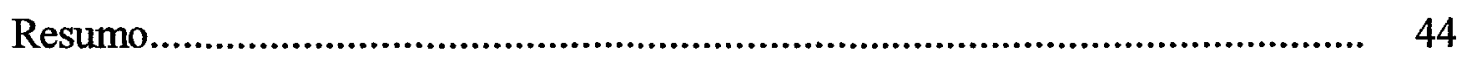

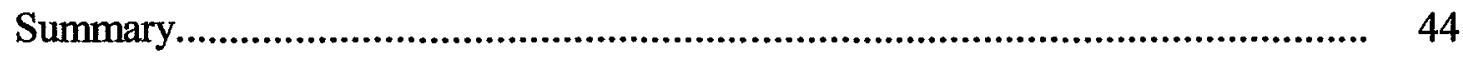

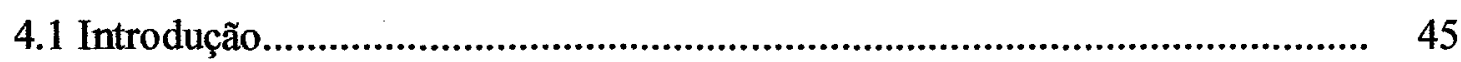

4.2 Material e Métodos.......................................................................... 48

4.3 Resultados e Discussão.............................................................................. 49

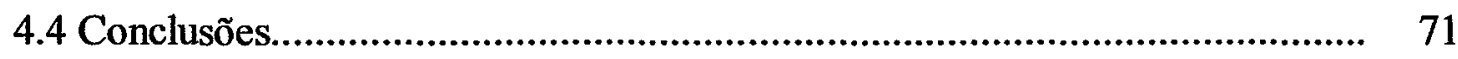

5 CONCLUSÕES GERAIS................................................................... 72

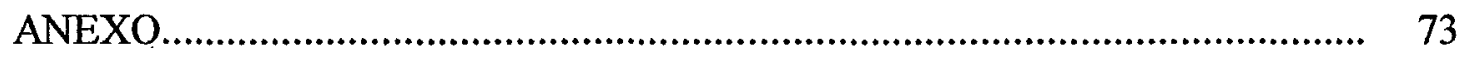

REFERÊNCIAS BIBLIOGRÁFICAS...................................................... 75 


\title{
ÁCAROS EM ARECACEAE DA MATA ATLÂNTICA dO ESTADO DE SÃo PAULO, COM ÊNFASE NA FAMÍLIA STIGMAEIDAE (ACARI: RAPHIGNATHOIDEA).
}

\author{
Autor: GERALDO PEREIRA DE ARRUDA FILHO \\ Orientador: Prof. Dr. GILBERTO JOSÉ DE MORAES
}

\section{RESUMO}

A diversidade de espécies de ácaros que ocorrem em palmeiras nativas da Mata Atlântica do Estado de São Paulo foi avaliada neste estudo, através de quatro coletas realizadas no ano 2000. Foram identificados os grupos de ácaros que ocorriam nas faces superior e inferior dos foliolos, nas flores, nos frutos e nos brotos terminais de cada uma das nove espécies vegetais amostradas. Os ácaros encontrados foram identificados até gênero ou espécie, exceto Eriophyoidea e Oribatida, que não foram identificados a níveis taxonômicos inferiores neste trabalho. Phytoseiidae foram encontrados em maior abundância e diversidade de espécies nos folíolos (tanto na face superior, quanto na face inferior destes). A segunda familia de ácaros predadores mais encontrada em folíolos foi Stigmaeidae. Foram encontradas 4 espécies desta família, sendo 2 novas para a Ciência. A espécie Agistemus floridanus Gonzalez foi redescrita com base nos diferentes estádios de desenvolvimento do ácaro. Uma chave dicotômica foi elaborada para auxiliar na identificação dos ácaros Stigmaeidae encontrados na Mata Atlântica do Estado de São Paulo. Os Ameroseiidae também foram encontrados em grande quantidade em inflorescências, principalmente das 
palmeiras Geonoma schottiana Mart. e Geonoma brevispatha Barb. Rodr.. Outros grupos de ácaros encontrados pertenciam às famílias Ascidae, Digamasellidae, Laelapidae e Uropodidae, na subordem Mesostigmata, Bdellidae, Cheyletidae, Cunaxidae, Eupodidae, Microtrombidiidae, Raphignathidae, Tarsonemidae, Tenuipalpidae, Tetranychidae e Tydeidae, na subordem Prostigmata, e Acaridae, Histiostomatidae e Winterschmidtiidae, na subordem Astigmata. Poucos exemplares de Metastigmata também foram encontrados. 


\title{
MITES ON ARECACEAE OF THE ATLANTIC FOREST OF THE STATE OF SÃO PAULO, WITH EMPHASIS ON THE FAMILY STIGMAEIDAE (ACARI: RAPHIGNATHOIDEA).
}

\author{
Author: GERALDO PEREIRA DE ARRUDA FILHO \\ Adviser: Prof. Dr. GILBERTO JOSÉ DE MORAES
}

\section{SUMMARY}

The diversity of mites species on native palm trees of the State of São Paulo was evaluated in this study, based on four samplinge conducted in the year 2000 . Mites were sampled separetely on the lower and upper surface of leaflets, flowers, fruits and terminal shoots of each of the nine palm species evaluated. Mites were identified to genus or species level, except for Oribatida and Eriophyoidea. Phytoseiidae were the most abundant and diverse group on the folioles (both on flower and upper surfaces). Stigmaeidae were the second most common mites on the folioles. Four species of this family were found, two of which are described as new species. Agistemus floridanus Gonzalez is redescribed based on all mobile stages of the development. A dicotomus key were prepared to help in the identification of the Stigmaeidae mites known in the Atlantic Forest of the State of São Paulo. Ameroseiidae were found in large numbers in the inflorescences, especially of the Geonoma schottiana Mart. and Geonoma brevispatha Barb. Rodr.. Other mite groups found belonged to the families Ascidae, Digamasellidae, Laelapidae, Uropodidae, in the suborder Mesostigmata, Bdellidae, Cheyletidae, Cunaxidae, Eupodidae, 
Microtrombidiidae, Raphignathidae, Tarsonemidae, Tenuipalpidae, Tetranychidae, Tydeidae in the suborder Prostigmata and Acaridae, Histiostomatidae, Winterschmidtiidae in the suborder Astigmata. A few Metastigmata were also found. 


\section{INTRODUÇÃO}

Arecaceae é uma família de plantas monocotiledôneas pertencentes à ordem Principes, vulgarmente chamadas de palmeiras. A maioria dos representantes desta família é constituída por plantas lenhosas que podem atingir tamanhos consideráveis, com flores pequenas reunidas em grandes inflorescências axilares. As flores nascem protegidas por uma ou várias brácteas grandes. Freqüentemente, flores de ambos os sexos são encontradas separadamente em uma inflorescência; em algumas espécies, são encontradas flores de um único sexo em cada planta. Geralmente, o fruto é seco e do tipo drupa, podendo às vezes ser carnoso. A semente apresenta endosperma abundante $\mathrm{e}$ em geral oleaginoso. Essa família é essencialmente tropical, ocorrendo em todo mundo. O número de gêneros e espécies nesta família é de aproximadamente 236 e 3400 , respectivamente (Joly,1991).

Ácaros são organismos do filo Arthropoda, subfilo Chelicerata, classe Arachnida e subclasse Acari. As espécies de ácaros são agrupadas em 2 ordens, 7 subordens e cerca de 400 famílias (Flechtmann \& Moraes, 1999). Os ácaros são separados facilmente dos insetos, seus principais concorrentes no usufruto e domínio de diversos ecossistemas, por geralmente apresentarem 4 pares de pernas nos estágios pós-larvais; as larvas têm usualmente 3 pares de pernas. De modo geral, apresentam corpo compacto, sem nenhuma segmentação. Rivalizam com os insetos em número de espécies e variedades de hábitats que ocupam (Borror \& DeLong, 1969).

Biodiversidade é o termo utilizado para definir a variabilidade de organismos vivos, em relação à diversidade taxonômica ou de espécies, diversidade de ecossistemas e diversidade genética (Gaston, 1996). Para se conhecer a biodiversidade de qualquer 
grupo, é necessário a determinação das espécies que o constituem. Entretanto, a diversidade de espécies de ácaros em plantas da família Arecaceae ainda é pouco conhecida no Brasil. Foram relatados em palmeiras, representantes das famílias Tetranychidae e Tenuipalpidae (Ferreira, 1997; Flechtmann, 1997b; Santana \& Flechtmann, 1998). Além destes, trabalhos específicos da superfamília Eriophyoidea têm sido desenvolvidos (Flechtmann, 1989, 1994, 1997, 1998; Gondim Jr. et al., 2000). As seguintes espécies de eriofidios foram relatadas sobre estas plantas no Brasil: Aceria guerreronis Keifer em Cocus nucifera L. (Aquino \& Arruda, 1967) e Lytocarium weddelianum (H. Wendl.) Tol. (Flechtmann, 1989), Amrineus cocofilus Flechtmann em C. nucifera (Flechtmann, 1994), Notostrix attenuata Keifer em C. nucifera (Flechtmann \& Santana, 1997), Notostrix exigua Flechtmann em Euterpe edulis Mart. (Flechtmann, 1989); Notostrix jamaicae Keifer em C. nucifera (Santana \& Flechtmann, 1998), Rhynacus palmeus Flechtmann em Syagrus romanzoffiana (Cham.) Glassman (Flechtmann, 1998) e Retracrus johnstoni Keifer em C. nucifera e S. romanzoffiana (Santana et al., 1994). Gondim Jr. (2000) encontrou cerca de 62 espécies de ácaros em folíolos de 24 espécies de Arecaceae nativas e 13 espécies de Arecaceae exóticas na Mata Atlântica dos Estados de São Paulo e Pernambuco, pertencentes a 12 familias. Este número ainda parece pequeno, se considerarmos que mais de 400 espécies de palmeiras são encontradas no Brasil.

Este trabalho teve por objetivo estudar a composição faunistica da subclasse Acari em Arecaceae nativas da "Mata Atlântica" do Estado de São Paulo, com atenção particular aos ácaros da família Stigmaeidae, cujos representantes encontrados neste estudo foram identificados até espécie. 


\section{REVISÃO DE LITERATURA}

\subsection{Estudos de biodiversidade}

A biodiversidade tem sido bastante reduzida nos últimos anos, devido em parte às práticas agrícolas em extensas áreas, que correspondem à intervenção cada vez maior do homem no ambiente, em busca de produções cada vez maiores de produtos agrícolas, a qualquer custo, segundo Altiere ${ }^{1}$ citado por Gondim Jr. (2000).

A degradação do ambiente, em larga escala, causada pela atividade humana pode eliminar um grande número de espécies, deixando amplas áreas biologicamente empobrecidas (Myers, 1996).

Para se estudar a biodiversidade, deve-se também analisar as interações dos diversos componentes bióticos do ecossistema, que se mantém naturalmente em equilíbrio. A adoção de práticas agrícolas sustentáveis pode ser facilitada pelo conhecimento da biodiversidade do ecossistema. Tal conhecimento pode auxiliar na avaliação do potencial de cada espécie em se tornar praga ou agir como agente de controle natural, além de possibilitar a previsão do impacto que tais espécies podem causar ao ambiente. Cada espécie desempenha um papel dentro do sistema, como inimigo natural de outros ácaros, insetos, outros animais ou plantas daninhas, como presa alternativa para diferentes grupos de predadores, ou ainda como praga de plantas (Flechtmann \& Moraes, 1999).

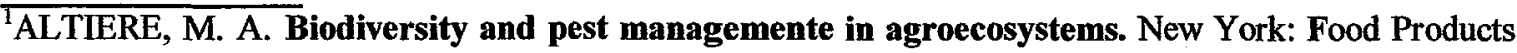
Press, 1994. 185p.
} 


\subsection{Arecaceae no Brasil}

A maior diversidade de espécies de arecáceas ocorre na Ásia, Ilhas do Pacífico e América (Lorenzi, 1996). Embora não seja a maior família em número de espécies, as arecáceas possuem uma enorme variabilidade morfológica (Evans, 1995). No Brasil, já foram assinaladas 132 espécies nativas e 152 exóticas (Lorenzi, 1996).

Diversas Arecaceae são de grande importância econômica pelos diferentes produtos que podem oferecer. Lorenzi (1996) cita as diversas utilidades de produtos ou partes de palmeiras nativas do Brasil. Do coqueiro, os frutos são extensamente comercializados para o consumo de "água de coco". A polpa pode ser utilizada para consumo direto, ou para produção de óleo comestível. As fibras são utilizadas na indústria automotiva.

O tucum (Bactris e Astrocarium) fornece material para tecelagem (Joly, 1991). As folhas são utilizadas na construção de habitações ou para a extração de cera, encontrada em maiores concentrações nas folhas jovens.

A carnaúba (Copernicia prunifera (Miller) H. E. Moore) é encontrada desde a Bahia até o Maranhão, principalmente nos Estados do Piaú e Ceará. Possui grande potencial paisagístico e madeira forte. As fibras das folhas são muito utilizadas na produção de artesanato. O principal produto da carnaúba é a cera extraída de suas folhas.

A juçara (E. edulis) é uma espécie de ampla distribuição ao longo do litoral brasileiro, ocorrendo naturalmente desde o sul da Bahia até o Rio Grande do Sul (Lorenzi, 1996). É uma planta com diversas aplicações em construções rurais, podendo ainda ser utilizada na produção de papel e celulose. Seu produto mais nobre é o palmito, utilizado na alimentação humana (Furia, 1993).

$\mathrm{O}$ açaí (Euterpe oleracea Mart.) e a pupunha (Bactris gasipaes Kunth.) também são utilizados para obtenção de palmito. $\mathrm{O}$ açai é uma palmeira rústica, originária da Amazônia (Lorenzi, 1993). O uso desta planta é bastante extenso. A raiz é utilizada como vermífugo, enquanto o estipe tem grande utilidade nas construções rurais e os frutos são bastante utilizados na alimentação (Jardim \& Anderson, 1987). A pupunha 
também é originária da Amazônia, e tem sido extensivamente cultivada nos dias atuais, para a extração do palmito.

Muitas arecáceas são utilizadas em projetos paisagísticos, na criação de ambientes de aspecto tropical (Lorenzi, 1996).

\subsection{Importância dos ácaros no ecossistema}

Os ácaros constituem um grupo de pequenos invertebrados que podem ser encontrados praticamente em todos os locais onde é possível a vida animal (Flechtmann, 1972). Representantes de diferentes grupos de ácaros têm sido encontrados nos mais diversos ecossistemas terrestres e aquáticos. $\mathrm{O}$ número total de espécies destes organismos encontrados em todo o mundo foi estimado em cerca de 35000 (Krantz, 1978).

Como acontece com diversos grupos de organismos, também entre os ácaros são encontradas diversas formas de vida. Quanto à alimentação, estes podem ser fitófagos, saprófagos, coprófagos, necrófagos, parasitos e predadores (Krantz, 1978). Muitos dos predadores alimentam-se de ácaros que danificam as plantas, desempenhando importante função no equilíbrio ecológico (Moraes, 1992; 2002). Vários ácaros são pragas responsáveis por muitos danos a plantas cultivadas em todo o mundo (Jeppson et al., 1975). O conhecimento das espécies presentes em um determinado ecossistema é o primeiro passo no entendimento do papel das espécies de ácaros como organismos prejudiciais.

\section{4 Ácaros em Arecaceae no Brasil}

A diversidade de espécies de ácaros que ocorrem em arecáceas no Brasil ainda é pouco conhecida. Dentre os ácaros fitófagos encontrados sobre estas plantas, a maior diversidade encontra-se na superfamília Eriophyoidea (Gondim Jr. et al., 2000). Este é o grupo mais estudado, tendo sido tratado em diversos trabalhos específicos. 
$\mathrm{O}$ ácaro A. guerreronis, causador da necrose e queda de frutos em coqueiro, foi o primeiro eriofideo relatado em palmeiras no Brasil, no Estado do Rio de Janeiro (Robbs \& Peracchi, 1965). Em seguida, este ácaro foi relatado no Estado de Pernambuco, causando a necrose do "olho do coqueiro" (Aquino \& Arruda, 1967). A. guerreronis é responsável pela depreciação dos frutos do coqueiro e em casos de ataques severos, até por queda de frutos. Segundo Ferreira (1987), A. guerreronis pode ocasionar a morte de plântulas de C. nucifera. Entretanto este dano, que até alguns anos atrás era muito comum no Estado de Pernambuco, por alguma razão, hoje não é mais observado de acordo com Arruda. ${ }^{2}$

Outros trabalhos foram publicados sobre a presença da superfamília Eriophyoidea em palmeiras no Brasil (Flechtmann, 1989; 1994; 1997a; 1998; Flechtmann \& Santana, 1997; Santana \& Flechtmann, 1994; 1998). Além destes, têm sido também relatados nestas plantas ácaros fitófagos das familias Tetranychidae e Tenuipalpidae (Ferreira, 1997; Flechtmann, 1997b; Santana \& Flechtmann, 1998). Associados aos ácaros fitófagos, também têm sido relatados ácaros predadores das familias Phytoseiidae, Bdellidae, Cunaxidae, Raphignathidae, Ascidae, Cheyletidae e Stigmaeidae (Flechtmann, 1967; Gondim Jr. \& Moraes, 2001).

\section{5 Ácaros Stigmaeidae}

Os Stigmaeidae são citados como predadores bastante abundantes em determinadas plantas (Smiley \& Knutson, 1983). Algumas espécies de Stigmaeidae dos gêneros Agistemus Summers e Zetzellia Oudemans têm sido relatadas como predadoras de ácaros fitófagos das familias Eriophyidae, Tetranychidae e Tenuipalpidae (Hoyt, 1969; Laing \& Knop, 1983; Santos \& Laing, 1985). O ácaro Agistemus longisetus Gonzalez, alimenta-se de ovos e estágios ativos de ácaros fitófagos que infestam a cultura da maçã na Nova Zelândia (Collyer, 1964).

\footnotetext{
${ }^{2}$ ARRUDA, G. P. de. (Empresa Pernambucana de Pesquisas Agropecuárias). Comunicação pessoal, 2000.
} 
Agistemus exsertus Gonzalez foi assinalado como predador de Panonychus citri (McGregor) em citros no Japão (Laing \& Knop, 1983) e outros ácaros fitófagos na cultura da maçã no Egito (Zaher et al., 1971). Em laboratório, este ácaro tem demonstrado que se alimenta muito bem do eriofideo Aculops lycopersici (Massee) (Osman \& Zaki, 1986). Segundo Woolhouse \& Harmsen (1984), o ácaro Zetzellia mali Ewing controla melhor a população do eriofideo Aculus schlechtendali (Nalepa) que outros predadores em Ontário, Canadá, além de ser tolerante aos inseticidas e fungicidas comumente utilizados naquela região, na cultura da maçã. Os tetraniquídeos Tetranychus urticae Koch e Tetranychus canadensis (Mc Gregor) são ocasionalmente fontes de alimento para o Z. mali em maçã, no mesmo país (Hoyt, 1969; White \& Laing, 1978). O ácaro Zetzellia graeciana Gonzalez foi citado como predador de Panonychus ulmi (Koch) em plantações de uva e maçã na Sicilia (Inserra, 1970). Dosse (1967) descreveu a espécie Agistemus faneri que se alimenta de tetraniquídeos no Líbano. Agistemus africanus (Meyer \& Ryke) é citado como predador de P. ulmi em maçã na África do Sul (Laing \& Knop, 1983). Uma correlação negativa entre os ácaros das familias Stigmaeidae e Phytoseiidae tem sido constatada em citros, no Estado de São Paulo de acordo com $\mathrm{Sato}^{3}$. Com a redução da população de Phytoseiidae, devido ao uso de produtos químicos, tem se verificado que a população de Stigmaeidae aumenta e a população do eriofídeo Phyllocoptruta oleivora (Ashmead) diminui. Não se conhece ainda exatamente a causa desta observação. Parece, entretanto, que isto se dá em função da interação entre ácaros Phytoseiidae e Stigmaeidae.

Alguns Stigmaeidae apresentam um comportamento eficiente no controle de Brevipalpus phoenicis (Geijskes), limitando a reprodução desses ácaros em cultura de chá na Indonésia (Oomen, 1982). Ferla (2001) estudou a biologia de Agistemus floridanus Gonzalez coletado em seringueira (Hevea brasiliensis Muell. Arg.) no Estado do Mato Grosso, concluindo que este ácaro pode ser mais importante para o controle de Calacarus heveae Feres e Tenuipalpus heveae Baker do que outros predadores encontrados no mesmo substrato.

\footnotetext{
${ }^{3}$ SATO, M.(Instituto Biológico). Comunicação pessoal, 2000.
} 
A familia Stigmaeidae pertence à subordem Prostigmata. De modo geral, os representantes desta família apresentam alguns escudos dorsais e coloração geralmente alaranjada, amarelada, esverdeada ou avermelhada (Flechtmann, 1975). O palpo apresenta o chamado complexo "unha - dedão". As coxas I e II são distintamente separadas das coxas III e IV. As quelíceras apresentam os dígitos móveis transformados em estiletes. Não apresentam escudos ventrais, e o ânus e a genitália são contíguos (Krantz, 1978). Os ácaros desta família se assemelham muito aos da família Eupalopsellidae, diferindo por apresentarem as bases das quelíceras totalmente livres, ou apenas parcialmente fundidas ao longo da linha mediana, e por possuírem o tarso do palpo relativamente curto (Flechtmann, 1975).

A familia Stigmaeidae é relativamente pequena quando comparada com Phytoseiidae, a família mais abundante de ácaros predadores plantícolas. Até 1990, eram conhecidos 24 gêneros e 314 espécies de Stigmaeidae (Sepasgosarian, 1990). Os gêneros citados por Sepasgosarian, (1990) foram: Agistemus Summers, Cheylostigmaeus Willmann, Eryngiopus Summers, Erynglupusopsis Tseng, Eustigmaeus Oudemans, Ledermuelleriopsis Willmann, Macrostigmaeus Oudemans, Mecognatha Wood, Mediolata Canestrini, Mendanaia Wood, Mullederia Wood, Parastigmaeus Kuznetzov, Paravillersia Kuznetzov, Pilonychiopus Meyer, Postumius Kuznetzov, Prostigmaeus Kuznetzov, Pseudostigmaeus Wood, Stigmaeus Koch, Storchia Oudemans, Summersiella Gonzalez, Villersia Oudemans, Villersiella Willmann, Zetzellia Oudemans e Zetzelliopsis Willmann. Gerson \& Meyer (1995) descreveram o gênero Neilstigmaeus. Matioli (2002) elaborou uma chave para identificação das espécies de Stigmaeidae que ocorrem em citros na qual é citado o gênero Makilingeria Rimando \& Corpuz-Raros.

Gonzalez (1965) publicou uma chave para as espécies de Stigmaeidae dos gêneros Mediolata, Zetzellia e Agistemus do continente americano. Summers (1966) publicou uma chave para identificação dos gêneros de Stigmaeidae conhecidos em todo mundo. Meyer (1969) publicou uma chave para identificação de gêneros e espécies de Stigmaeidae da África do Sul. Por se referir esta última publicação a um país de condições climáticas semelhantes às de extensas regiões do Brasil, aquele trabalho é de grande importância para os trabalhos de taxonomia de Stigmaeidae em nosso país. 
Alguns relatos de representantes da família Stigmaeidae têm sido publicados no Brasil. A maioria dos trabalhos foi realizada no Estado de São Paulo. Flechtmann (1968, 1981) relatou os seguintes Stigmaeidae: Agistemus sp., Eustigmaeus (=Ledermuelleria) sp. e Zetzellia sp., Storchia navicella (Grandjean), Storchia pacificus (Summers), Eustigmaeus (=Ledermuelleria) microsengnis (Chaudri) e Stigmaeus constrictus Summers em diferentes áreas do Estado de São Paulo. Vila \& Flechtmann (1970) relataram alguns gêneros de ácaros em essências florestais, incluindo Eustigmaeus (=Ledermuelleria), Macrostigmaeus, Muellederia e Zetzellia. Chiavegato $(1971,1972)$ assinalou a presença de Agistemus sp.. Flechtmann (1985) descreveu a espécie, Eustigmaeus brionemus, coletado no município de Campinas. Feres (1993) assinalou a presença de Agistemus sp. em seringueira e em plantas silvestres, enquanto Feres (2000) citou a ocorrência de Zetzellia sp. Mineiro (2000), trabalhando com ácaros edáficos no Município de Piracicaba, encontrou 4 espécies do gênero Eustigmaeus (=Ledermuelleria). As espécies de Stigmaeidae relatadas no Estado de São Paulo foram sumarizadas na base de dados para os ácaros daquele Estado, publicada por Flechtmann \& Moraes (2000). Flechtmann (1995) publicou um trabalho sobre os ácaros coletados no Rio de Janeiro, no qual descreveu Agistemus tarsilobus. Ferla \& Moraes (1998) citaram a ocorrência de Agistemus sp. e Eustigmaeus sp. em pomares de maçã no Rio Grande do Sul. 


\section{GRUPOS DE ÁCAROS (ARTHROPODA, ACARI) ENCONTRADOS EM ARECACEAE DA MATA ATLÂNTICA DO ESTADO de SÃo PAULO.}

\section{Resumo}

Este trabalho relata 96 espécies de ácaros pertencentes a 54 gêneros de 22 familias e 4 subordens (Prostigmata, Mesostigmata, Astigmata e Metastigmata) encontradas em inflorescências, frutos, brotos terminais e folíolos de 9 espécies nativas de Arecaceae da Mata Atlântica do Estado de São Paulo, nos municípios de Cananéia, Pariquera-Açu, Piracicaba e São Pedro. As coletas foram realizadas nos meses de janeiro e fevereiro (verão), abril e maio (outono), julho e agosto (inverno) e outubro e novembro (primavera). Maior quantidade de ácaros foi encontrada em abril e maio. A maioria dos ácaros foi coletada nas inflorescências (50,2\% dos indivíduos coletados). Mesostigmata foi a mais abundante, representando $62,4 \%$ dos ácaros coletados (Eriophyoidea $\mathrm{e}$ Oribatida não foram considerados neste estudo). Prostigmata foi a subordem mais diversa (13 famílias). Ameroseiidae foi a família mais numerosa ( $49,2 \%$ dos ácaros coletados); mais de $99 \%$ dos representantes desta familia foram encontrados em inflorescências de Geonoma brevispatha Barb. Rodr. e Geonoma schottiana Mart.. Phytoseiidāe foi a segunda família mais numerosa ( $11,2 \%$ dos ácaros coletados), sendo a mais abundante em folíolos. 


\section{MITES GROUPS (ARTHROPODA, ACARI) FOUND ON ARECACEAE IN THE ATLANTIC FOREST OF THE STATE OF SÃo PAULO.}

Summary

This work reports 96 mite species belonging to 54 genera in 22 families and 4 suborders (Prostigmata, Mesostigmata, Metastigmata and Astigmata) found on inflorescences, fruits, terminal shoots and foliage of native Arecaceae plants in the Atlantic Forest of the State of São Paulo, in Cananéia, Pariquera-Açu, Piracicaba and São Pedro. Samplings were conducted in January and February (summer) April and May (fall), July and August (winter) and October and November (spring). Mites were more numerous in the fall. The majority of the mites were found in the inflorescences $(50,2 \%$ of the mites collected). Mesostigmata was the most abundant suborder, representing $62,4 \%$ of the mites collected (Eriophyoidea and Oribatida were not considered in this study). Prostigmata was the most diverse suborder (13 families). Ameroseiidae was the most numerous family $(49,2 \%$ of the mites collected); more than $99 \%$ of the mites of this family were found in the inflorescences of Geonoma brevispatha Barb. Rodr. e Geonoma schottiana Mart.. Phytoseiidae was the second most numerous family $(11,2 \%$ of the mites collected); it was the most abundant family on the folioles. 


\subsection{Introdução}

Em sua maioria, as Arecaceae são de grande importância econômica pelos diferentes produtos que podem oferecer. Do coqueiro, os frutos são extensamente comercializados para o consumo de "água de coco", a polpa pode ser utilizada para consumo direto ou produção de óleo comestível e as fibras são utilizadas na indústria automotiva. O tucum (Bactris e Astrocarium) fornece material para tecelagem (Joly, 1991). As folhas são utilizadas na construção de habitações ou na extração de cera. A juçara (Euterpe edulis Mart.), o açaí (Euterpe oleracea Mart.) e a pupunha (Bactris gasipaes Kunth) são utilizadas para obtenção de palmito. A juçara ( $E$. edulis ) é uma espécie de ampla distribuição ao longo do litoral brasileiro, ocorrendo naturalmente desde o sul da Bahia até o Rio Grande do Sul (Lorenzi, 1996). É uma planta com diversas aplicações em construções rurais, podendo ainda ser utilizada na produção de papel e celulose. O açaí é uma palmeira rústica originária da Amazônia (Lorenzi, 1993). O uso desta planta é bastante extenso, sendo a raiz empregada como vermífugo, o estipe nas construções rurais e os frutos na alimentação (Jardim \& Anderson, 1987). A pupunha também é originária da Amazônia e tem sido extensivamente cultivada nos dias atuais em algumas regiões do Brasil. O babaçu (Orbignya martiana, Barb.Rodr.) é utilizado na produção de palmito e óleo lubrificante; suas fibras são utilizadas na confecção de chapéu (Gonsalves, 1955). Muitas arecáceas são utilizadas em projetos paisagísticos, na criação de ambientes de aspecto tropical (Lorenzi,1996).

A diversidade de espécies de ácaros que ocorrem em arecáceas no Brasil ainda é pouco conhecida. Em um extenso trabalho para se conhecer os ácaros de arecáceas do litoral dos Estados de São Paulo e Pernambuco, Gondim Jr. (2000) encontrou cerca de 62 espécies de ácaros em folíolos de arecáceas na Mata Atlântica nos Estados de São Paulo e Pernambuco, pertencentes a 12 familias.

Dentre os ácaros fitófagos encontrados neste grupo de plantas no Brasil, os mais diversos têm sido os representantes da superfamilia Eriophyoidea (Flechtmann, 1994; 1997a;1998; Flechtmann \& Santana, 1997; Santana \& Flechtmann, 1994; 1998). Até o momento, 11 espécies de eriofídeos foram identificadas em arecáceas (Gondim Jr. \& 
Moraes, 2000). O ácaro Aceria guerreronis Keifer, causador da necrose e queda de frutos em coqueiro (Cocus nucifera L.) foi o primeiro eriofideo relatado em palmeiras no Brasil (Robbs \& Peracchi, 1965). O ácaro é responsável pela depreciação dos frutos do coqueiro, e em casos de ataques severos, até pela queda de frutos. Atualmente, o ácaro encontra-se disseminado em todas as regiões tropicais do mundo, constituindo-se uma das mais importantes pragas do coqueiro (Moore \& Howard, 1996).

Ácaros fitófagos das famílias Tetranychidae e Tenuipalpidae (Ferreira, 1997; Flechtmann, 1997b; Santana \& Flechtmann, 1998) e ácaros predadores das famílias Phytoseiidae, Bdellidae, Cunaxidae, Raphignathidae, Ascidae, Cheyletidae e Stigmaeidae (Santana \& Flechtmann,1998; Gondim Jr. \& Moraes, 2001) também têm sido relatados em arecáceas no Brasil. $\mathrm{O}$ maior número de ácaros predadores encontrados nestas plantas pertence à família Phytoseiidae, tendo sido identificadas até o momento 44 espécies desta família (Flechtmann, 1967; Santana \& Flechtmann,1998; Gondim Jr. \& Moraes, 2001).

Este trabalho foi realizado com o intuito de aprimorar os conhecimentos sobre a acarofauna em arecáceas nativas da Mata Atlântica do Estado de São Paulo.

\subsection{Material e Métodos}

Foram realizadas 4 coletas de amostras na Mata Atlântica, uma em cada estação do ano, no período de janeiro a agosto de 2000.

As coletas foram realizadas nas regiões de Cananéia, Pariquera-Açu, Piracicaba e São Pedro (Tabela 1). O período dedicado para as coletas foi de aproximadamente 3 dias em cada região, sendo estas realizadas em 3 plantas de 5 espécies distintas de arecáceas nativas, em cada região de coleta, em um total de 9 espécies de palmeiras, a saber: Syagrus oleracea (Mart.) Becc, Syagrus romanzoffiana (Cham.), Euterpe edulis Mart, Attalea dubia (Mart.) Burret, Acrocomia aculeata (Jacq.) Lodd, Geonoma schottiana Mart, Geonoma brevispatha Barb. Rodr, Astrocarium aculeatissimum (Schott) Burret e Bactris setosa Mart. A amostra de cada planta constou da brotação terminal (apenas as folhas em desenvolvimento foram tomadas, sem retirar o meristema apical) e 20 folíolos 
tomados de folhas da região mediana da copa de cada planta. Os folíolos foram retirados de uma única folha, sendo 5 do terço apical, 10 do terço mediano e 5 do terço basal. Sempre que presentes, 20 ráquilas (ramificações do eixo principal da inflorescência) e 20 frutos por planta também foram amostrados. Estes foram tomados ao acaso.

Tabela 1. Locais das coletas realizadas no ano 2000, coordenadas e respectivos tipos de vegetação.

\begin{tabular}{|c|c|c|c|c|}
\hline & CANANÉIA & $\begin{array}{l}\text { PARIQUERA- } \\
\text { AÇU }\end{array}$ & PIRACICABA & SÃO PEDRO \\
\hline Localização & $\begin{array}{l}\text { Área particular } \\
\text { - SP226, } \\
\text { Rodovia J.H. } \\
\text { de Oliveira } \\
\text { Rosa, km } 16\end{array}$ & $\begin{array}{l}\text { Núcleo de } \\
\text { Agronomia do } \\
\text { Vale do Ribeira } \\
\text { - IAC }\end{array}$ & $\begin{array}{l}\text { Estação } \\
\text { Ecológica de } \\
\text { Ibicatu }\end{array}$ & $\begin{array}{l}\text { Area particular - } \\
\text { SP304, Rodovia } \\
\text { Geraldo de } \\
\text { Barros, km } 204\end{array}$ \\
\hline Coordenadas & $\begin{array}{l}24^{\circ} 53^{\prime} 45^{\prime \prime} \mathrm{S} \mathrm{e} \\
47^{\circ} 50^{\prime} 17^{\prime \prime} \mathrm{W}\end{array}$ & $\begin{array}{l}24^{\circ} 36^{\prime} 41^{\prime \prime S ~ e ~} \\
47^{\circ} 53^{\prime} 23^{\prime \prime} \mathrm{W}\end{array}$ & $\begin{array}{l}22^{\circ} 46^{\prime} 43^{\prime \prime S ~ e ~} \\
47^{\circ} 49^{\prime} 32^{\prime \prime} \mathrm{W}\end{array}$ & $\begin{array}{l}22^{\circ} 33^{\prime} 57^{\prime \prime S ~ e ~} \\
47^{\circ} 57^{\prime} 28^{\prime \prime} \mathrm{W}\end{array}$ \\
\hline $\begin{array}{l}\text { Tipo de } \\
\text { vegetação }\end{array}$ & $\begin{array}{l}\text { Restinga } \\
\text { arbórea }\end{array}$ & $\begin{array}{l}\text { Floresta } \\
\text { umbrófila } \\
\text { densa }\end{array}$ & $\begin{array}{l}\text { Floresta } \\
\text { estacional } \\
\text { semidecídua }\end{array}$ & $\begin{array}{l}\text { Floresta } \\
\text { estacional } \\
\text { decídua }\end{array}$ \\
\hline
\end{tabular}

Todos os foliolos de cada folha foram acondicionados em saco de papel, que por sua vez foi colocado em um saco plástico, que foi acondicionado em uma caixa de isopor refrigerada $\left(12-21^{\circ} \mathrm{C}\right)$ para evitar perda de ácaros durante o transporte. Flores, frutos ou broto terminal de cada planta foram colocados separadamente em recipientes de plástico de 5 litros, sendo 30\% deste volume ocupado com álcool etílico a 70\%; logo em seguida, os recipientes foram agitados para imobilizar os ácaros e fazê-los cair na solução. 
O material coletado foi levado ao laboratório de Acarologia do Setor de Zoologia do Departamento de Entomologia, Fitopatologia e Zoologia Agrícola da Escola Superior de Agricultura "Luiz de Queiroz" - Universidade de São Paulo, sendo os recipientes com as inflorescências, os frutos ou os brotos terminais mantidos à temperatura ambiente e os folíolos armazenados em refrigerador (aproximadamente $10^{\circ} \mathrm{C}$ ), por um período máximo de 10 dias, até a coleta dos ácaros.

Os folíolos foram examinados sob microscópio estereoscópio, coletando-se os ácaros em álcool etílico a 70\% para posterior preparação de lâminas. Os ácaros foram coletados separadamente, de acordo com a face do folíolo em que se encontravam. Diferentemente dos outros ácaros, os Eriophyoidea foram conservados em AGA (ácool etílico 240,0cc, ácido acético glacial 30,0cc, glicerina $30,0 \mathrm{cc}$, sorbitol 23,8g), até serem montados para identificação (Amrine \& Manson, 1996). Para comparação das densidades de ácaros em cada espécie vegetal, os números de ácaros encontrados em cada época de coleta e em cada espécie vegetal foram divididos pela área estimada dos folíolos amostrados. Em cada caso, a área considerada correspondeu à somatória de ambas as faces dos folíolos.

Os frutos coletados foram separados das brácteas, recolocados nos recipientes onde estavam armazenados e agitados novamente para que os ácaros caíssem na solução. Posteriormente, o material mais grosseiro foi retirado manualmente e o restante da solução foi passado por uma peneira de 400 aberturas por polegada quadrada (ABNT 400). O resíduo retido na peneira foi transferido para siracusa e levado ao microscópio estereoscópio para separação dos ácaros. Estes foram acondicionados em álcool etilico a $70 \%$, onde permaneceram até a montagem. As inflorescências e os brotos terminais foram processados de forma semelhante.

Os ácaros de corpo delicado foram montados entre lâmina e lamínula de microscópio em meio de Hoyer (Flechtmann, 1975), sem qualquer tratamento prévio. Ácaros muito esclerotizados ou escuros foram previamente tratados com lactofenol (Flechtmann, 1975) e lavados com água destilada antes da montagem em meio de Hoyer. A identificação de muitas espécies de Tetranychidae comumente exige a montagem de machos na posição lateral para a observação do edéago, e por isso estes 
foram assim montados. Os demais ácaros foram montados na posição dorso-ventral. No caso dos ácaros da família Ameroseiidae, encontrados em grande quantidade (mais de 1000 ácaros) em inflorescências de G. schottiana e G. brevispatha, apenas uma amostra destes organismos foi montada, conservando-se o restante em álcool etilico a 70\% para eventuais estudos futuros. Concluída a preparação, as lâminas foram colocadas em estufa a $45-50^{\circ} \mathrm{C}$ por uma semana, sendo em seguida efetuada a lutagem com resina aquídica (Verniz Cristal ${ }^{\circledR}$ ). Ao final, estas foram etiquetadas.

Os ácaros foram separados por familias, através de observações feitas ao microscópio, usando uma chave para separação dos principais grupos de ácaros plantícolas, elaborada pelo Professor G. J. de Moraes para uso na disciplina Acarologia, oferecida no curso de graduação da ESALQ - USP, e as chaves elaboradas por Krantz (1978). Os ácaros foram identificados até gênero, principalmente com base nas chaves para diferentes familias, utilizadas no Curso de Verão de Acarologia da "Ohio State University" , Estados Unidos da América do Norte (não publicadas). A identificação foi facilitada pela consulta à tese de doutorado de Gondim Jr. (2000), que fez um estudo dos ácaros da face ventral dos folíolos de arecáceas da Mata Atlântica de Pernambuco e São Paulo.

Os ácaros pertencentes à família Stigmaeidae tiveram um tratamento diferenciado, tendo sido identificados até espécie. Estes serão tratados em maior detalhe no capítulo 4.

Todos os ácaros foram coletados por G. P. de Arruda Filho, sendo os espécimes representativos de todas as espécies coletadas depositados na coleção de referência de ácaros do Setor de Zoologia da ESALQ - USP.

\subsection{Resultados e Discussão}

Foi encontrado neste estudo um total de 5.853 ácaros, sem incluir os Eriophyoidea. A maioria dos ácaros (50,2\% dos indivíduos) foi coletada nas inflorescências (Figura 1). Poucos ácaros foram encontrados nos frutos e brotos terminais. 


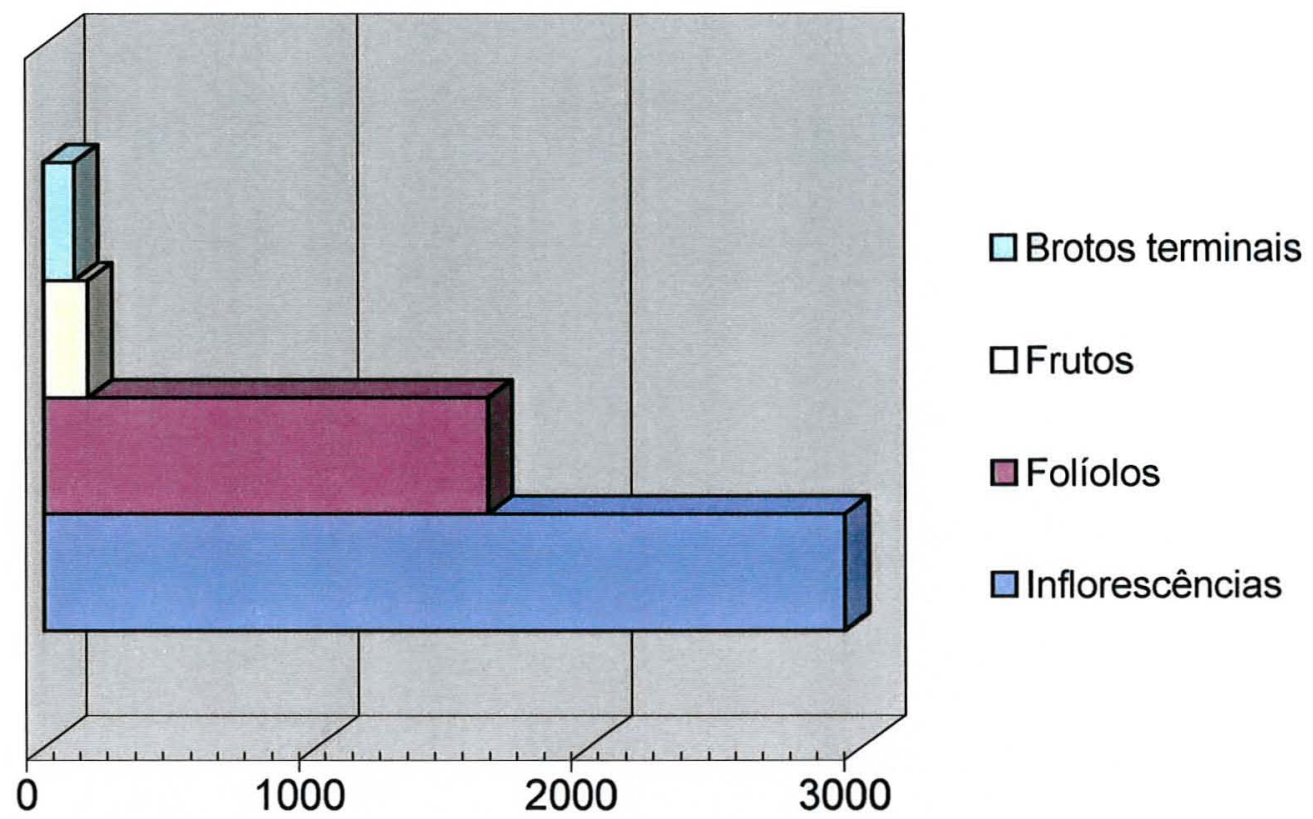

Figura 1 - Totais de ácaros encontrados em inflorescências, folíolos, frutos e brotos terminais de Arecaceae em regiões da Mata Atlântica do Estado de São Paulo, 2000.

Os ácaros encontrados pertencem às subordens Mesostigmata, Metastigmata, Prostigmata, Astigmata e Cryptostigmata. A subordem mais numerosa foi Mesostigmata, representando mais de 62,4\% de todos os ácaros coletados (Figura 2). Os percentuais das demais subordens somados representaram pouco mais que a metade do percentual daquela subordem. 


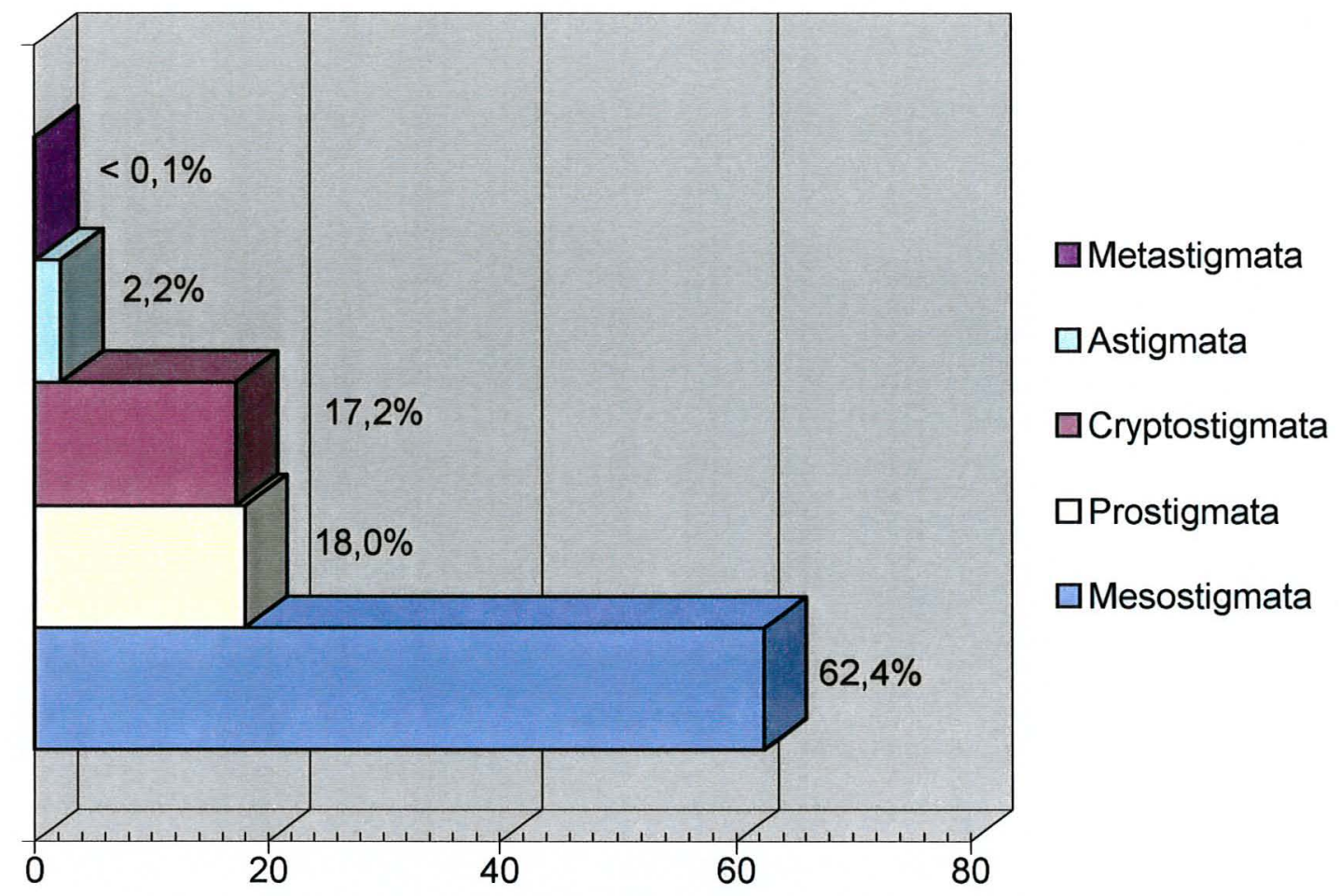

Figura 2 - Proporções dos ácaros em cada subordem encontrados em Arecaceae em regiões da Mata Atlântica do Estado de São Paulo, 2000.

\subsubsection{Diversidade de ácaros nas subordens encontradas}

A família Ameroseiidae representou 78,7\% dos ácaros da subordem Mesostigmata (Figura 3). As outras duas famílias mais numerosas, Phytoseiidae e Ascidae, representaram 17,9 e 3,1\%, respectivamente, dos ácaros desta subordem. Outras famílias encontradas foram Ologamasidae, Polyaspididae, Uropodidae, Digamasellidae e Laelapidae; a somatória dos ácaros destas famílias correspondeu a cerca de $0,3 \%$ dos Mesostigmata encontrados.

Não considerando os Eriophyoidea, os ácaros da subordem Prostigmata, apesar de menos numerosos que aqueles da subordem Mesostigmata, apresentaram maior diversidade de famílias (Figura 3). Três grupos de famílias podem ser distinguidos dentro desta subordem. As famílias Stigmaeidae, Tenuipalpidae, Tydeidae e 
Tretranychidae correspondem ao grupo das famílias mais abundantes; Cunaxidae, Eupodidae, Tarsonemidae, Cheyletidae e Bdellidae

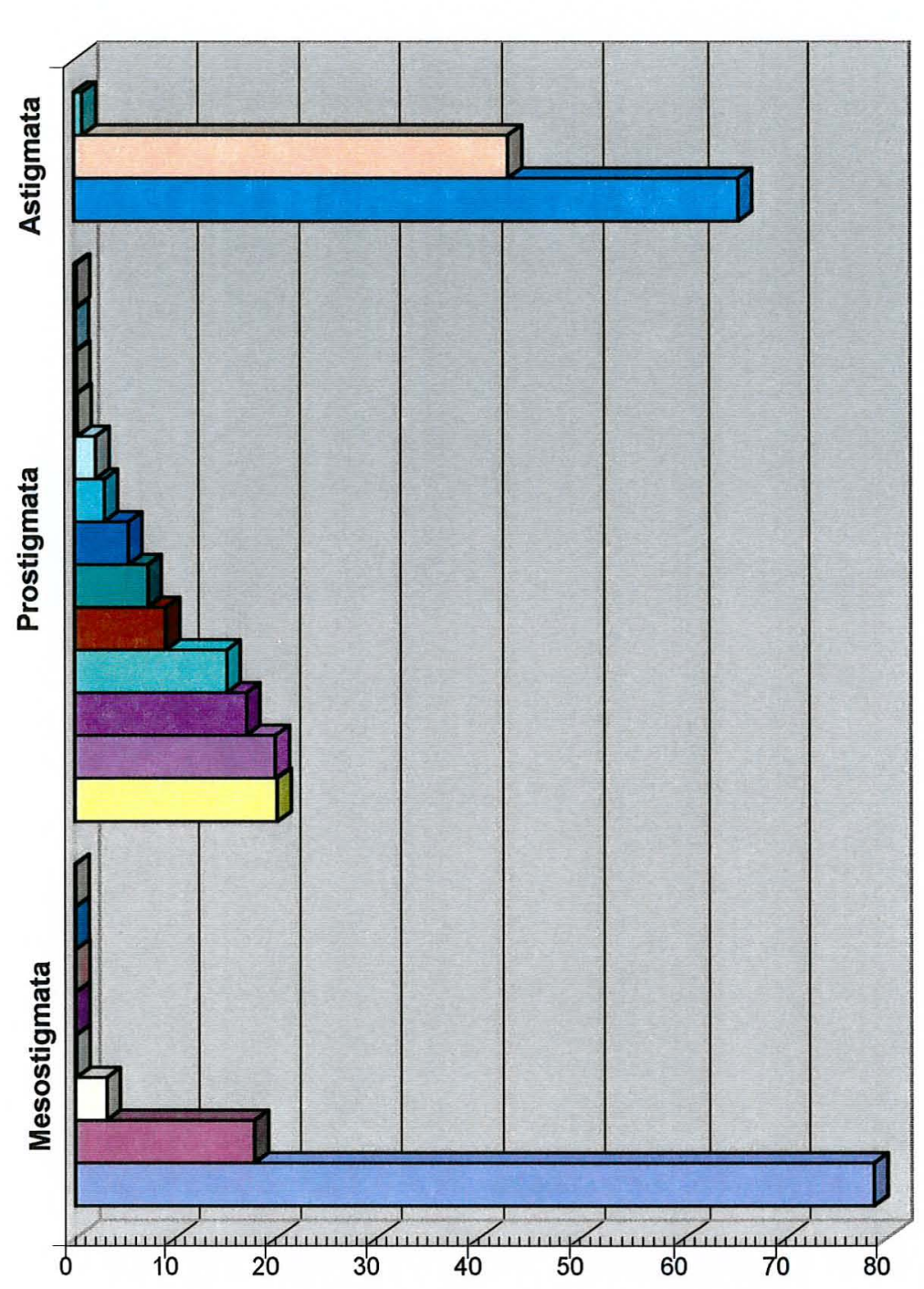

$\square$ Histiostomatidae

$\square$ Acaridae

$\square$ Winterschmidtiidae

$\square$ Microtrombidiidae

$\square$ Raphignathidae

$\square$ Anystidae

$\square$ Camerobiidae

口Bdellidae

$\square$ Cheyletidae

$\square$ Tarsonemidae

口Eupodidae

口Cunaxidae

$\square$ Tetranychidae

$\square$ Tydeidae

口Tenuipalpidae

$\square$ Stigmaeidae

口Laelapidae

口Digamaselidae

口Uropodidae

口Polyaspididae

口Ologamasidae

$\square$ Ascidae

$\square$ Phytoseiidae

$\square$ Ameroseiidae

Figura 3 - Proporç̃ões das famílias de ácaros dentro de cada subordem, encontradas em Arecaceae em regiões da Mata Atlântica do Estado de São Paulo, 2000.

correspondem ao grupo de famílias de abundância intermediária; Anystidae Camerobiidae, Microtrombidiidae e Raphignathidae correspondem ao grupo de famílias 
menos abundantes. Somados, os ácaros do primeiro grupo representaram $72,4 \%$ dos ácaros da subordem Prostigmata; os do segundo grupo, 26,8\%, e os do terceiro grupo, $0,7 \%$. Tivessem os Eriophyidae sido quantificados, estariam certamente entre as familias mais numerosas.

As famílias Acaridae e Winterschmidtiidae representaram 99,2\% dos ácaros da subordem Astigmata encontrados neste estudo (Figura 3). Este resultado está comparável com a literatura, que cita estas como as famílias da subordem Astigmata mais freqüentes em folhas de plantas (Walter \& Proctor, 1999). Os Winterschmidtiidae, familia mais numerosa desta subordem em folíolos das espécies vegetais amostradas, apresentaram diferença significativa (Duncan 5\%) quanto à espécie vegetal em que foram encontrados. Ocorreram em maior quantidade sobre $A$. aculeata e $A$. dubia. Há que se considerar, entretanto, que estas plantas apresentam maior superficie foliar dentre as palmeiras consideradas, com exceção de A. aculeatissimum.

Os 3 representantes da subordem Metastigmata encontrados neste trabalho pertenciam à familia Ixodidae, e foram encontrados em frutos de A. aculeata. Entretanto, é possível que estes ácaros estivessem presentes no solo, uma vez que ao serem cortados, os frutos caíram ao solo, antes de serem coletados.

\section{3. 2 Ácaros nos folíolos}

Não foram observadas diferenças significativas entre as espécies vegetais estudadas em relação à densidade de ácaros nos folíolos (Tabela 2). Entretanto, considerando-se as 6 famílias mais numerosas encontradas neste estudo, diferenças significativas (Duncan 5\%) foram verificadas para as famílias Phytoseiidae, Stigmaeidae, Tenuipalpidae e Tetranychidae (Tabela 2). Os fitoseídeos foram significativamente mais numerosos em $G$. brevispatha do que em $E$. edulis, A. dubia, $A$. aculeatissimum, $S$. romanzoffiana, A. aculeata e $S$. oleracea. Os stigmeídeos foram significativamente mais numerosos em $G$. schottiana do que nas demais espécies de palmeiras amostradas. Os tenuipalpídeos foram significativamente mais numerosos em G. brevispatha do que em G. schottiana, B. setosa, A. aculeatissimum, A. aculeata e $S$. 
oleracea. Os tetraniquídeos foram significativamente mais numerosos em $S$. oleracea do que em $G$. brevispatha, G. schottiana, B. setosa, A. dubia, A. aculeatissimum e $A$. aculeata.

Tabela 2. Número de ácaros por $10000 \mathrm{~cm}^{2}$ de folíolo, (considerando-se tanto a face ventral quanto a dorsal) para as familias mais abundantes e para o total de todas as famílias encontradas.

\begin{tabular}{llllllll}
\hline \multicolumn{1}{c}{ Espécie vegetal } & $\begin{array}{c}\text { Ácaros } \\
\text { (global) }\end{array}$ & \multicolumn{1}{c}{ Phy. } & \multicolumn{1}{c}{ Stig. } & Ten. & \multicolumn{1}{c}{ Tetra. } & Tyd. & Cun. \\
\hline G. brevispatha & $42,1 a$ & $23,4 a$ & $0,0 b$ & $\mathbf{9 , 6 a}$ & $1,4 b c$ & $5,5 a$ & $1,4 a$ \\
G.schottiana & $43,7 a$ & $13,7 a b$ & $20,6 a$ & $1,4 b$ & $0,0 c$ & $2,7 a$ & $2,7 a$ \\
B. setosa & $27,3 a$ & $13,2 a b$ & $2,5 b$ & $0,6 b$ & $0,6 c$ & $5,3 a$ & $2,5 a$ \\
E. edulis & $27,4 a$ & $10,5 b$ & $2,2 b$ & $4,2 a b$ & $4,4 a b$ & $1,9 a$ & $1,2 a$ \\
A. dubia & $25,6 a$ & $\mathbf{8 , 3 b}$ & $2,5 b$ & $2,9 a b$ & $0,0 c$ & $3,4 a$ & $0,5 a$ \\
A. aculeatissimum & $12,8 a$ & $4,9 b$ & $3,1 b$ & $0,0 b$ & $0,5 c$ & $1,2 a$ & $1,2 a$ \\
S. romanzoffiana & $15,8 a$ & $4,3 b$ & $1,5 b$ & $3,5 a b$ & $1,8 a b c$ & $1,4 a$ & $0,5 a$ \\
A. aculeata & $11,7 a$ & $3,2 b$ & $4,4 b$ & $0,0 b$ & $0,2 c$ & $1,5 a$ & $0,5 a$ \\
S. oleracea & $10,5 a$ & $1,1 b$ & $0,7 b$ & $1,3 b$ & $4,9 a$ & $1,9 a$ & $0,0 a$
\end{tabular}

Phy.= Phytoseiidae; Stig. $=$ Stigmaeidae; Ten. $=$ Tenuipalpidae; Tetra. $=$ Tetranychidae; Tyd. $=$ Tydeidae; Cun. $=$ Cunaxidae.

Em uma mesma coluna, médias seguidas pela mesma letra não diferem significativamente entre si pelo teste de Duncan (5\%).

Quase todas as familias de ácaros determinadas foram encontradas em ambas as faces dos folíolos (Figura 4). As densidades de Phytoseiidae, Stigmaeidae e Tydeidae foram significativamente maiores (Duncan 5\%) na face inferior que na face superior dos folíolos. Dentro de cada uma das outras famílias, não se observaram diferenças significativas entre as densidades nas faces superior e inferior dos folíolos.

Possivelmente há uma preferência da maioria das espécies de ácaros pela face inferior dos folíolos, por ser menos exposta às intemperies. Há que se considerar que os folíolos foram transportados do campo ao laboratório para a coleta dos ácaros. Durante 
este período, alguns ácaros poderiam ter se movido de uma face para outra, de forma que as diferenças observadas podem ter sido subestimadas.

Outros estudos têm indicado que alguns grupos de ácaros preferem a parte superior dos folíolos, como é o caso de diversas espécies do gênero Oligonychus da família Tetranychidae (Jeppson et al., 1975).

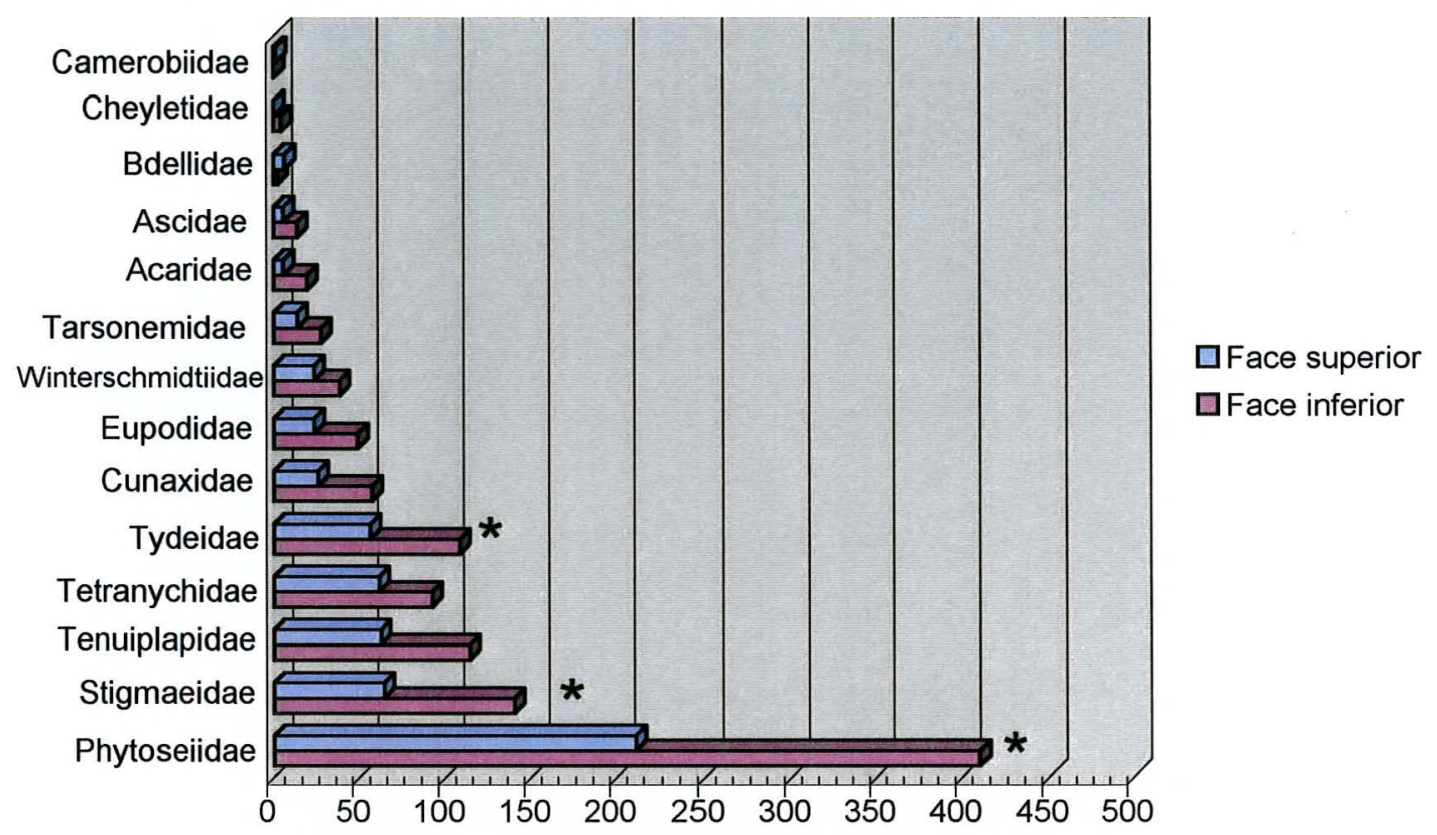

Figura 4 - Totais de ácaros de cada família encontrados na face superior e inferior dos folíolos das espécies vegetais estudadas. (*) indica que o número médio de ácaros por folíolo foi significativamente maior na face inferior (Duncan 5\%).

Um número significativamente maior de ácaros foi encontrado em folíolos na coleta realizada no inverno (julho e agosto) que na primavera (outubro e novembro).

A redução na quantidade de ácaros durante as coletas da primavera provavelmente está relacionada com o aumento da precipitação observada nos meses em que foram realizadas (Figuras 5-6 do anexo), visto que esta pode atuar diretamente nos ácaros, lavando-os das folhas. Yaninek et al.(1989) constataram uma redução substancial em populações de Mononychelus tanajoa (Bondar) sobre mandioca (Manihot esculenta Crantz) na África, por influência direta da precipitação. O número de ácaros dos estágios 
ativos foi reduzido em até $82,4 \%$ em função da ação da chuva. Outra causa da redução do número de ácaros na primavera pode estar relaciónada ao possível favorecimento da ação de patógenos de ácaros durante este período de maior precipitação, umidade relativa e temperatura (Alves \& Lecuona, 1998). Alguns trabalhos têm sido publicados sobre patógenos que afetam ácaros em agroecossistemas no Brasil (Van der Geest et al., 2000). Entretanto, nada tem sido publicado sobre patógenos de ácaros na Mata Atlântica de São Paulo. Van der Geest et al. (2000) reviu o que se conhece sobre patógenos de ácaros em todo mundo, esclarecendo que os grupos aparentemente mais eficientes são vírus e fungos.

\section{3. 3 Ácaros nas inflorescências}

Foram encontrados 2.938 ácaros nas inflorescências avaliadas, das quais aproximadamente $98 \%$ pertenciam à familia Ameroseiidae. Cerca de $99 \%$ destes ácaros foram encontrados em inflorescências de G. schottiana e G. brevispatha (Tabela 3). Estes ácaros podem ser predadores, fungívoros ou alimentar-se de pólen. Podem ser encontrados no solo, em produtos armazenados, inflorescências e associados foreticamente a outros animais (Halliday, 1997). O Ameroseiidae Neocypholaelaps cocos Evans foi descrito de inflorescências de C. nucifera em Guadalcanal (Ilhas Solomon). Alguns Ameroseiidae dispersam-se por meio de associação forética com beija-flores (Halliday, 1997).

Ascidae foi a segunda família mais abundante, mas corresponderam a apenas 1,3\% do total de ácaros. Outras familias encontradas, em proporções de no máximo $0,2 \%$ cada uma foram Phytoseiidae, Tarsonemidae, Stigmaeidae, Winterschmidtiidae e Acaridae.

Espécies de Ascidae também usam beija-flores para se dispersar, sendo transportados de uma inflorescência a outra nas cavidades nasais destas aves (Naskrecki \& Colwell, 1998). Fain et al. (1977) estudaram uma espécie de Ascidae do gênero Rhinoseius Baker e Yunker coletada em narinas de beija-flor em Trinidad e em Belém do Pará, Brasil. 
Tabela 3. Totais de ácaros encontrados em inflorescências de 9 espécies nativas de arecáceas da Mata Atlântica do Estado de São Paulo, nas quatro estações do ano.

\begin{tabular}{lccccc}
\hline \multirow{2}{*}{ Espécie vegetal } & \multicolumn{5}{c}{ Meses de Coleta } \\
\cline { 2 - 5 } & I - II & IV - V & VII - VIII & X - XI & Totais \\
\hline A. aculeata & - & - & - & 18 & 18 \\
A. aculeatissimum & - & - & - & - & - \\
A. dubia & - & - & - & - & - \\
B. setosa & - & - & - & 22 & 22 \\
E. edulis & 12 & - & - & 30 & 42 \\
G. brevispatha & - & 1227 & 21 & 168 & 1416 \\
G. schottiana & - & 1213 & 18 & 163 & 1394 \\
S. oleracea & 0 & 0 & - & 0 & 0 \\
S. romanzoffiana & 30 & - & - & 16 & 46 \\
\hline \multicolumn{1}{c}{ Totais } & 42 & 2440 & 39 & 417 &
\end{tabular}

(-) Não foram coletadas inflorescências.

Outra possibilidade de dispersão dos ácaros de uma inflorescência a outra seria a associação forética com insetos da ordem Coleoptera, freqüentemente observados nas inflorescências coletadas. Fain et al. (1995), estudando ácaros associados a coleópteros da familia Carabidae na Bélgica, encontrou alguns Ascidae do gênero Antennoseius além de outras familias.

Walter \& Proctor (1999) relataram vários casos de associação de ácaros em inflorescências, incluindo Ascidae (Rhinoseius, Tropicoseius, Proctolelaps e Lasioseius), Ameroseiidae (Neocypholaelaps e Afrocypholaelaps) e Cryptostigmata (Scheloribatidae, Haplozetidae e Mochlozetidae).

Além destes, são citados em inflorescências alguns representantes da subordem Prostigmata como Eriophyoidea e Tarsonemidae (Krantz, 1978).

Não foi possivel obter inflorescências de $A$. dubia e $A$. aculeatissimum durante este estudo. Apesar das espécies de Geonoma apresentarem uma abundância muito maior de ácaros em relação às demais palmeiras analisadas, há que se considerar, 
entretanto, que as espécies vegetais coletadas apresentaram florescimento desigual ao longo do ano, e por esta razão a comparação estatística entre os números obtidos neste estudo não é adequada.

Aproximadamente $83 \%$ dos ácaros nas inflorescências foram coletados no outono. Quantidades relativamente elevadas de ácaros também foram coletados na primavera. Provavelmente esta maior quantidade de indivíduos está relacionada à maior produção de flores por planta nesta época do ano. Outra possível causa para esta maior abundância de ácaros nas coletas do outono é a diminuição da precipitação nesta época do ano, por motivos similares aos citados para os ácaros em folíolos.

As inflorescências de $S$. oleracea não apresentaram nenhum ácaro, entretanto estas continham sempre grande quantidade de insetos da ordem Thysanoptera. Três familias desta ordem contêm espécies citadas como predadoras de tetraniquídeos (Chazeau, 1985). Por outro lado, certos grupos de ácaros, principalmente Phytoseiidae, também têm sido citado como predadores de Thysanoptera (Eickwort, 1983).

\section{3. 4 Ácaros nos frutos}

Foram encontrados 164 ácaros nos frutos das palmeiras estudadas, não se observando grandes diferenças entre o número de ácaros coletados em cada estação. As quantidades de ácaros foram sempre pequenas, obtendo-se no máximo um total de 14 indivíduos em frutos de $S$. romanzoffiana no verão (Tabela 4). Há que se considerar, entretanto, que os frutos das palmeiras estudadas variavam muito de tamanho além de que as espécies de palmeiras apresentaram frutificação desigual ao longo do ano. Estes fatores dificultam uma comparação estatística dos números obtidos.

Embora não muito abundantes, os ácaros coletados em frutos foram bastante diversos, representando 20 famílias diferentes. A família mais abundante foi Ascidae, correspondendo a $26 \%$ de todos os ácaros coletados. Outras familias encontradas em proporções variando de 10-12\% dos ácaros coletados foram Phytoseiidae, Cheyletidae e Winterschmidtiidae. 
Tabela 4. Totais de ácaros encontrados em frutos de 9 espécies nativas de arecáceas da Mata Atlântica do Estado de São Paulo, nas quatro estações do ano.

\begin{tabular}{lccccc}
\hline \multirow{2}{*}{ Espécie vegetal } & \multicolumn{5}{c}{ Meses de Coleta } \\
\cline { 2 - 5 } & I - II & IV - V & VII - VIII & X - XI & Totais \\
\hline A. aculeata & 0 & 4 & 3 & 2 & 9 \\
A. aculeatissimum & - & 10 & 5 & 6 & 21 \\
A. dubia & 2 & 2 & 3 & 6 & 13 \\
B. setosa & - & 4 & 6 & 4 & 14 \\
E. edulis & 4 & 12 & 6 & 12 & 34 \\
G. brevispatha & - & 3 & 5 & 5 & 13 \\
G. schottiana & 0 & 7 & 8 & 4 & 19 \\
S. oleracea & 0 & 0 & 4 & 4 & 8 \\
S. romanzoffiana & 14 & 10 & 4 & 4 & 32 \\
\hline \multicolumn{1}{c}{ Totais } & 20 & 53 & 44 & 47 &
\end{tabular}

$(-)$ não foram coletados frutos.

As demais familias encontradas em proporções sempre menores que $10 \%$ foram Tydeidae, Tenuipalpidae, Cunaxidae, Eupodidae, Acaridae, Ixodidae, Microtrombidiidae, Raphignathidae, Stigmaeidae, Tarsonemidae, Polyaspididae, Laelapidae e Camerobiidae.

Ácaros da superfamilia Eriophyoidea têm sido citados em frutos de Arecaceae. Até recentemente, o ácaro $A$. guerreronis era conhecido em vários países das Américas e da África. Nesta, o primeiro relato do A. guerreronis foi feito em 1967, em Benin (Mariau, 1977). Recentemente, o ácaro foi também encontrado na Ásia, onde o coqueiro tem importância maior que em outros continentes. Em Sri Lanka, A. guerreronis foi relatado pela primeira vez em 1997 (Fernando et al., 2000). Na Índia, este ácaro foi encontrado pela primeira vez em 1998 (Nair \& Koshy, 2000). O ácaro vem causando sérios prejuízos à agricultura daqueles países (Haq, 1999). A. guerreronis, causador da necrose e queda de frutos em coqueiro foi o primeiro eriofideo relatado em palmeiras no Brasil, no Estado do Rio de Janeiro (Robbs \& Peracchi, 1965). Em seguida, este ácaro 
foi relatado no Estado de Pernambuco, causando a necrose do "olho do coqueiro" (Aquino \& Arruda, 1967). Populações deste ácaro desenvolvem-se na região meristemática dos frutos, coberta pelas brácteas. A alimentação dos ácaros nesta região pode causar danos fisicos de maneira que o tecido em formação danificado se expande, tornando-se evidente sobre o fruto uma superfície necrótica e suberificada, ocasionando frutos sem valor comercial devido a atrofia e deformação dos mesmos. (Mariau, 1986).

Outro ácaro encontrado em frutos de coqueiro, causando danos semelhantes ao $A$. guerreronis, é Steneotarsonemus furcatus DeLeon da familia Tarsonemidae (Ochoa et al., 1991). Além destes, têm sido relatados os ácaros Brevipalpus deleoni Prichard \& Baker, Dolichotetranychus vandergooti (Oudemans) e D. cocos Flechtmann \& Fernando da familia Tenuipalpidae (Flechtmann \& Fernando,2000).

\section{3. 5 Ácaros nos brotos terminais}

Foram coletados 114 ácaros nos brotos terminais das palmeiras examinadas (Tabela 5). Pelos mesmos motivos citados em relação às inflorescências e frutos, a comparação estatística entre os números obtidos em cada época de coleta para cada espécies de planta não é conveniente.

O eriofidio $A$. guerreronis foi encontrado por Flechtmann (1989) em bainhas foliares e brotos terminais da palmeira Lytocarium weddellianum (H. A. Wendland) proveniente de viveiro comercial.

Embora não muito abundantes, os ácaros coletados em brotos terminais apresentaram certa diversidade representando 15 familias diferentes. A familia mais abundante foi Tenuipalpidae, correspondendo a $21 \%$ de todos os ácaros coletados. Outras familias encontradas em proporções variando de $10-13 \%$ dos ácaros coletados foram Ascidae, Phytoseiidae e Tarsonemidae. As demais familias encontradas em proporções sempre menores que $10 \%$ foram Bdellidae, Acaridae, Cheyletidae, Cunaxidae, Tetranychidae, Tydeidae, Ologamasidae, Stigmaeidae, Uropodidae, Digamasellidae e Histiostomatidae. 
Embora não muito abundantes, os ácaros coletados em brotos terminais apresentaram certa diversidade representando 15 famílias diferentes. A familia mais abundante foi Tenuipalpidae, correspondendo a $21 \%$ de todos os ácaros coletados. Outras familias encontradas em proporções variando de $10-13 \%$ dos ácaros coletados foram Ascidae, Phytoseiidae e Tarsonemidae. As demais familias encontradas em proporções sempre menores que $10 \%$ foram Bdellidae, Acaridae, Cheyletidae, Cunaxidae, Tetranychidae, Tydeidae, Ologamasidae, Stigmaeidae, Uropodidae, Digamasellidae e Histiostomatidae.

Tabela 5. Totais de ácaros encontrados em brotos terminais de 9 espécies nativas de arecáceas da Mata Attântica do Estado de São Paulo, nas quatro estações do ano.

\begin{tabular}{lccccc}
\hline \multirow{2}{*}{\multicolumn{1}{c}{ Espécie vegetal }} & \multicolumn{5}{c}{ Meses de coleta } \\
\cline { 2 - 5 } & I - II & IV - V & VII - VIII & X - XI & Totais \\
\hline A. aculeata & 11 & 2 & 0 & 2 & 15 \\
A. aculeatissimum & 8 & 2 & 0 & 0 & 10 \\
A. dubia & 0 & 0 & 0 & 0 & 0 \\
B. setosa & 8 & 6 & 8 & 4 & 26 \\
E. edulis & 8 & 6 & 6 & 0 & 20 \\
G. brevispatha & 7 & 0 & 0 & 0 & 7 \\
G. schottiana & 0 & 2 & 2 & 0 & 4 \\
S. oleracea & 0 & 2 & 3 & 4 & 9 \\
S. romanzoffiana & 2 & 10 & 7 & 4 & 23 \\
\hline \multicolumn{1}{c}{ Totais } & 44 & 30 & 26 & 14 & \\
\hline
\end{tabular}

\subsubsection{Gêneros dos ácaros encontrados}

Os gêneros dos ácaros encontrados no presente trabalho são abaixo relacionados, com os respectivos dados de coleta além de outras informações pertinentes. 


\section{SUBORDEM MESOSTIGMATA \\ SUPERFAMÍLIA ASCOIDEA \\ ASCIDAE Voigts \& Oudemans}

Asca spp.

Material Examinado: Cananéia: E. edulis - folíolos (19-I) e frutos (18-IV); G. schottiana - folíolos (11-X) e frutos (19-IV); Pariquera-Açu: B. setosa - brotos terminais (18-IV); S. romanzoffiana - brotos terminais (11-VII) e folíolos (11-VII); $A$. dubia - folíolos (12-X); E. edulis - brotos terminais (11-VII); São Pedro: S. oleracea brotos terminais (11-XI).

Lasioseius spp.

Material Examinado: Cananéia: E. edulis - inflorescências (11-X) e frutos (18-I); B. setosa - frutos (19-IV e 12-VII); A. aculeatissimum - frutos (19-IV); G. schottiana inflorescências (19-IV) e frutos (11-X); Pariquera-Açu: $A$. aculeatissimum - frutos (11VII e 10-X); Piracicaba: E. edulis - brotos terminais (07-II); São Pedro: S. oleracea frutos $(11-\mathrm{XI})$.

Melichares spp.

Material Examinado: Pariquera-Açu: $E$. edulis - inflorescências (18-I e 10-X); $S$. romanzoffiana - inflorescências (18-I); A. aculeatissimum - brotos terminais (17-I).

\section{Proctolaelaps sp.}

Material Examinado: Pariquera-Açu: $A$. dubia - frutos (18-IV); S. romanzoffiana - frutos (11-VII); B. setosa - inflorescências (10-X); Cananéia: A. aculeatissimum frutos (19-IV); B. setosa - frutos (11-X).

Gênero novo

Material Examinado: Pariquera-Açu: S. romanzoffiana - inflorescências (17-I). 
Observações: Ácaros da Familia Ascidae foram bastante abundantes neste estudo. Dentre os gêneros encontrados, apenas Asca foi ocasionalmente verificado em folíolos.

\section{SUPERFAMÍLIA DERMANYSSOIDEA}

LAELAPIDAE Berlese

Pseudoparasitus sp.

Material Examinado: Piracicaba: A. aculeata - frutos (17-V).

\section{SUPERFAMÍLIA PHYTOSEIOIDEA \\ AMEROSEIIDAE Evans}

Ameroseius sp.

Material Examinado: Cananéia: G. schottiana - inflorescências (19-IV, 12-VII e 11-X); E. edulis - inflorescências (11-X); B. setosa - brotos terminais (19-IV); São Pedro: G. brevispatha - inflorescências (16-V, 10-VIII e 16-XI).

Observações: Apesar da abundância com que foram encontrados, estes ácaros nunca foram verificados nos foliolos das palmeiras estudadas.

\section{PHYTOSEIIDAE Berlese}

Amblyseius spp.

Material Examinado: Cananéia: S. romanzoffiana - folíolos (18-I e 11-X); E. edulis - folíolos e frutos (18-I, 19-IV, 12-VII e 11-X); B. setosa - foliolos (19-IV, 12VII e 11-X); G. schottiana - folíolos e frutos (12-VII); A. aculeatissimum - folíolos (12VII); Pariquera-Açu: E. edulis - folíolos (18-I), frutos (19-I); S. romanzoffiana folíolos (18-I, 11-VII e 12-X), frutos (17-I e 11-VII); A. aculeatissimum - folíolos (16-I, 11-VII e 12-X); B. setosa - folíolos (18-IV, 11-VII e 12-X); Piracicaba: $S$. romanzoffiana - brotos terminais e folíolos (17-V, 11-VIII); E. edulis - folíolos (16-V e 
11-XI); A. aculeata - folíolos (11-VIII); São Pedro: $S$. oleracea - foliolos e frutos (16V e 11-XI); G. brevispatha - frutos (10-VIII).

Coccoseius sp.

Material Examinado: Cananéia: $S$. romanzoffiana - folíolos (11-X).

Euseius spp.

Material Examinado: Pariquera-Açu: E. edulis - folíolos (11-VII e 12-X); $B$. setosa - folíolos (12-X); Piracicaba: E. edulis - folíolos (07-II, 16-V e 10-XI); $A$. aculeata - foliolos (17-V e 11-XI).

Iphiseiodes sp.

Material Examinado: Piracicaba: A. aculeata - folíolos (17-V e 11-VIII); E. edulis - folíolos (16-V e 11-XI), S. romanzoffiana - folíolos (16-V, 11-VIII e 11-XI); Pariquera-Açu: S. romanzoffiana - folíolos (11-VII); São Pedro: G. brevispatha folíolos (11-VIII e 11-XI); S. oleracea - folíolos (11-XI)

Leonseius sp.

Material Examinado: Cananéia: $B$. setosa - folíolos (12-VII).

Neoseiulus sp.

Material Examinado: Cananéia: E. edulis - brotos terminais e folíolos (12-VII).

Proprioseiopsis spp.

Material Examinado: Cananéia: $B$. setosa - folíolos (19-IV); Pariquera-Açu: $B$. setosa - folíolos (18-I e 11-VII); S. romanzoffiana - frutos (10-X).

Phytoseius sp.

Material Examinado: Piracicaba: A. aculeata - folíolos (17-V) 
Typhlodromips spp.

Material Examinado: Cananéia: A. aculeatissimum - foliolos (18-I); E. edulis folíolos (18-I, 12-VII e 11-X); B. setosa - folíolos (18-I); G. schottiana - folíolos (12VII); S. romanzoffiana - folíolos (11-X); Pariquera-Açu: E. edulis - folíolos (16-I, 18IV e 11-VII); A. aculeatissimum - folíolos (16-I, 18-IV e 11-VII); $A$. dubia - folíolos (16-I e 11-VII); B. setosa - folíolos (16-I, 18-IV e 12-X); Piracicaba: E. edulis folíolos (11-VIII e 11-XI).

Typhlodromus (Anthoseius) sp.

Material Examinado: Cananéia: S. romanzoffiana - folíolos (11-X); Piracicaba: S. romanzoffiana - folíolos (7-II).

Observações: As diferentes espécies desta família tão abundante foram encontradas em todas as partes das palmeiras examinadas.

\section{SUPERFAMÍLIA RHODACAROIDEA \\ DIGAMASELLIDAE Evans}

Dendrolaelaps sp.

Material Examinado: Piracicaba: S. romanzoffiana - brotos terminais (16-V).

\section{OLOGAMASIDAE Ryke}

Cyrtolaelaps sp.

Material Examinado: Piracicaba: $A$. aculeata - brotos terminais (07-II).

\section{SUPERFAMÍLIA POLYASPIDOIDEA \\ POLYASPIDIDAE Berlese}

Material Examinado: Cananéia: $A$. aculeatissimum - frutos (19-IV). 
Observações:Foram coletados apenas dois indivíduos imaturos desta família, o que impossibilitou sua identificação.

\section{SUPERFAMÍLIA UROPODOIDEA \\ UROPODDAE Berlese}

Phaulodinychus sp.

Material Examinado: Pariquera-Açu: A. aculeatissimum - frutos (18-IV); $E$. edulis - brotos terminais (18-IV).

\section{SUBORDEM PROSTIGMATA}

SUPERFAMÍLIA ANYSTOIDEA

\section{ANYSTIDAE Oudemans}

Erythracarus sp.

Material Examinado: Pariquera-Açu: A. aculeatissimum - frutos (18-IV e 10-X).

\section{SUPERFAMÍLIA BDELLOIDEA}

\section{BDELLIDAE Dugès}

Bdella sp.

Material Examinado: Pariquera-Açu: $E$. edulis - frutos (19-1); $A$. aculeatissimum - folíolos (18-IV); B. setosa - brotos terminais (10-X); Piracicaba: G. brevispatha - brotos terminais (07-II); São Pedro: S.oleracea - brotos terminais (16-V); G. brevispatha - frutos (16-II).

Observações: Apenas em uma ocasião ácaros desta familia foram encontrados em foliolos. Foram muito mais comuns em frutos e brotos terminais. 


\section{CUNAXIDAE Thor}

Cunaxa sp.

Material Examinado: Pariquera-Açu: A. aculeatissimum - frutos (18-IV).

Rubroscirus sp.

Material Examinado: Pariquera-Açu: $E$. edulis - folíolos (16-I); $A$. aculeatissimum - folíolos (16-I, 18-IV e 11-VII); $A$. dubia - folíolos (11-VII).

Armascirus sp.

Material Examinado: Cananéia: G. schottiana - folíolos (12-VII); Piracicaba: $S$. romanzoffiana - folíolos (16-V).

Neocunaxoides sp.

Material Examinado: Cananéia: E. edulis - folíolos (18-I); B. setosa-frutos (19IV); Pariquera-Açu: E. edulis - frutos (18-IV); B. setosa - foliolos (11-VII).

Pulaeus sp.

Material Examinado: Cananéia: $B$. setosa - folíolos (12-VII); Pariquera-Açu: $B$. setosa - foliolos (16-I e 18-IV) e frutos (19-IV); $A$. aculeatissimum - folíolos (11-VII).

Scutopalus sp.

Material Examinado: Pariquera-Açu: E. edulis - foliolos (16-I); $A$. aculeatissimum - folíolos (16-I); S. romanzoffiana - folíolos (11-VII); Piracicaba: $A$. aculeata - brotos terminais (17-V).

Observações: Ainda que também encontrados em certas ocasiões em frutos e em brotos terminais, os ácaros desta familia foram mais comuns nos folíolos das palmeiras estudadas. 


\section{SUPERFAMÍLIA CHEYLETOIDEA \\ CHEYLETIDAE Leach}

\section{Cheletomimus sp.}

Material Examinado: Pariquera-Açu: A. aculeatissimum - brotos terminais (17-I); A. dubia - folíolos (11-VII); Piracicaba: E. edulis - frutos (30-V).

Hemicheyletia sp.

Material Examinado: Pariquera-Açu: A. dubia - frutos (18-IV); E. edulis - frutos (30-V e 11-VII); Piracicaba: G. brevispatha - brotos terminais (07-I); A. aculeata frutos (11-VIII); São Pedro: G. brevispatha - frutos (16-V).

Mexecheles spp.

Material Examinado: Pariquera-Açu: S. romanzoffiana - frutos (17-I e 18-IV); $A$. dubia - frutos (11-X).

Prosocheyla sp.

Material Examinado: São Pedro: S. oleracea - folíolos (11-XI).

Observações: Em apenas 2 ocasiões estes ácaros foram encontrados em folíolos e brotos terminais. Foram muito mais comuns em frutos.

\section{SUPERFAMÍLIA EUPODOIDEA}

\section{EUPODIDAE Koch}

\section{Eupodes sp.}

Material Examinado: Cananéia: S. romanzoffiana - folíolos (12-VII), B. setosa frutos (12-VII); G. schottiana - frutos (12-VII); Pariquera-Açu: S. romanzoffiana folíolos (16-I, 18-IV e 11-VII); E.edulis -folíolos (16-I, 18-IV, 11-VII e 12-XI); $B$. setosa - folíolos (16-I); A. dubia - folíolos (11-VII). 


\section{SUPERFAMÍLIA RAPHIGNATHOIDEA \\ CAMEROBIIDAE Southcott}

Decaphyllobius sp.

Material Examinado: São Pedro: G. brevispatha - folíolos (16-V) e frutos (16$\mathrm{XI})$.

\section{RAPHIGNATHIDAE Kramer}

Raphignathus sp.

Material Examinado: São Pedro: G. brevispatha - frutos (16-V).

\section{STIGMAEIDAE Oudemans}

Agistemus spp.

Material Examinado: Cananéia: $A$. aculeatissimum - brotos terminais (IV-00) e foliolos (VII-00 e X-00); G. schottiana - foliolos (I-00, IV-00 e VII-00); E. edulis folíolos (I-00) e frutos (I-00); $S$. romanzoffiana - folíolos (IV-00, VII-00 e X-00); Pariquera-Açu: A. aculeatissimum - folíolos (I-00 e IV-00); S. romanzoffiana - folíolos (IV-00 e VII-00); E. edulis - foliolos (IV-00 e VII-00); A. dubia - folíolos (VII-00); Piracicaba: A. aculeata - inflorescências (XI-00), brotos terminais (II-00) e foliolos (II00, V-00 e XI-00); E. edulis - folíolos (II-00 e XI-00); S. romanzoffiana - folíolos (VIII00 e XI-00).

\section{Zetzellia sp.}

Material Examinado: Pariquera-Açu: S. romanzoffiana - folíolos (IV-00).

Observações: Esta foi a segunda família mais numerosa nos folíolos das palmeiras estudadas, sendo esporadicamente encontrada em inflorescências, frutos e brotos terminais. 


\section{SUPERFAMÍLIA TARSONEMOIDEA}

\section{TARSONEMIDAE Kramer}

\section{Daidalotarsonemus sp.}

Material Examinado: Pariquera-Açu: A. dubia - folíolos (11-VII); São Pedro: $S$. oleracea - folíolos (16-V).

Excelsotarsonemus sp.

Material Examinado: Pariquera-Açu: E. edulis - foliolos (16-I).

Fungitarsonemus sp.

Material Examinado: Cananéia: E. edulis - folíolos (18-I); Pariquera-Açu: $B$. setosa - folíolos (12-X); Piracicaba: E. edulis - folíolos (7-II).

Rhynchotarsonemus sp.

Material Examinado: Cananéia: $A$. aculeatissimum - brotos terminais (18-I); $B$. setosa - brotos terminais (19-IV e 12-VII).

Stenotarsonemus sp.

Material Examinado: Cananéia: B. setosa - brotos terminais (19-IV) e frutos (12VII); Pariquera-Açu: $B$. setosa-brotos terminais (18-IV).

Tarsonemus sp.

Material Examinado: Pariquera-Açu: $A$. dubia - folíolos (11-VII); Piracicaba: $S$. romanzoffiana - folíolos (07-II); São Pedro: S. oleracea - folíolos (16-V).

Xenotarsonemus sp.

Material Examinado: Cananéia: A. aculeatissimum - folíolos (12-VII); Pariquera-Açu: $A$. dubia - folíolos (11-VII). 


\section{SUPERFAMÍLIA TETRANYCHOIDEA \\ TENUIPALPIDAE Berlese}

Brevipalpus sp.

Material Examinado: Cananéia: E. edulis - folíolos (18-I) e frutos (19-IV); $G$. schottiana - inflorescências (19-IV) e frutos (12-VII); Pariquera-Açu: E. edulis folíolos (11-VII e 12-X); A. dubia - foliolos (12-X); Piracicaba: E. edulis - folíolos (07-II, 16-V e 11-VIII); S. romanzoffiana - folíolos (11-VIII); G. brevispatha - brotos terminais (07-II); São Pedro: S. oleracea - folíolos (16-V e 10-VIII); G. brevispatha foliolos (10-VIII) e frutos (16-XI).

\section{Tenuipalpus sp.}

Material Examinado: Cananéia: S. romanzoffiana - folíolos (18-I, 19-IV e 12-VII) e brotos terminais (12-VII); E. edulis - folíolos e brotos terminais (19-IV e 19-IV); Pariquera-Açu: E. edulis - folíolos e brotos terminais (17-I, 18-IV, 11-VII e 11-VII); $S$. romanzoffiana - folíolos e brotos terminais (18-IV); A. dubia - folíolos (11-VII e 12X); Piracicaba: S. romanzoffiana - folíolos (07-II, 17-V e 16-V) e brotos terminais (11VIII e 11-XI); G. brevispatha - brotos terminais (07-II); E. edulis - brotos terminais (07-II); São Pedro: S. oleracea - folíolos (16-V) e brotos terminais (10-VIII).

Observaçoes: Ácaros desta família tão numerosa foram encontrados em todas as partes das plantas.

\section{TETRANYCHIDAE Donnadieu}

Eutetranychus spp.

Material Examinado: Pariquera-Açu: E. edulis - folíolos (16-I); S. romanzoffiana - folíolos (11-VII); Piracicaba: S. romanzoffiana - folíolos (07-II, 16-V e 11-XI); São Pedro: S. oleracea - folíolos (16-V-2000); G. brevispatha-folíolos (10-VIII). 
Oligonychus sp.

Material Examinado: Pariquera-Açu: E. edulis - folíolos (18-IV); Piracicaba: $E$. edulis - foliolos (16-V e 11-VIII); A. aculeata - brotos terminais (17-V) e frutos (11$\mathrm{XI})$; São Pedro: S. oleracea - folíolos (16-V e 10-VIII) e brotos terminais (11-XI).

Schizotetranychus sp.

Material Examinado: Cananéia: E. edulis - folíolos (18-I e 12-VII); PariqueraAçu: E. edulis - foliolos (18-IV).

Tetranychus sp.

Material Examinado: Cananéia: A. aculeatissimum - folíolos (18-I e 19-IV); B. setosa - folíolos (18-I e 19-IV); S. romanzoffiana - folíolos (12-VII); Pariquera-Açu: E. edulis - folíolos (16-I e 18-IV); $S$. romanzoffiana - foliolos (18-IV e 12-X); Piracicaba: S. romanzoffiana - folíolos (07-II, 16-V e 11-XI); São Pedro: S. oleraceafolíolos (16-V) e brotos terminais (11-XI).

Observações: Com exceção das raras vezes em que foram observados em brotos terminais, estes ácaros foram encontrados quase exclusivamente nos folíolos.

\section{SUPERFAMÍLIA TROMBIDIOIDEA MICROTROMBIDIIDAE Thor}

Material Examinado: Cananéia: G. schottiana - frutos (19-IV).

Observações: apenas um indivíduo foi encontrado e este não estava em condições adequadas para identificação até o nível de gênero. 


\section{SUPERFAMÍLIA TYDEOIDEA}

TYDEIDAE Kramer

Afrotydeus sp.

Material Examinado: Cananéia: $B$. setosa - folíolos (12-VII); Pariquera-Açu: $A$. dubia - folíolos (16-I e 11-VII); E. edulis - folíolos (16-I e 11-VII); B. setosa - folíolos (11-VII).

Lorryia spp.

Material Examinado: Pariquera-Açu: E. edulis - folíolos (18-IV); $S$. romanzoffiana - foliolos (11-VII); Piracicaba: E. edulis - brotos terminais (07-II e 30V) e frutos (10-XI); A. aculeata - folíolos (17-V) e frutos (11-XI); São Pedro: $S$. oleracea - folíolos (16-V) e frutos (10-VIII); G. brevispatha - frutos (10-VIII).

Metatriophtydeus spp.

Material Examinado: Cananéia: S. romanzoffiana - folíolos (18-I, 19-IV, 12-VII e 11-X); A. aculeatissimum - folíolos (12-VII); B. setosa - folíolos (12-VII); PariqueraAçu: $A$. aculeatissimum - folíolos (16-I); S. romanzoffiana - folíolos (16-I e 12-X); Piracicaba: A. aculeata - folíolos (07-II); E. edulis - folíolos (11-XI); São Pedro: $S$. oleracea - folíolos (16-V).

Metapronematus sp.

Material Examinado: Pariquera-Açu: B. setosa-folíolos (18-IV); Piracicaba: $A$. aculeata - foliolos (07-II).

Neolorryia sp.

Material Examinado: Cananéia: A. aculeatissimum - folíolos (12-VII); B. setosa folíolos (12-VII). 
Parapronematus sp.

Material Examinado: Cananéia: B. setosa - foliolos (12-VII); Pariquera-Açu: $S$. romanzoffiana - folíolos (11-VII); Piracicaba: $A$. aculeata - folíolos (07-II); $S$. romanzoffiana - folíolos (11-XI); E. edulis - brotos terminais (07-II).

Pretydeus sp.

Material Examinado: Pariquera-Açu: B. setosa - folíolos (16-I); E. edulis foliolos (16-I); A. aculeatissimum - folíolos (16-I); A. dubia - folíolos (12-X); Cananéia: A. aculeatissimum - folíolos (19-IV); São Pedro: G. brevispatha - folíolos $(11-\mathrm{XI})$.

\section{SUBORDEM ASTIGMATA \\ SUPERFAMÍLIA ACAROIDEA}

ACARIDAE Ewing \& Nesbitt

Neotropacarus sp.

Material Examinado: Cananéia: A .aculeatissimum - foliolos (18-I); B. setosa folíolos (18-I); E. edulis - folíolos (19-IV); Pariquera-Açu: S. romanzoffiana - folíolos (11-VII); A. aculeatissimum - folíolos (12-X); B. setosa - folíolos (12-X); Piracicaba: E. edulis - foliolos (16-V, 11-VIII); S. romanzoffiana - foliolos (11-VIII).

Tyrophagus sp.

Material Examinado: Cananéia: S. romanzoffiana - brotos terminais (11-X); Pariquera-Açu: S. romanzoffiana - frutos (18-IV); A. aculeatissimum - frutos (11VII). 


\section{WINTERSCHMIDTIIDAE Oudemans}

Saproglyphus sp.

Material Examinado: Cananéia: A. aculeatissimum - folíolos (18-I, 12-VII); B. setosa - brotos terminais (18-I); S. romanzoffiana - inflorescências e frutos (18-I e 11$\mathrm{X}$ ); Pariquera-Açu: E. edulis - folíolos (16-I), frutos (19-I); S. romanzoffiana - frutos (18-IV e 11-VII); A. aculeatissimum - folíolos (16-I); A. dubia - folíolos (16-I, 11VII); Piracicaba: E. edulis - folíolos (07-II); A. aculeata-folíolos (07-II e 11-XI); $S$. romanzoffiana - frutos (30-V); São Pedro: G. brevispatha - inflorescências (10-VIII); S. oleracea - frutos (10-VIII).

Acalvolia sp.

Material Examinado: Cananéia: S. romanzoffiana - folíolos (19-IV).

Calvolia sp.

Material Examinado: São Pedro: G. brevispatha - frutos (16-XI).

\section{SUPERFAMILIA HISTIOSTOMATOIDEA HISTIOSTOMATIDAE Berlese}

Material Examinado: Cananéia: G. schottiana - brotos terminais (19-IV).

Observações: Foi coletado apenas 1 indivíduo imaturo desta família o que impossibilitou sua identificação.

\subsection{Conclusões}

1) Não considerando os Eriophyidae, os ácaros da família Phytoseiidae apresentam maior diversidade de espécies nas Arecaceae estudadas. 
2) Os ácaros da família Ameroseiidae são os mais abundantes em inflorescências de Geonoma brevispatha e Geonoma schottiana.

3) Os folíolos das espécies vegetais amostradas apresentam maior diversidade de espécies de ácaros que as inflorescências, brotos terminais e frutos. 


\section{4 ÁCAROS STIGMAEIDAE (ACARI: RAPHIGNATHOIDEA) DE ARECACEAE DA MATA ATLÂNTICA do ESTADO DE SÃo PAULO.}

\section{Resumo}

Este trabalho relata os ácaros Stigmaeidae encontrados em plantas nativas da familia Arecaceae em áreas da Mata Atlântica no Estado de São Paulo. As coletas foram realizadas uma vez em cada estação do ano 2000 em Cananéia, Pariquera-Açu, Piracicaba e São Pedro, em nove espécies nativas de palmeiras. Duas espécies novas de Stigmaeidae foram encontradas e descritas, Agistemus palmae sp. n. e Agistemus caissara sp. n.

STIGMAEIDAE MITES (ACARI: RAPHIGNATHOIDEA) FROM ARECACEAE OF THE ATLANTIC FOREST IN THE STATE OF SÃO PAULO.

\section{Summary}

This work reports the Stigmaeidae mites found on native plants of the family Arecaceae, in areas of Atlantic Forest in the State of the São Paulo. The collections were done once in each season of the year 2000 in Cananéia, Pariquera-Açu, Piracicaba and São Pedro from nine native species of palm trees. Two new species of Stigmaeidae were found and species are described, Agistemus palmae sp. n. and Agistemus caissara sp. n.. 


\subsection{Introdução}

Tem aumentado recentemente a área plantada com espécies da familia Arecaceae na região sudeste do Brasil, principalmente dos palmitos juçara (Euterpe edulis Mart.) e pupunha (Bactris gasipes Kunth.). E. edulis é uma planta nativa do litoral sul do Brasil, enquanto B. gasipes é natural da Região Amazônica. $\mathrm{O}$ aumento da área plantada com estas palmeiras pode favorecer a ocorrência de populações elevadas de ácaros fitófagos, principalmente em locais onde a planta esteja sob algum tipo de estresse frequente (Deluchi, 1989).

A diversidade de espécies de ácaros que ocorrem em arecáceas no Brasil ainda é pouco conhecida. Estudos sobre a fauna de ácaros em palmeiras no Brasil têm sido conduzidos por Robbs \& Peracchi (1965), Aquino \& Arruda (1967), Flechtmann (1967; 1989; 1994; 1997a; 1997b;1998), Ferreira (1987), Santana \& Flechtmann (1994; 1998), Flechtmann \& Santana (1997), Gondim Jr. (2000), Gondim Jr. \& Moraes (2001).

Associados aos ácaros fitófagos, têm sido relatados ácaros predadores de diferentes familias, incluindo Stigmaeidae. De maneira geral, os Stigmaeidae correspondem ao segundo grupo de ácaros predadores mais frequentes e abundantes em plantas, após os ácaros da família Phytoseiidae. Algumas espécies de Stigmaeidae dos gêneros Agistemus Summers e Zetzellia Oudemans são predadoras conhecidas de ácaros fitófagos das familias Eriophyidae, Tetranychidae e Tenuipalpidae (Santos \& Laing, 1985; Gerson \& Smiley, 1990). Agistemus longisetus Gonzalez, alimenta-se de ovos e estágios ativos de ácaros fitófagos que infestam a cultura da maçã na Nova Zelândia (Collyer, 1964). Alguns Stigmaeidae têm sido citados como eficientes no controle de Brevipalpus phoenicis (Geijskes), limitando a reprodução desses ácaros em cultura de chá na Indonésia (Oomen, 1982). Agistemus exsertus Gonzalez foi assinalado como predador de Panonychus citri (McGregor) em citros no Japão (Tanaka, 1966) e outros ácaros fitófagos na cultura da maçã no Egito (Zaher et al., 1971). Em laboratório, tem sido demonstrado que este ácaro alimenta-se muito bem do eriofideo Aculops lycopersici (Massee) (Osman \& Zaki, 1986). Segundo Woolhouse \& Harmsen (1984), o ácaro Zetzellia mali Ewing controla melhor a população do eriofideo Aculus schlechtendali 
(Nalepa) que outros predadores em Ontário, Canadá, além de serem tolerantes aos inseticidas e fungicidas comumente utilizados no sul daquela localidade na cultura da maçã. Os tetraniquídeos Tetranychus urticae Koch e Tetranychus canadensis (McGregor) são ocasionalmente fontes de alimento para o Z. mali em maçã no mesmo país (Hoyt, 1969; White \& Laing, 1978). Zetzellia graeciana Gonzalez foi citado como predador de Panonychus ulmi (Koch) em plantações de uva e maçã na Itália (Inserra, 1970). Dosse (1967) descreveu Agistemus faneri alimentando-se de tetraniquídeos no Libano. Agistemus africanus (Meyer \& Ryke) é citado como predador de P. ulmi em maçã na África do Sul (Laing \& Knop, 1983). Uma correlação negativa entre os ácaros das familias Stigmaeidae e Phytoseiidae foi observada, em citros, no Estado de São Paulo. Com a redução da população de Phytoseiidae, devido ao uso de produtos químicos, a população de Stigmaeidae aumentou e a população do eriofídeo Phyllocoptruta oleivora (Ashmead) diminuiu de acordo com Sato ${ }^{3}$. Não se conhece ainda exatamente a causa desta observação. Parece, entretanto, que isto se dá em função da interação de ácaros Phytoseiidae e Stigmaeidae. Segundo Croft \& MacRae (1993), Z. mali preda e pode ser predado pelos fitoseídeos Typhlodromus pyri Scheuten e Metaseiulus occidentalis (Nesbitt), especialmente quạndo há escassez de ácaros fitófagos nas folhas de maçã nos Estados Unidos da América.

Ferla (2001) estudou a biologia de Agistemus floridanus Gonzalez coletado em seringueira (Hevea brasiliensis Muell. Arg.) no Estado do Mato Grosso, concluindo que este ácaro pode ser mais importante para o controle de Calacarus heveae Feres e Tenuipalpus heveae Baker do que outros predadores encontrados no mesmo substrato.

A familia Stigmaeidae pertence à subordem Prostigmata. De modo geral, os representantes desta familia apresentam alguns escudos dorsais e coloração geralmente alaranjada, amarelada, esverdeada ou avermelhada (Flechtmann, 1975). O palpo apresenta o chamado complexo "unha - dedão". As coxas I e II são distintamente separadas das coxas III e IV.

\footnotetext{
${ }^{3}$ SATO, M. (Instituto Biológico). Comunicação pessoal, 2000.
} 
As quelíceras apresentam os dígitos móveis transformados em estiletes. Não apresentam escudos ventrais, e as aberturas genital e anal são contíguas (Krantz, 1978). Stigmaeidae é uma família relativamente pequena. Até 1990, eram conhecidos nesta familia 24 gêneros e 314 espécies (Sepasgosarian, 1990).

Os gêneros conhecidos nesta família são: Agistemus Summers, Cheylostigmaeus Willmann, Eryngiopus Summers, Erynglupusopsis Tseng, Eustigmaeus Oudemans, Ledermuelleriopsis Willmann, Macrostigmaeus Oudemans, Makilingeria Rimando \& Corpuz-Raros, Mecognatha Wood, Mediolata Canestrini, Mendanaia Wood, Mullederia Wood, Neilstigmaeus Gerson \& Meyer, Parastigmaeus Kuznetzov, Paravillersia Kuznetzov, Pilonychiopus Meyer, Postumius Kuznetzov, Prostigmaeus Kuznetzov, Pseudostigmaeus Wood, Stigmaeus Koch, Storchia Oudemans, Summersiella Gonzalez, Villersia Oudemans, Villersiella Willmann, Zetzellia Oudemans e Zetzelliopsis Willmann (Sepasgosarian, 1990; Gerson \& Meyer, 1995; Matioli, 2002).

André (1977), Chaudri (1965), Chaudri et al. (1974), Ehara \& Oomen (1983), Ehara \& Wongsiri (1984), Flechtmann et al (1999), Gerson (1972), Gonzalez-Rodriguez (1963; 1965), Meyer (1969), Meyer \& Ueckermann (1989), Simons (1967), Soliman (1975), Summers $(1960 ; 1962 ; 1966)$, Summers \& Ehara (1965), Summers \& Price (1961), Tseng (1982) e Wood $(1966 ; 1967 ; 1971 ; 1972 a ; 1972 b ; 1974)$, contribuíram com importantes trabalhos para identificação de espécies de Stigmaeidae. As publicações de Meyer (1969) e Meyer \& Ueckermann (1989) têm importância significativa para os trabalhos de taxonomia de Stigmaeidae no Brasil, por se referir às espécies de um pais com condições climáticas semelhantes às de algumas regiões do Brasil.

Alguns representantes da familia Stigmaeidae têm sido relatados no Brasil, principalmente no Estado de São Paulo. Flechtmann $(1968,1981)$ relatou os seguintes taxa : Agistemus sp., Eustigmaeus (=Ledermuelleria) sp. e Zetzellia sp., Storchia (=Apostigmaeus) pacificus, Eustigmaeus (=Ledermuelleria) microsengnis (Chaudri) e Stigmaeus constrictus Summers.Vila \& Flechtmann (1970) relataram alguns gêneros de ácaros em essências florestais, incluindo Eustigmaeus (=Ledermuelleria), Macrostigmaeus, Mullederia e Zetzellia. Chiavegato $(1971,1972)$ assinalou a presença 
de Agistemus sp. na cultura do algodão. Flechtmann (1985) descreveu Eustigmaeus brionemus, coletado sobre briófitas em Campinas. Feres (1993) constatou a presença de Agistemus sp. e Zetzellia sp., em seringueiras e plantas silvestres, enquanto Feres (2000) citou a ocorrência de Zetzellia sp.. Mineiro (2000) encontrou 4 espécies do gênero Eustigmaeus (=Ledermuelleria) no Município de Piracicaba. Matioli (2002) descreveu duas espécies de Stigmaeidae coletados em citros. Flechtmann \& Moraes (2000) sumarizaram as espécies de Stigmaeidae relatadas no Estado de São Paulo; poucos relatos se referem a Stigmaeidae de outros estados brasileiros. Flechtmann (1995) descreveu Agistemus tarsilobus, coletado em bambu no Estado do Rio de Janeiro. Ferla \& Moraes (1998) citaram a ocorrência de Agistemus sp. e Eustigmaeus sp. em pomares de maçã no Rio Grande do Sul. Ferla (2001) estudou a biologia de Agistemus floridanus Gonzalez coletado em seringueira no Estado do Mato Grosso.

O objetivo deste trabalho foi identificar as espécies de Stigmaeidae em arecáceas nativas da Mata Atlântica no Estado de São Paulo e preparar uma chave dicotômica para auxiliar na identificação das espécies encontradas sobre estas plantas.

\subsection{Material e Métodos}

Realizou-se um levantamento de ácaros da família Stigmaeidae, no período de janeiro a agosto de 2000, nos municípios de Cananéia, Pariquera-Açu, Piracicaba e São Pedro.

Foram amostradas 9 dentre as espécies mais comuns de Arecaceae nativas dos locais considerados.

As palmeiras amostradas foram Euterpe edulis Mart., Syagrus oleracea (Mart.) Becc., Syagrus romanzoffiana (Cham.), Attalea dubia (Mart.) Burret, Acrocomia aculeata (Jacq.) Lodd., Geonoma schottiana Mart., Geonoma brevispatha Barb. Rodr., Astrocarium aculeatissimum (Schott) Burret e Bactris setosa Mart.. Estas corresponderam as espécies visualmente mais comuns de Arecaceae nativas dos locais considerados. Algumas destas estavam presentes em mais de um local de coleta. A amostra de cada planta constou da brotação terminal (apenas as folhas em 
desenvolvimento foram tomadas, sem retirar o meristema apical) e vinte folíolos tomados de folhas da região mediana da copa de cada planta, os folíolos foram retirados de uma única folha, sendo 5 do terço apical, 10 do terço mediano e 5 do terço basal. Sempre que presentes, 20 ráquilas (ramificações do eixo principal da inflorescência) e 20 frutos por planta também foram amostrados. Estes foram tomados ao acaso.

Todos os foliolos de cada folha foram acondicionados em saco de papel, que por sua vez foi colocado em um saco plástico que foi acondicionado em uma caixa de isopor refrigerada $\left(12-21^{\circ} \mathrm{C}\right)$, para evitar perda de ácaros durante o transporte. Frutos, flores e brotos terminais foram colocados em recipientes de plástico de 5 litros, sendo $30 \%$ deste volume ocupado com álcool etilico a $70 \%$. Logo após a colocação, os recipientes foram agitados para imobilizar os ácaros e fazê-los cair na solução.

O material coletado foi levado para o laboratório de Acarologia do Setor de Zoologia do Departamento de Entomologia, Fitopatologia e Zoologia Agrícola da Escola Superior de Agricultura "Luiz de Queiroz" - Universidade de São Paulo, sendo os recipientes com inflorescências, frutos ou brotos terminais mantidos à temperatura ambiente, enquanto os folíolos foram armazenados em refrigerador a aproximadamente $10^{\circ} \mathrm{C}$, por um período máximo de 10 dias, até a coleta dos ácaros. No laboratório, os Stigmaeidae foram coletados com auxilio de pincel de cerdas finas sob microscópio estereoscópio, sendo posteriormente montados entre lâmina e lamínula para microscopia em meio de Hoyer (Flechtmann, 1975). As espécies novas foram desenhadas e medidas com auxilio de microscópio óptico. As medições são dadas em micrômetros $(\mu \mathrm{m})$.

Todos os espécimes analisados foram coletados por G. P. de Arruda Filho, sendo os holótipos depositados no Setor de Zoologia da ESALQ - USP. Representantes de outras espécies encontradas foram também depositados na mesma Instituição.

\subsection{Resultados e Discussão}

São citadas a seguir as espécies de Stigmaeidae encontradas neste trabalho. 
Agistemus palmae Arruda Filho \& Moraes, sp. n.

(Figuras 7-8)

DIAGNOSE - Essa espécie difere de Agistemus striolatus Gonzalez, 1965 por apresentar a razão vi/vi-vi distintamente maior, distância $c_{l}-c_{I}$ cerca de metade do comprimento de $c_{1}$ e o comprimento de $h_{2}$ menor. Difere também de Agistemus brideliae Gonzalez, 1965 por apresentar a placa mediana levemente esclerotizada e com estrias longitudinais.

FÊMEA ADULTA:

Gnatossoma: palpo (Figura 7A): fềmur com 3 setas, das quais 2 são pilosas, gênu com apenas 1 seta; tíbia com 2 setas e 2 "garras"; tarso com 6 setas, sendo 2 delas solenídia e 1 eupatídia na extremidade. Propodossoma (Figura 7B): placa propodossomal inteira, não ornamentada, com 3 pares de setas ( $v i$, ve e $s c i)$ pilosas e bifurcadas na extremidade; corpos pós-oculares presentes; seta pré-ocular (ve) aproximadamente tão longa (102) quanto a seta dorso-lateral $e_{2} 103$; vi 75, sci 99, vi-vi 28, vi-ve 20, ve-sci 42. Histerossoma: (Figura 7B) placa mediana dorsal levemente esclerotizada com 5 pares de setas e com discretas estrias longitudinais; setas dorsais alongadas, pilosas, bifurcadas na extremidade e inseridas em pequenos tubérculos; $c_{1} 83$, $d_{1} 85, e_{1} 101, d_{2} 99, e_{2} 103, v i-v i 35, c_{1}-d_{1} 66, e_{1}-e_{1} 22, d_{2}-e_{2} 52$; setas $c_{2}(75)$ e $f_{1}(74) \mathrm{em}$ placas separadas; placa suranal: $h_{1} 45, h_{2} 29, h_{1}-h_{1} 15$. Ventre (Figura 7C): 4 pares de setas anogenitais $\left(g, p s_{1}, p s_{2}, p s_{3}\right)$ e 1 par de setas aggenitais (ag). Pernas (Figura 8): quetotaxia da coxa para o tarso, (solenídia entre parênteses): I 2 - 1 - 5 - 3 - 5 (1) - 12 (1); II 1 - 1 - 4 - 1 - 5 (1) - 9 (1); III 2 - 1 - 2 - 0 - 5 (1) - 7 (1); IV 2 - 1 - 2 - 0 - 6 (1) - 7. MACHO: desconhecido.

LOCALIDADE E MATERIAL TIPO: Holótipo fềmea, em folíolo $S$. oleracea, São Pedro, Estado de São Paulo, 16-V-00, G. P. de Arruda Filho.

ETIMOLOGIA: palmae, referente ao nome comumente atribuído às plantas da familia (Arecaceae) a que pertence a espécie da planta em que o ácaro foi encontrado. 


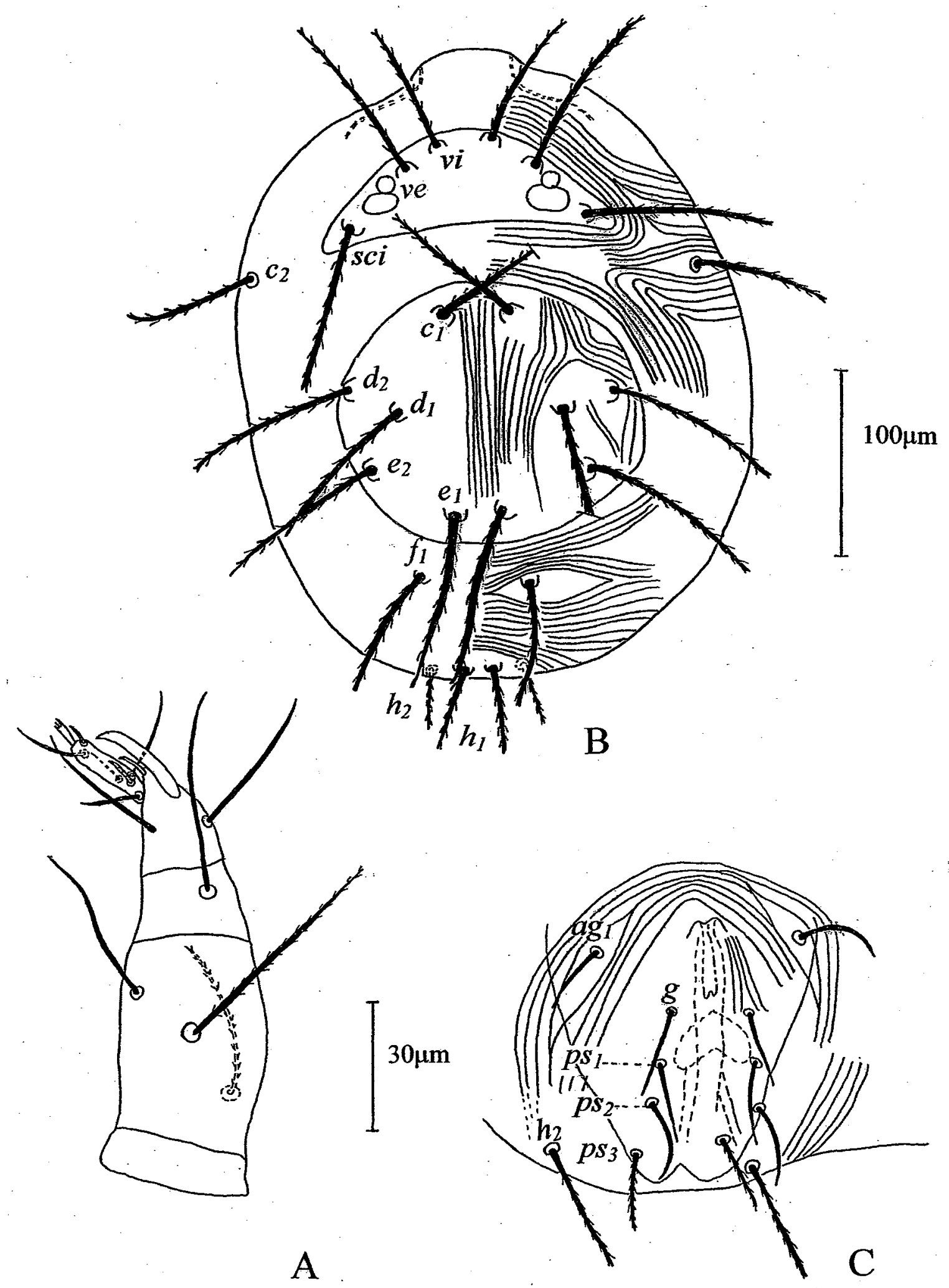

Figura 7- Fêmea adulta de Agistemus palmae sp. n. A, palpo direito ; B dorso; $\mathrm{C}$ abertura anogenital. 

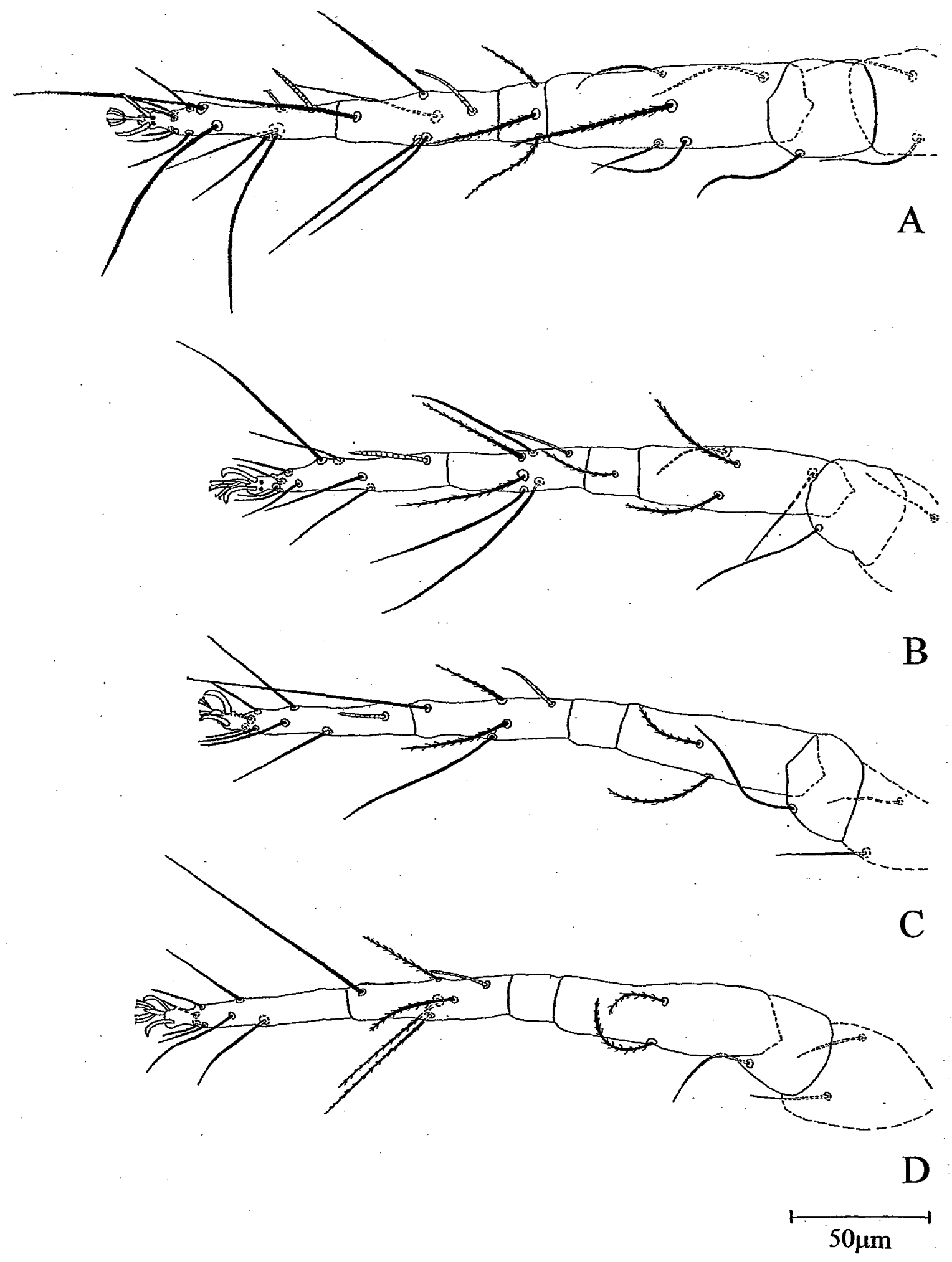

Figura 8- Fêmea adulta de Agistemus palmae sp. n. A, perna I; B, perna II; C, perna III; $D$, perna IV. 
Agistemus caissara Arruda Filho \& Moraes, sp. n.

(Figuras 9-10)

DIAGNOSE: Esta espécie difere de Agistemus novazelandicus Gonzalez, 1963 por apresentar a seta sci mais que 2 vezes tão longa quanto a seta $c_{2}, h_{2}$ bem menor, seta pilosa do fềmur I menor, seta $c_{2}$ menor em comprimento que as setas $c_{1}$ e $d_{1} ; p s_{3}$ maior que outras setas anogenitais; com 2 setas pilosas nas tíbias I e II.

FÊMEA ADULTA:

Gnatossoma: palpo (Figura 9A) fềmur com 2 setas dorsais, 1 das quais pilosa, e 1 ventral; gênu com apenas 1 seta dorsal; tíbia com 1 seta dorsal, 1 ventral e 2 garras; tarso com 7 setas, sendo 2 destas solenídia e 1 eupatídia na extremidade. Propodossoma: placa propodossomal (Figura 9B) inteira, areolada, com 3 pares de setas (vi, ve e $s c i$ ) pilosas $\mathrm{e}$ bifurcadas na extremidade; corpos pós-oculares presentes; vi 30, ve 61, sci 56, vi-vi 25 , vi-ve 20, ve-sci 30. Histerossoma (Figura 9): placa mediana dorsal bem delimitada $\mathrm{e}$ areolada, com 5 pares de setas; setas dorsais robustas, pilosas e bifurcadas na extremidade; $c_{1} 44, d_{1} 44, e_{1} 51, d_{2} 49, \mathrm{e}_{2} 57, c_{1}-c_{1} 49, c_{1}-d_{1} 52, e_{1}-e_{1} 33, d_{2}-e_{2} 53$; setas $c_{2}$ (22) e $f_{1}(40)$ em placas separadas; placa suranal: $h_{1} 32, h_{2} 22, h_{1}-h_{1} 9$. Ventre (Figura 9C): 4 pares de setas anogenitais $\left(g, p s_{l}, p s_{2}, p s_{3}\right)$ e 2 pares de setas aggenitais $\left(a g_{l} \mathrm{e}\right.$ $a g_{2}$ ). Pernas (Figura 10): quetotaxia da coxa para o tarso (solenídia entre parênteses):I 2 - 1 - 5 - 3 - 5 (1) - 12 (1); II 1 - 1 - 4 - 1 - 5 (1) - 9 (1); III 2 - 1 - 2 - 0 - 4 (1) - 7 (1); IV 2 $-1-2-0-5(1)-7$.

MACHO: desconhecido.

LOCALIDADE E MATERIAL TIPO: Holótipo fềmea e um parátipo fềmea em folíolo de A. aculeatissimum, Cananéia, Éstado de São Paulo, 12-VII-2000, G. P. de Arruda Filho.

ETIMOLOGIA: caissara, referente ao habitante de Cananéia, municipio onde o ácaro foi coletado. 

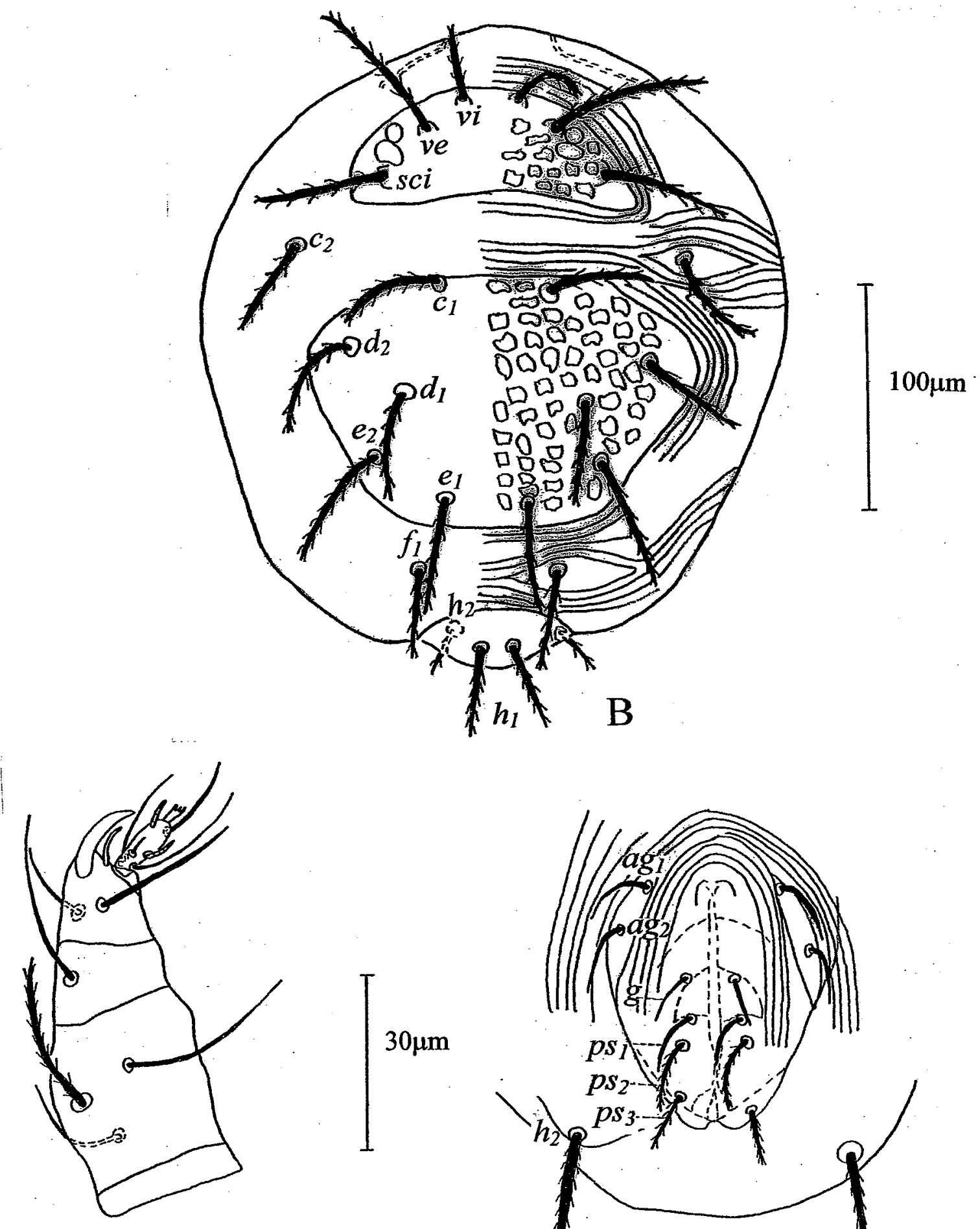

A

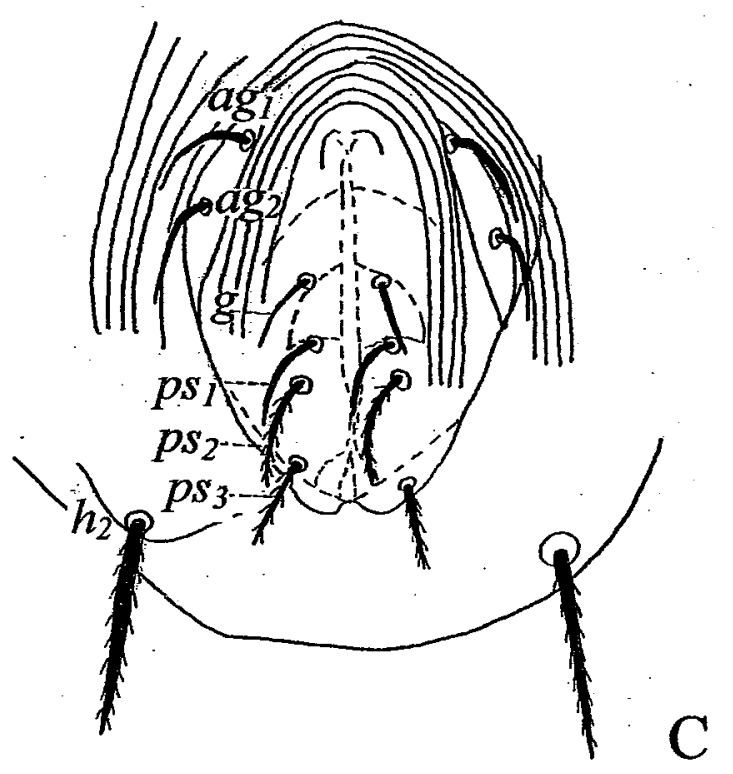

Figura 9- Fêmea adulta de Agistemus caissara sp. n. A, palpo esquerdo; B, dorso; C, abertura anogenital. 


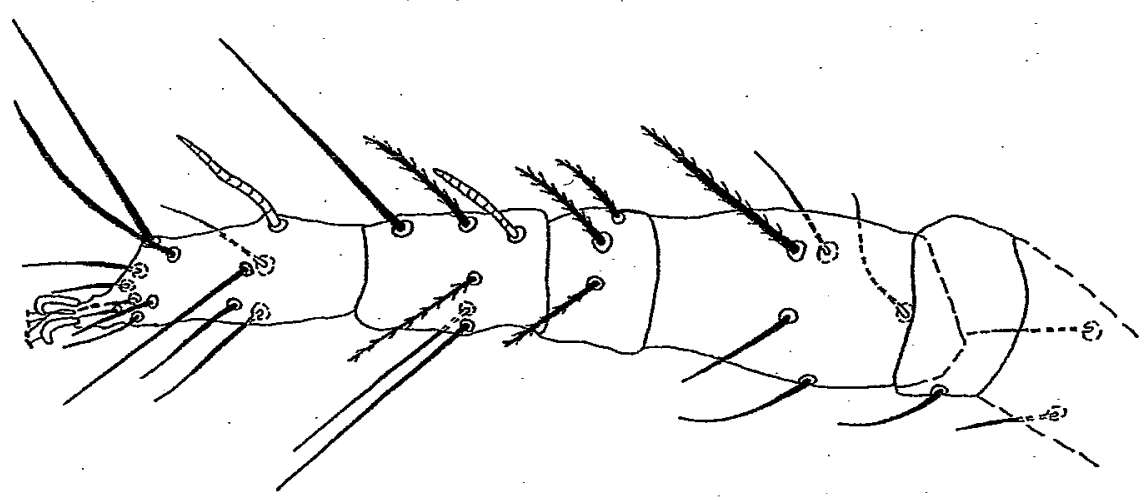

A

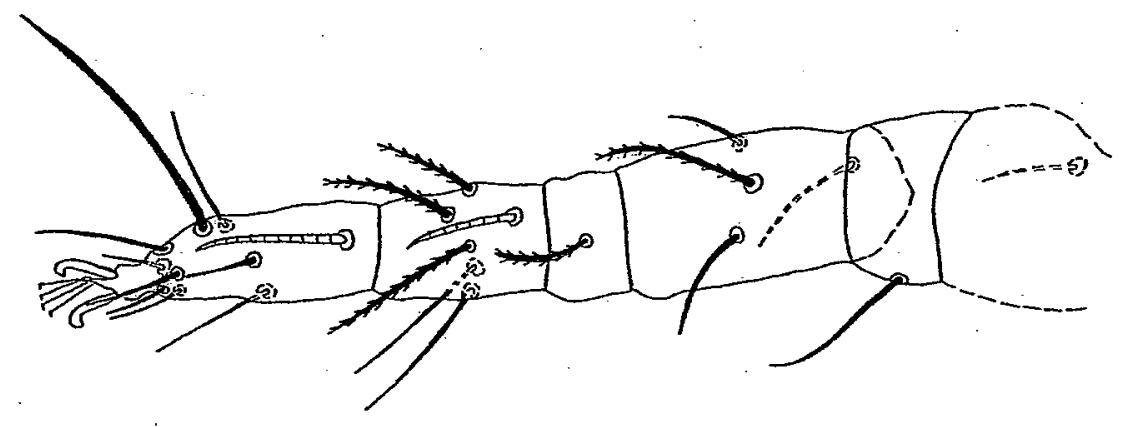

B

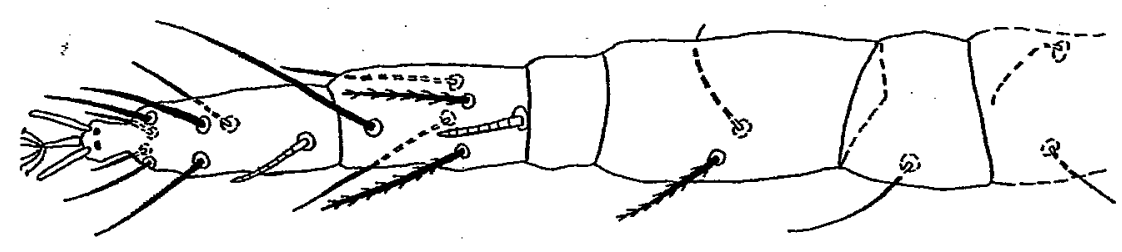

$\mathrm{C}$

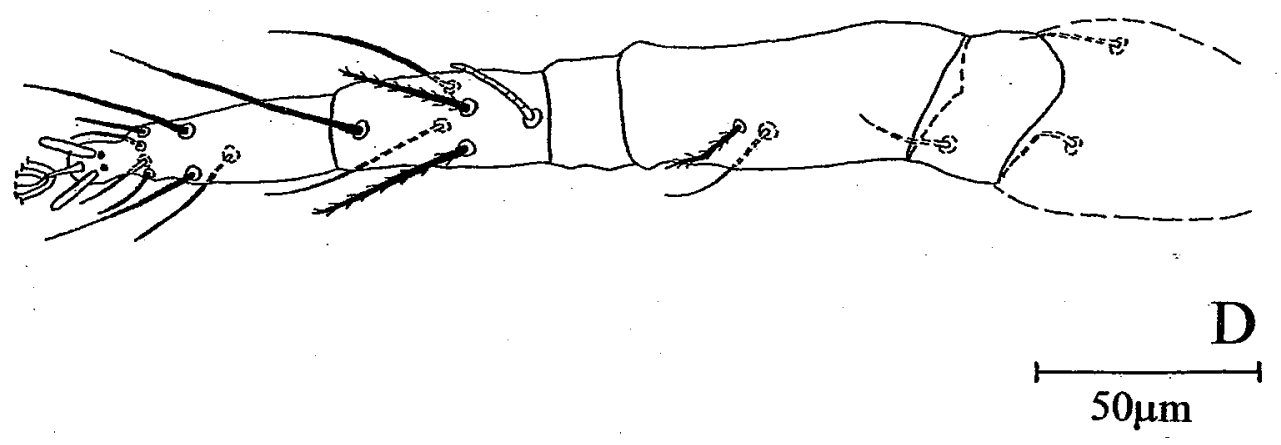

Figura 10- Fêmea adulta de Agistemus caissara sp. n. A, perna I; B, perna II; C perna II; D, perna IV. 


\section{Agistemus floridanus Gonzalez}

Agistemus floridanus Gonzalez, 1965: 42.

DISTRIBUIÇÃO: Brasil, Costa Rica, Estados Unidos da América do Norte e México. ESPÉCIMES EXAMINADOS: Cananéia, A. aculeatissimum VII-00, X-00; $G$. schottiana I-00, IV-00, VII-00; S. romanzoffiana IV-00, VII-00, X-00; Pariquera-Açu, A. aculeatissimum I-00, IV-00; S. romanzoffiana IV-00, VII-00; E. edulis IV-00, VII-00; A. dubia VII-00; Piracicaba, A. aculeata II-00, V-00, XI-00; E. edulis II-00, XI-00; S. romanzoffiana VIII-00, XI-00; 1 fềmea identificada como A. floridanus em uma lâmina com a indicação "Paratype series; R. H. Gonzalez, 20/7/60, Parrish Fruit, Florida", da Florida State Collection of Arthropods (F. S. C. A) e 2 machos identificados como parátipos em uma lâmina da Florida State Collection of Arthropods (F. S. C. A) com a indicação "Paratypes, 06/1/53, Lake Alfred, Florida".

OBSERVAÇõES: Foram encontradas 61 fêmeas adultas desta espécie, 15 das quais foram medidas. As fềmeas medidas apresentaram: o comprimento das setas ve aproximadamente 2 vezes maior que a distância ve-sci, diferindo da informação apresentada na chave a qual acompanha a descrição original, que indica ser a seta ve no máximo 1,5 vezes maior que a distância ve-sci. $\mathrm{Na}$ fêmea da série de tipos examinados neste estudo a seta ve é cerca de 1,7 vezes maior que a distância ve-sci. As fềmeas medidas apresentaram também a seta $d_{2}$ aproximadamente 1,3 vezes maior que a distância $d_{2}-e_{2}$, sendo também observado no parátipo fêmea e diferindo da descrição original a qual indica ser aquela seta igual ou menor que a distância $d_{2}-e_{2}$. Apresenta-se a seguir uma descrição da larva, protoninfa e deutoninfa, assim como redescrição da fêmea e macho adultos. Os adultos foram obtidos neste estudo, $\mathrm{e}$ as formas jovens foram criadas em laboratório a partir de uma população obtida de Hevea brasiliensis Muell. Arg. do Estado do Mato Grosso, identificada como A. floridanus.

\section{LARVA $(\mathrm{N}=4)$ :}

Prodorso (figura 11A): placa propodossomal inteira, não ornamentada, com 3 pares de setas e corpos pós-oculares visíveis: $v i=27,5-28,7 ; v e=45-50$ e $s c i=40-42,5$. 
Histerossoma (Figura 11A): placa mediana ausente; setas $c_{l}, d_{l}$ e $d_{2}$ inseridas individualmente em pequenas placas; setas $e_{1}$ e $e_{2}$ inseridas em uma única placa: $c_{1}=35-$ $39 ; c_{2}=21-23 ; d_{1}=35-38 ; d_{2}=35-38 ; e_{1}=35-40 ; e_{2}=34-38 ; f_{1}=21-23 ; h_{1}=13-15$ e $h_{2}=13-14$. Região ventral do epistossoma (Figura 11B): três pares de setas anais ( $p s_{1}, p s_{2}$ e $\left.p s_{3}\right)$. Pernas (Figura 12): quetotaxia da coxa para o tarso (solenídia entre parênteses) I 1 - 0 - 4 - 2 - 4 (1) - 11 (2); II 0 - 0 - 4 - 1- 4 (1) - 8 (2); III 0 - 0 - 2 - 0 - 5 (1) - 8 .

PROTONINFA $(\mathrm{N}=4)$ :

Prodorso (Figura 13A): placa propodossomal inteira, não ornamentada, com três pares de setas e corpos pós-oculares visíveis: vi=30-35; ve=45-53; $s c i=43-48$. Histerossoma (Figura 13A): placa mediana presente, não ornamentada, setas humerais $\left(c_{2}\right)$ e intercalares dorsais $\left(f_{1}\right)$ localizadas em placas separadas: $c_{1}=36-43 ; c_{2}=23-28$; $d_{1}=36-40 ; d_{2}=33-38 ; e_{1}=40-44 ; e_{2}=39-43 ; f_{1}=23-25 ; h_{1}=13-18 ; h_{2}=9-11$. Região ventral do epistossoma (Figura 13B): 3 pares de setas anais $\left(p s_{1}, p s_{2}\right.$ e $\left.p s_{3}\right)$ e 1 par de setas aggenitais $\left(a g_{1}\right)$. Pernas (Figura 14): quetotaxia da coxa para o tarso, (solenídia entre parênteses) I 2 - 0 - 4 - 3 - 5 (1) - 12 (1); II 0 - 0 - 4 - 1 - 5 (1) - 8 (1); III 2 - 0 - 2 - 0 - 5 (1) - 7 (1); IV 0 - 0 - 1 - 0 - 5 (1) - 6.

DEUTONINFA $(\mathrm{N}=2)$ :

Prodorso (Figura 15A): placa propodossomal inteira, não ornamentada, com 3 pares de setas e corpos pós-oculares visíveis: $v i=38 ; v e=59 ; s c i=46-53$. Histerossoma (Figura 15A): placa mediana presente, não ornamentada; setas humerais $\left(c_{2}\right) \mathrm{e}$ intercalares dorsais $\left(f_{1}\right)$ localizadas em placas separadas: $c_{1}=45-50 ; c_{2}=28-35 ; d_{1}=43-48$; $d_{2}=40-43 ; \quad e_{1}=45-50 ; \quad e_{2}=45-48 ; f_{1}=28-33 ; h_{1}=18-23 ; h_{2}=15$. Região ventral do epistossoma (Figura 15B): 3 pares de setas anais $\left(p s_{1}, p s_{2}\right.$ e $\left.p s_{3}\right)$ e 2 pares de setas aggenitais ( $a g_{1}$ e $a g_{2}$ ). Pernas (Figura 16): quetotaxia da coxa para o tarso, (solenídia entre parênteses) I 2 - 1 - 5 - 4 - 5 (1) - 12 (1); II 1 - 1 - 4 - 1 - 5 (1) - 9 (1); III 2 - 1 - 2 $0-5(1)-7(1) ;$ IV $2-0-2-0-5(1)-7$. 

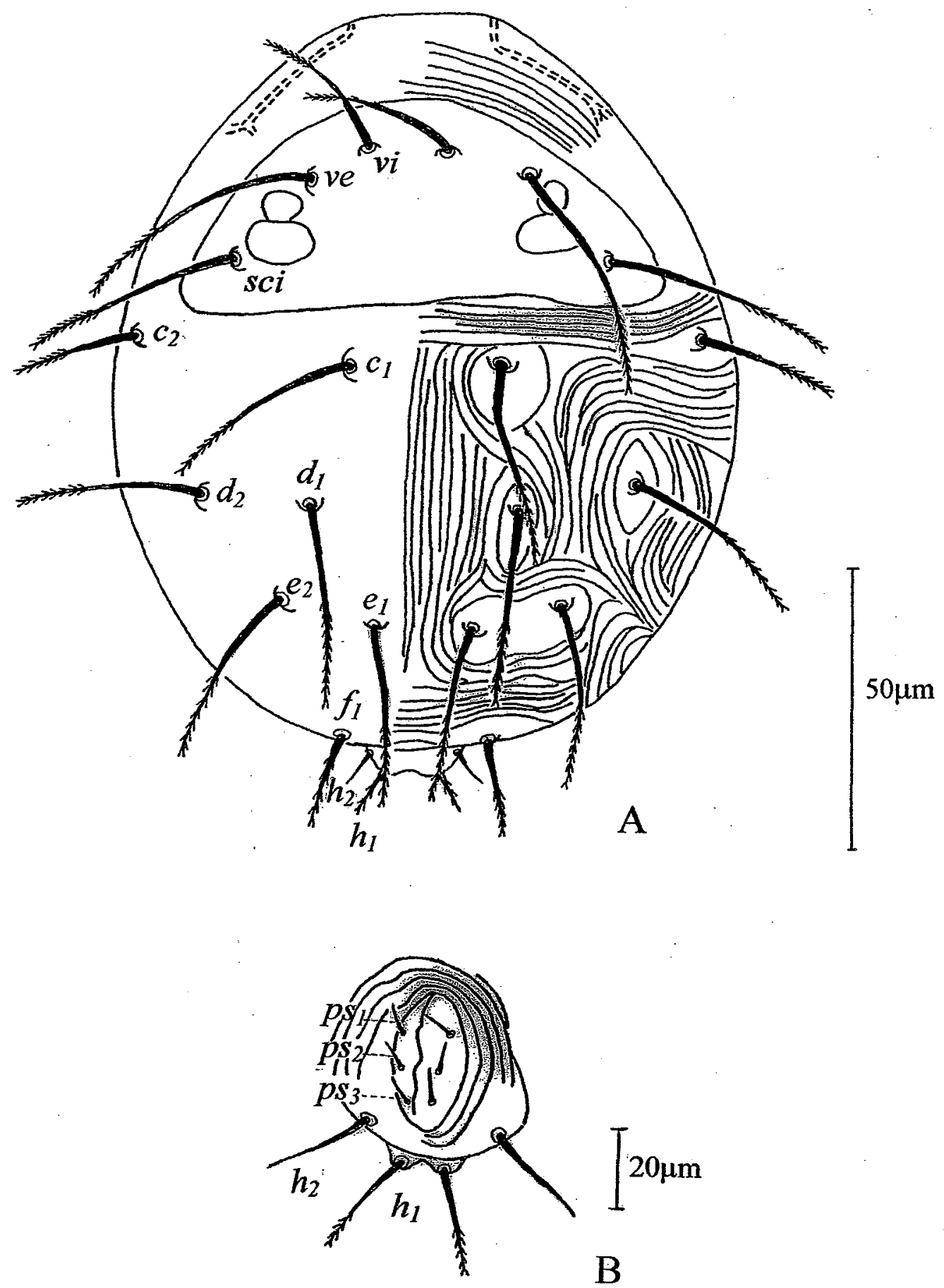

Figura 11 - Larva de Agistemus floridanus. A, idiossoma; B, opistogáster. 

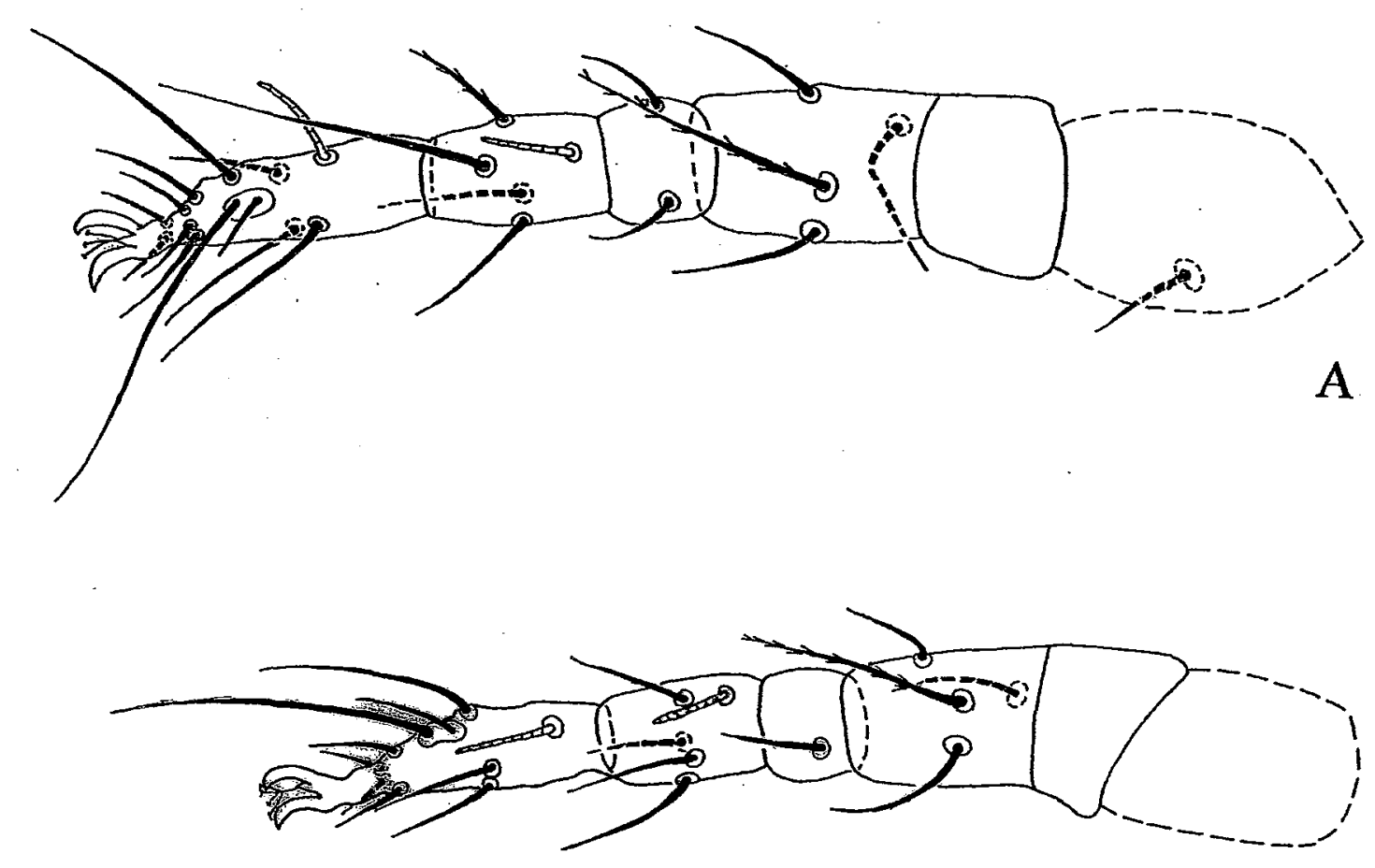

B

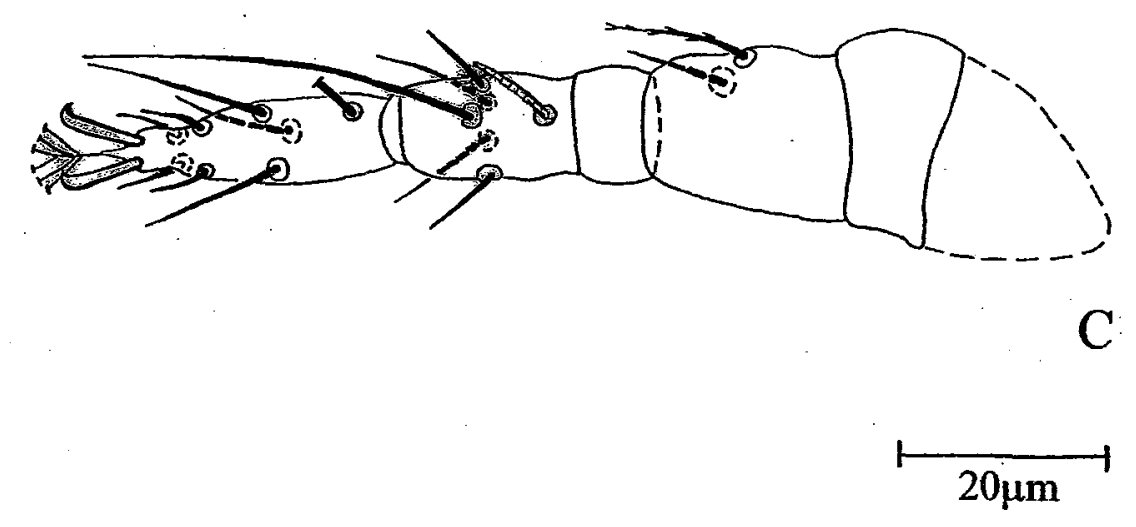

Figura 12 - Larva de Agistemus floridonus. A, perna I; B, perna II; C, perna III. 

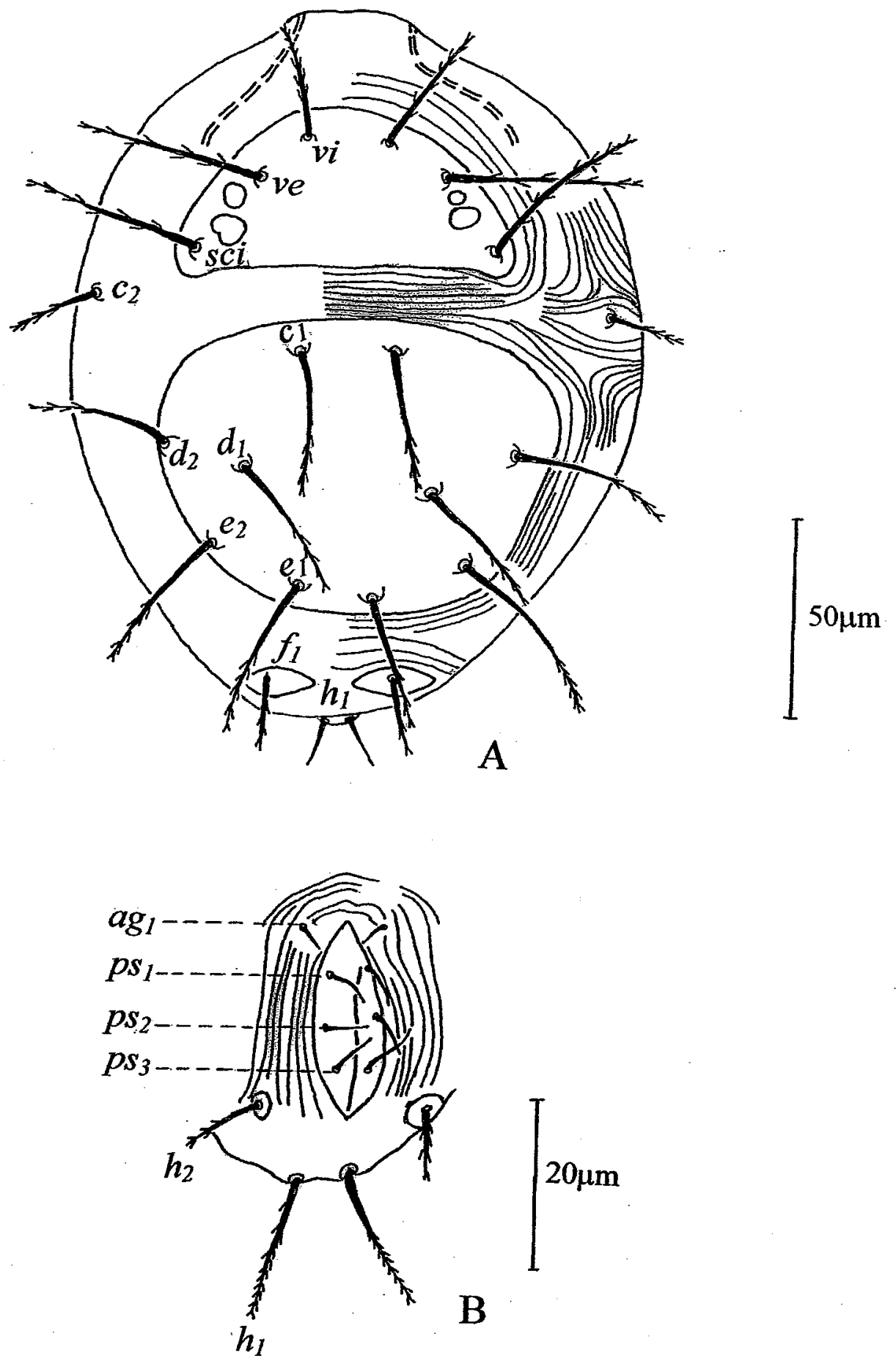

Figura 13 - Protoninfa de Agistemus floridanus. A, idiossoma; B, opistogáster. 

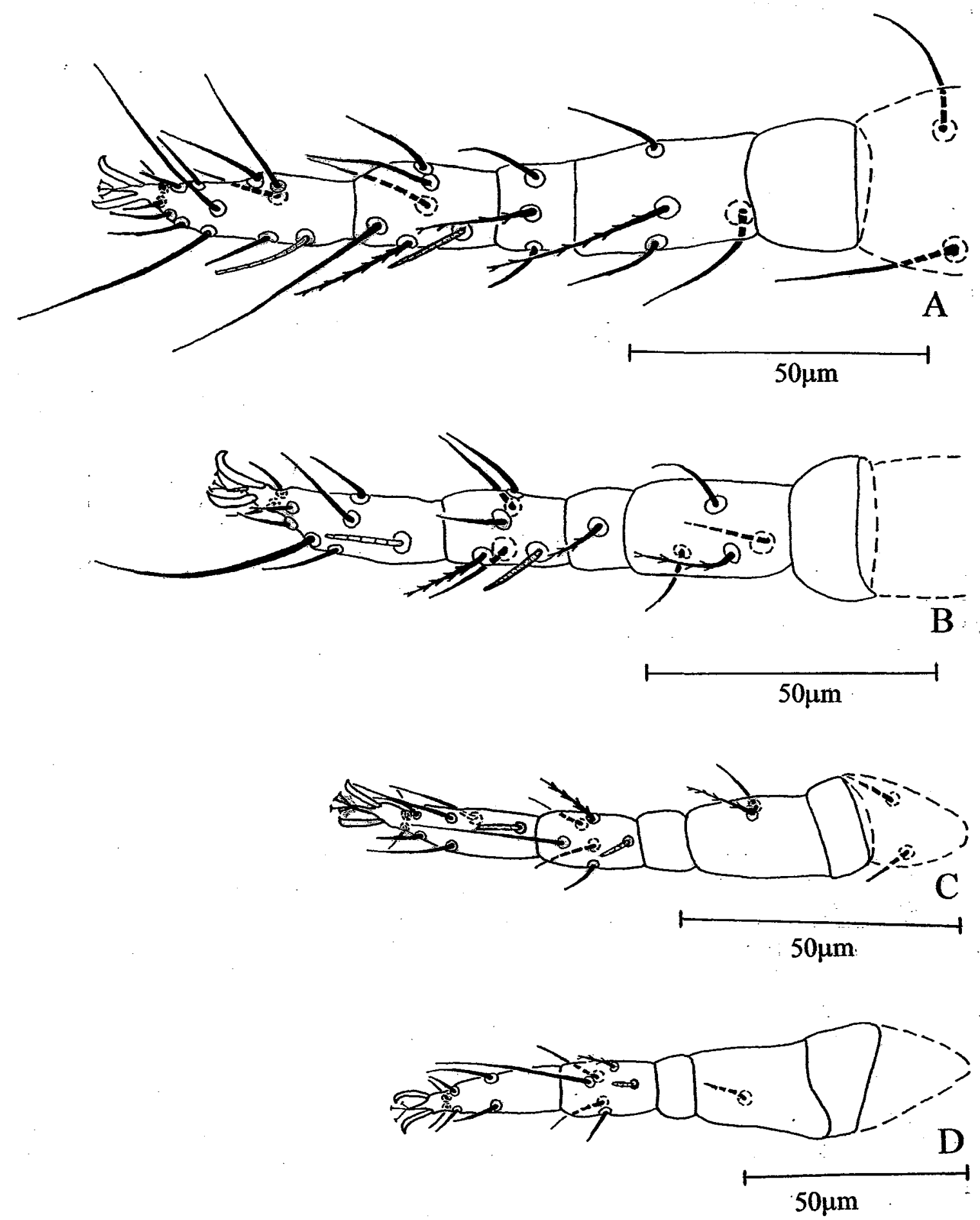

Figura 14 - Protoninfa de Agistemus floridanus. A, perna I; B, perna II; C, perna III; D, perna IV. 

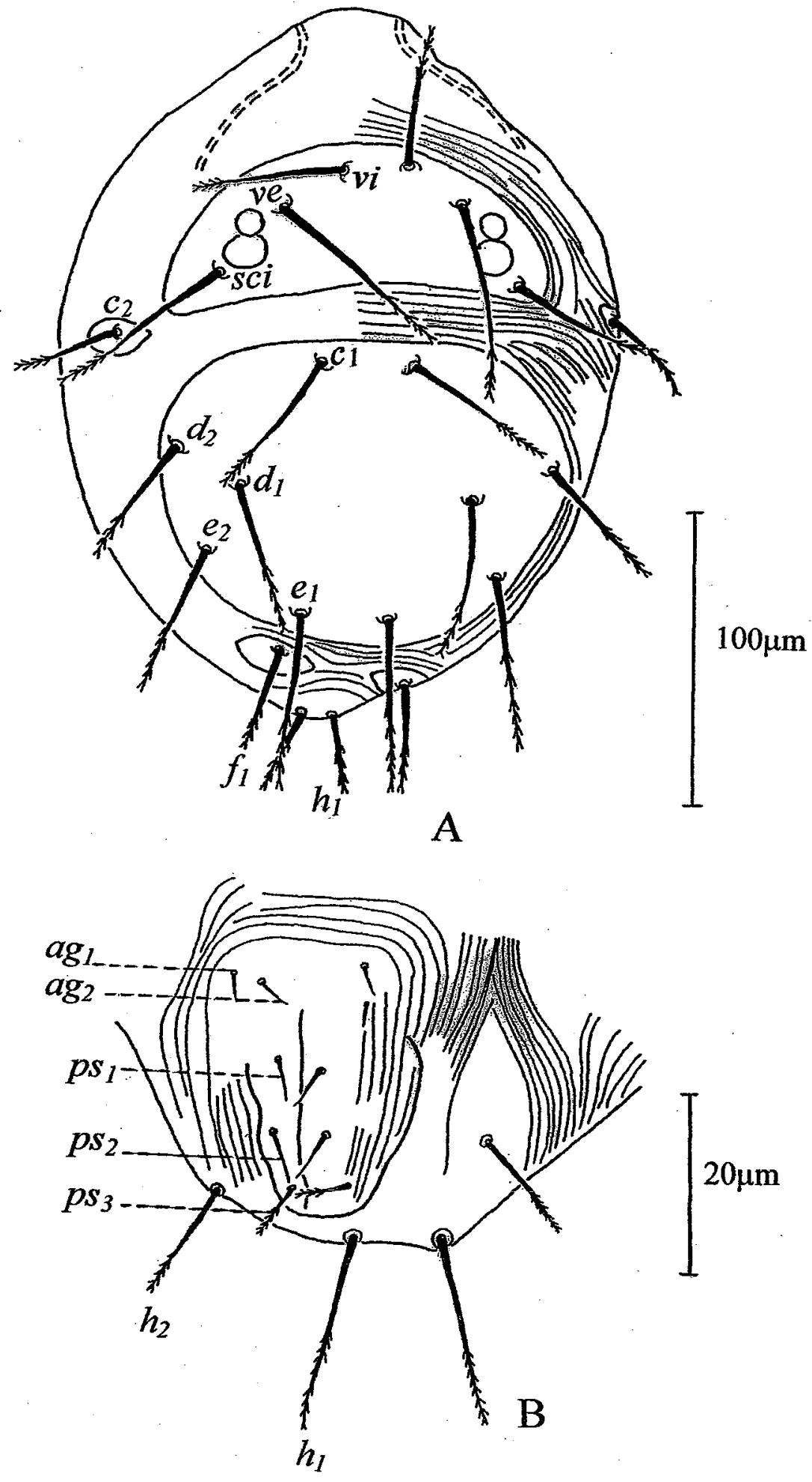

Figura 15 - Deutoninfa de Agistemus floridanus. A, idiossoma; B, opistogáster. 

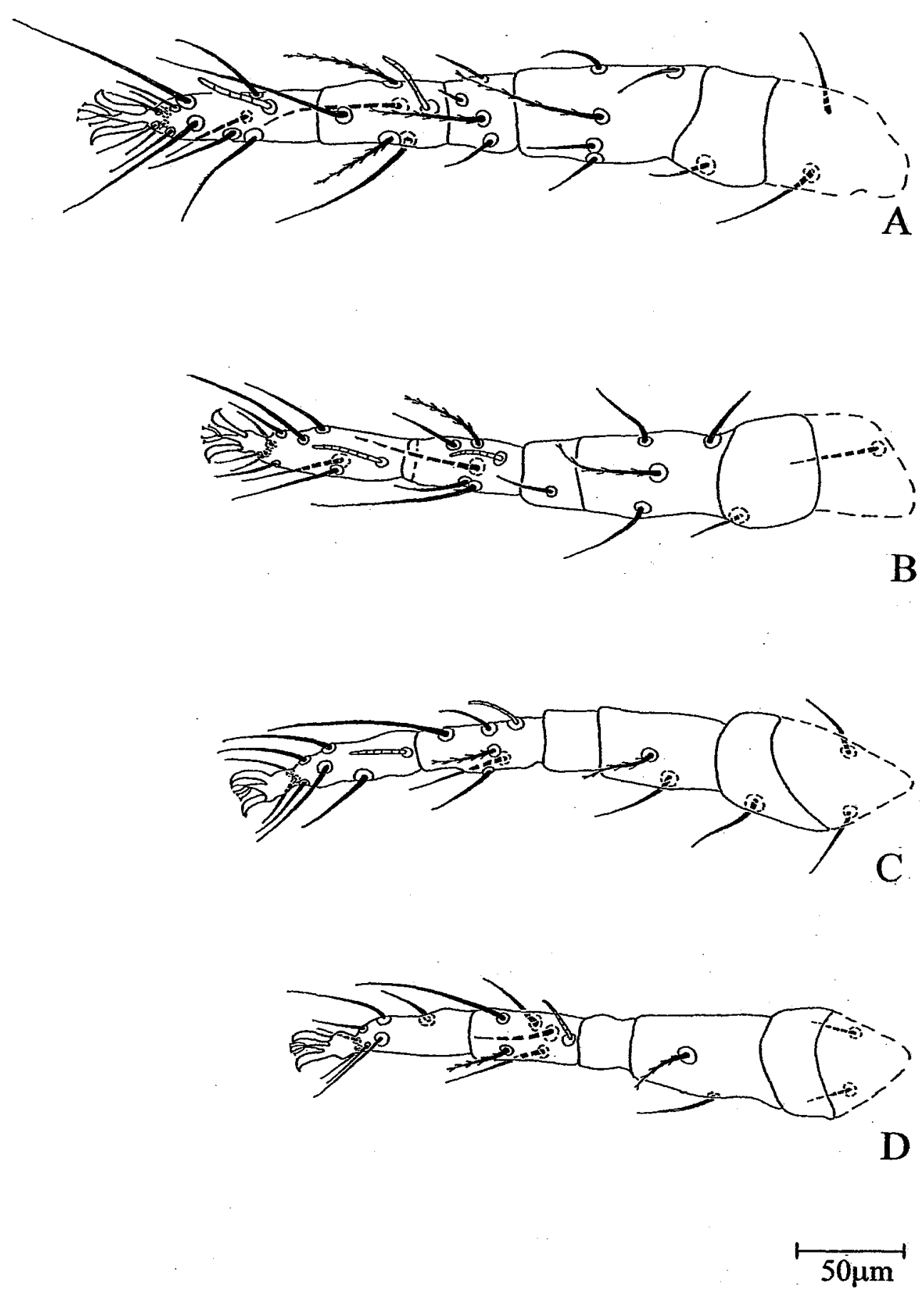

Figura 16 - Deutoninfa de Agistemus floridanus. A, perna I; B, perna II; C, perna III; D, perna IV. 


\section{FÊMEA ADULTA $(\mathrm{N}=4)$}

Gnatossoma: palpo (figura 17A) fêmur com 3 setas das quais 1 é pilosa, gênu com apenas 1 seta pilosa; tíbia com 2 setas e 2 "garras"; tarso com 7 setas, sendo 2 delas solenídias e 1 eupatídia na extremidade. Propodossoma: placa propodossomal (Figura 17B) inteira, não ornamentada, com 3 pares de setas ( $v i$, ve e $s c i$ ) inseridas em pequenos tubérculos, sendo as setas pré-oculares maiores em comprimento que as demais setas dorsais, corpos pós-oculares visíveis. Histerossoma (Figura 17B): placa mediana presente, não ornamentada; setas dorsais conspicuamente pilosas, afilando-se na extremidade e inseridas em pequenos tubérculos, setas humerais $\left(c_{2}\right)$ e intercalares $\left(f_{1}\right)$ localizadas em placas separadas. Ventre (Figura 17C): 4 pares de setas anogenitais ( $g$, $p s_{1}, p s_{2}$ e $\left.p s_{3}\right)$ e 2 pares de setas aggenitais $\left(a g_{1}\right.$ e $\left.a g_{2}\right)$. Medições dos exemplares coletados neste estudo, seguidas (entre parênteses) pelas medições de 1 dos parátipos medidos são apresentadas a seguir: idiossoma $=305-310,(290)$; razão vi/vi-vi=1,6 $(1,3)$; $v i=38$ (40); $v e=63-64,(60) ; v e-s c i=28-30$ (33); $s c i=55-58$ (58); $c_{1}=48-50$ (48); $c_{l}-d_{l}=53-$ 58 (53); $c_{2}=43-49 ; d_{1}=48-54$ (49); $d_{2}=49-50(53) ; d_{2}-e_{2}=40-43$ (40); $e_{1}=51-55$ (55); $e_{1}$ $e_{l}=25-33(30) ; e_{2}=52-55(55) ; f_{1}=46-49(52) ; h_{1}=30-33(35) ; h_{l}-h_{l}=9-14(13) ; h_{2}=23-24$ (20). Pernas (Figura 18): quetotaxia da coxa para o tarso, (solenídia entre parênteses) I 2 - 1 - 5 - 3 - 5 (1) - 12 (1); II 1 - 1 - 4 - 1 - 5 (1) - 9 (1); III 2 - 1 - 2 - 0 - 5 (1) - 7 (1); IV 2 $1-2-0-5(1)-7$.

\section{MACHO ADULTO:}

Gnatossoma: palpo (Figura 19A) com 3 setas no fềmur, das quais 1 é pilosa, gênu com apenas 1 seta; tíbia com 2 setas e 2 "garras"; tarso com 7 setas, sendo 2 delas solenídias e 1 eupatídia na extremidade. Propodossoma: placa propodossomal (Figura 19B) inteira, não ornamentada, com 3 pares de setas ( $v i$, ve e $s c i$ ) inseridas em pequenos tubérculos, sendo as setas pré-oculares maiores em comprimento que as demais setas dorsais, corpos pós-oculares visíveis. Histerossoma (Figura 19B): placa mediana presente, não ornamentada; setas dorsais conspicuamente pilosas, afilando-se na extremidade e inseridas em pequenos tubérculos. Medições em micrômetros de exemplares coletados neste estudo, seguidas (entre parênteses) das medições dos 2 parátipos analisados são apresentadas a seguir: $v i=30-35$ (33-35); vi-vi=23-25 (28-35); 
$v i-v e=23-25(21-23) ; v e=45-53(51) ; v e-s c i=33-35(28-30) ; s c i=40-46(40-45) ; c_{1}=40-43$ (30-38); $c_{1}-d_{1}=48-62$ (43-48); $c_{2}=30-34$ (33-40); $d_{1}=28-33$ (29-33); $d_{2}=38-43$ (35-40); $d_{2}-e_{2}=43-45$ (37); $e_{1}-e_{1}=30-33(20-25) ; e_{1}=11-18(28) ; e_{2}=38-40$ (35-45); $f_{1}=38-43$ (48); $h_{1}=10-15$ (13-15); $h_{2}=13-18$ (15-18). Pernas (Figura 20): quetotaxia da coxa para o tarso, (solenídia entre parênteses) I 2 - 1 - 4 - 3 - 5 (1) - 12 (2); II 1 - 1 - 4 - 1 - 5(1) - 9 (2); III 2 - 1 - 2 - 0 - 5 (1) - 7 (1); IV 2 - 1 - 2 - 0 - 5 (1) - 7 (1). 


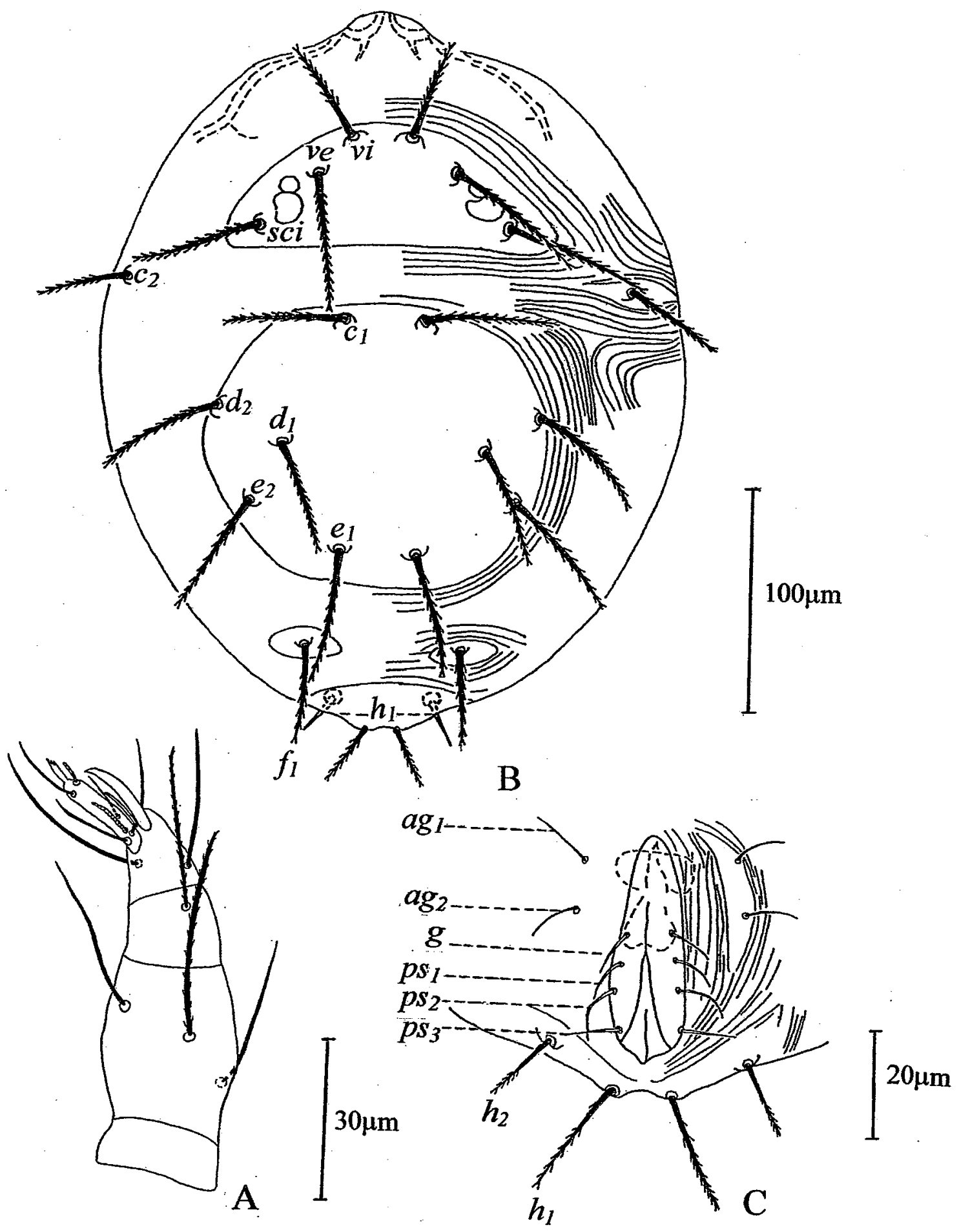

Figura 17 - Fêmea adulta de Agistemus floridanus. A, palpo direito; B, idiossoma; C, abertura anogenital. 

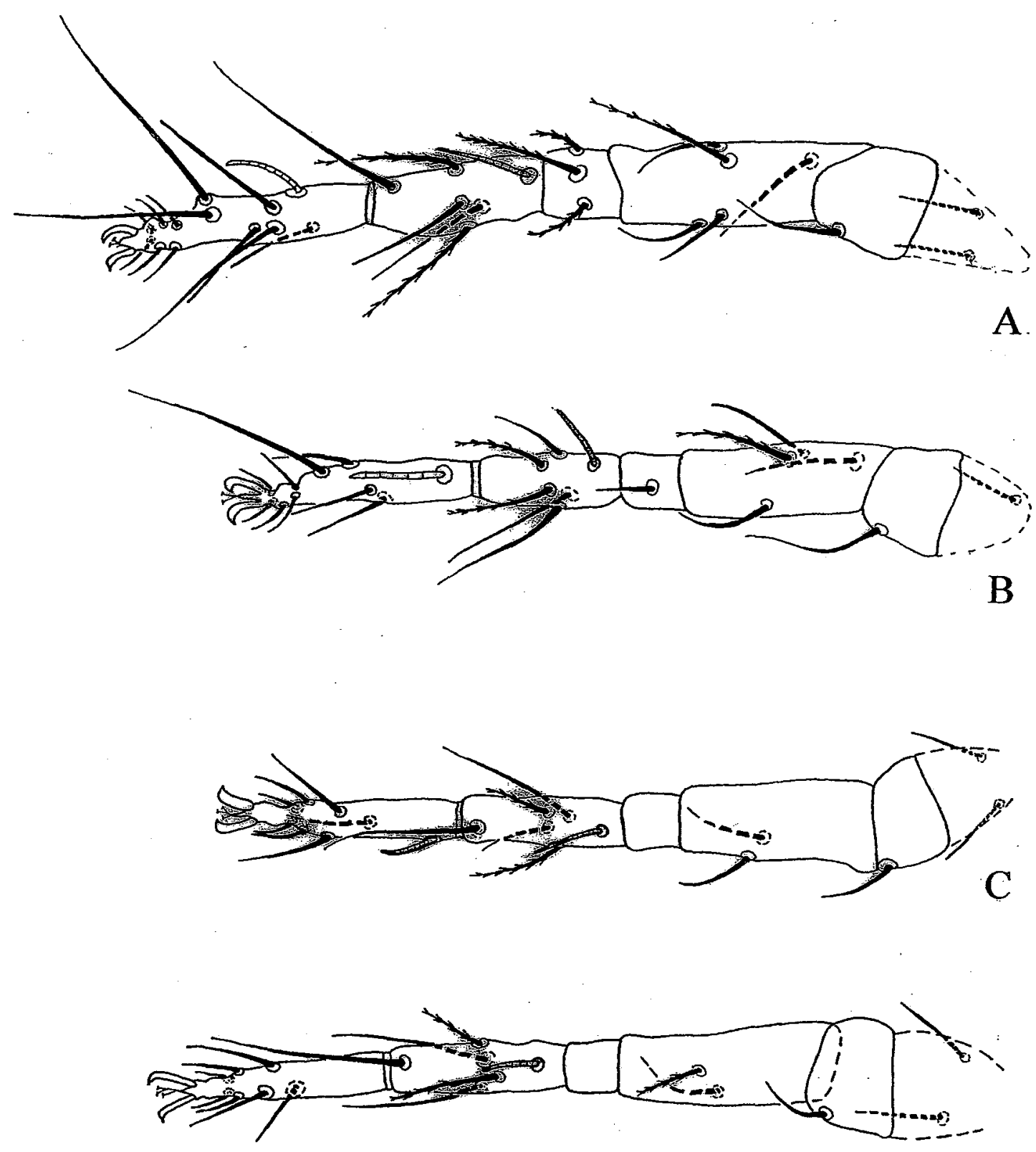

D

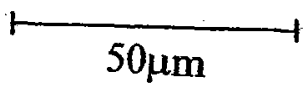

Figura 18 - Fêmea adulta de Agistemus floridanus. A, perna I; B, perna II; C, perna III; D, perna IV. 

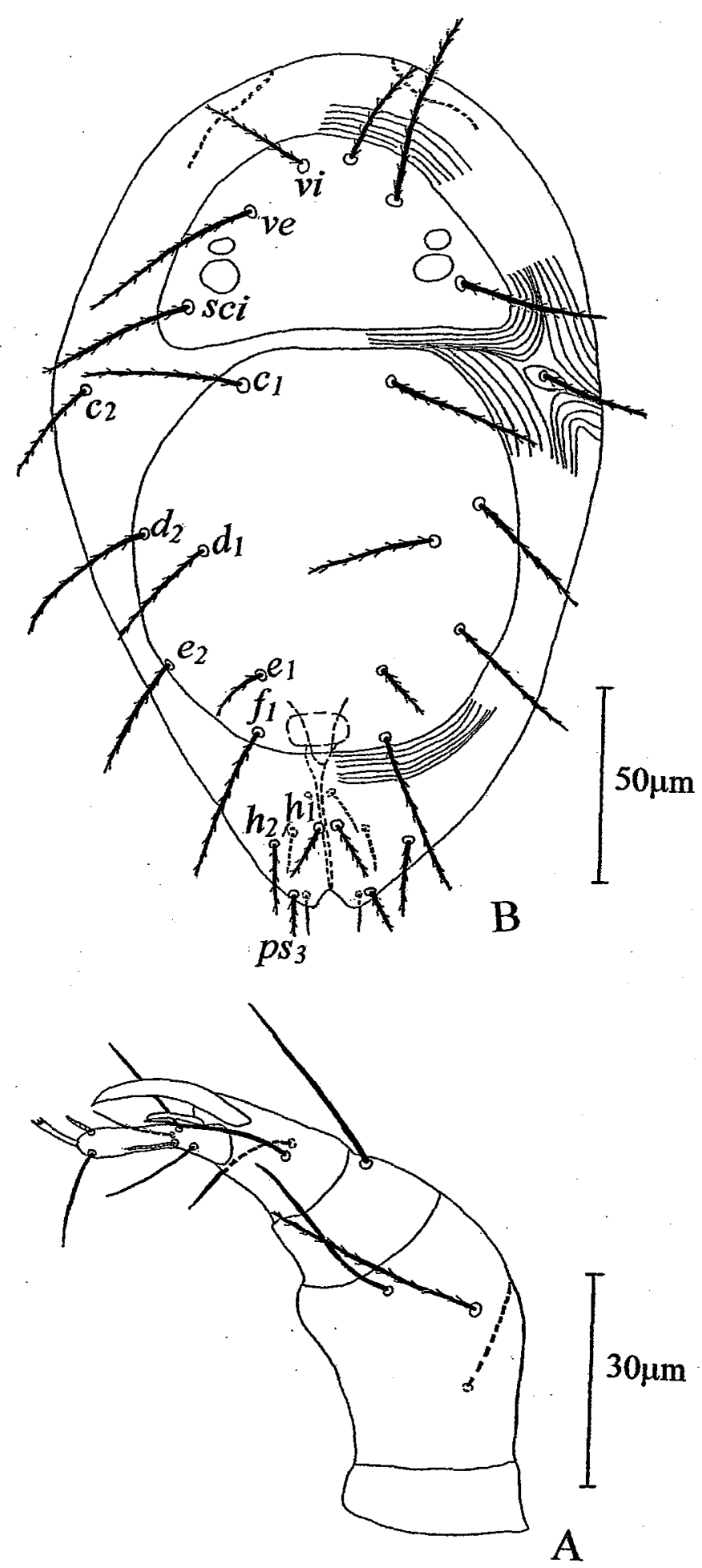

Figura 19 - Macho adulto de Agistemus floridanus. A, palpo direito; B, idiossoma. 

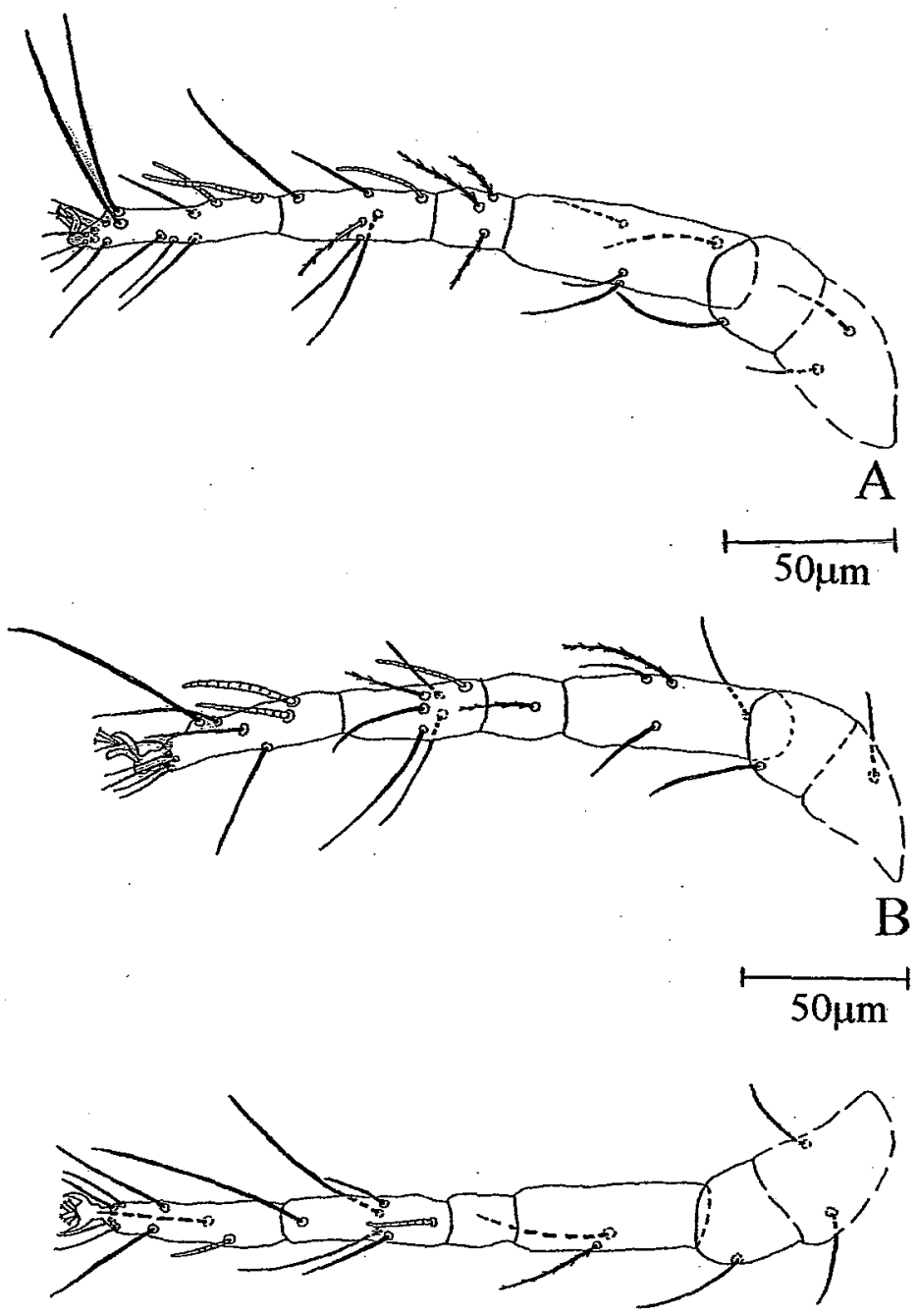

$\mathrm{C}$

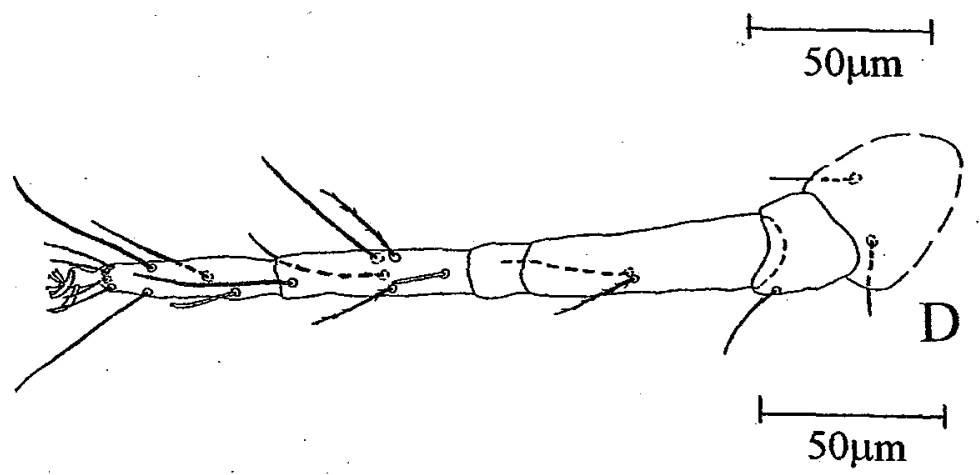

Figura 20 - Macho adulto de Agistemus floridanus. A, perna I; B, perna II; C, perna III; D, perna IV. 
Agistemus sp.

OBSERVAÇÕES: 58 ácaros do gênero Agistemus encontrados nestes estudos eram machos. Estes indivíduos foram identificados apenas até o nível de gênero, por não haver dados suficientes na literatura que permitissem sua identificação específica.

\section{Zetzellia languida Gonzalez}

Zetzellia languida Gonzalez, 1965: 21.

DISTRIBUIÇÃO: África do Sul, Brasil e Zaire.

ESPÉCIMES EXAMINADOS: São Paulo: Pariquera-Açu, S. romanzoffiana IV-00. OBSERVAÇõES: Foi encontrada apenas uma fềmea adulta desta espécie. As medições do exemplar coletado concordam com a descrição original.

Para auxiliar a identificação dos ácaros da familia Stigmaeidae registrados na Mata Atlântica do Estado de São Paulo, foi elaborada a seguinte chave dicotômica. A elaboração foi feita com base nos exemplares coletados neste estudo e no estudo conduzido por Gondim Jr. (2000) na mesma região.

\section{Chave dicotômica para auxiliar na separação de fêmeas adultas de Stigmaeidae encontrados em Arecaceae da Mata Atlântica do Estado de São Paulo.}

1 Placa propodossomal com 4 pares de setas Eustigmaeus sp.

1' Placa propodossomal com 3 pares de setas.

2 Dorso do idiossoma com 7 placas; placa mediana dorsal do histerossoma com 5 pares de setas $\left(c_{l}, d_{l}, e_{l}, d_{2}\right.$ e $\left.e_{2}\right)$; setas $h_{1}$ curtas em relação as demais setas. gênero Agistemus. 3

2'. Dorso do idiossoma com mais de 7 placas; placa mediana com 4 pares de setas $\left(c_{1}, d_{l}, e_{l}\right.$ e $\left.e_{2}\right) ; 1$ par de pequenas placas mediolaterais onde estão inseridas as setas $\left(d_{2}\right)$; Setas $h_{1}$ mais longas que as demais setas dorsais......Zetzellia languida Gonzalez 
31 par de setas aggenitais $\left(a g_{I}\right)$; placa mediana levemente esclerotizada e com estrias longitudinais. Agistemus palmae sp. $\mathrm{n}$.

3'. 2 pares de setas aggenitais $\left(a g_{1}\right.$ e $\left.a g_{2}\right)$; placa mediana bem esclerotizada e sem estrias longitudinais.

4. Placas propodossomal e mediana reticuladas; razão vi/vi-vi

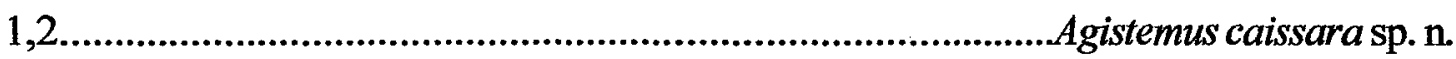
4'. Placas propodossomal e mediana sem reticulações; razão vi/vi-vi

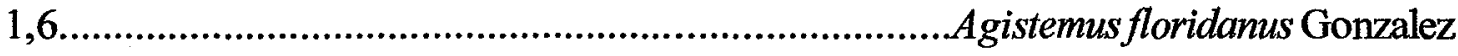

\section{4 - Conclusões}

1) Agistemus é o gênero de Stigmaeidae mais comumente encontrado nas arecáceas amostradas neste trabalho nas regiões de Cananéia, Pariquera-Açu, Piracicaba e São Pedro. 


\section{CONCLUSÕES GERAIS}

* Não considerando os Eriophyidae, os ácaros da familia Phytoseiidae apresentam maior diversidade de espécies nas Arecaceae estudadas.

* Os ácaros da família Ameroseiidae são os mais abundantes em inflorescências de Geonoma brevispatha e Geonoma schottiana.

* Os folíolos das espécies vegetais amostradas apresentam maior diversidade de espécies de ácaros que as inflorescências, brotos terminais e frutos.

* Agistemus é o gênero de Stigmaeidae mais comumente encontrado nas arecáceas amostradas neste trabalho nas regiões de Cananéia, Pariquera-Açu, Piracicaba e São Pedro. 
ANEXO 


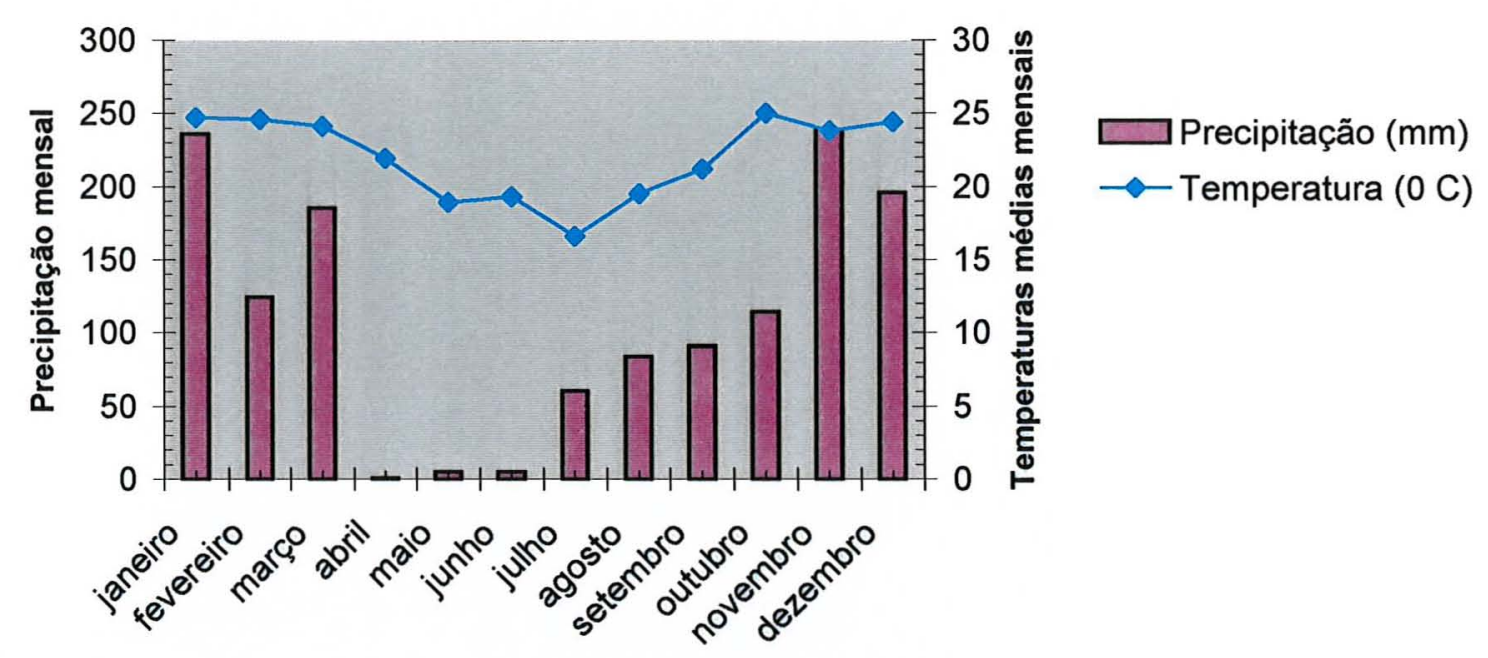

Figura $5{ }^{\circ}$ - Pluviosidade anual $\left(\mathrm{mm}\right.$ : barras) e temperatura média do ar $\left({ }^{\circ} \mathrm{C}\right.$ : linha pontilhada) de janeiro a dezembro de 2000 para região de Piracicaba.

Fonte: posto agrometeorológico da Escola Superior de Agricultura "Luiz de Queiroz" USP.

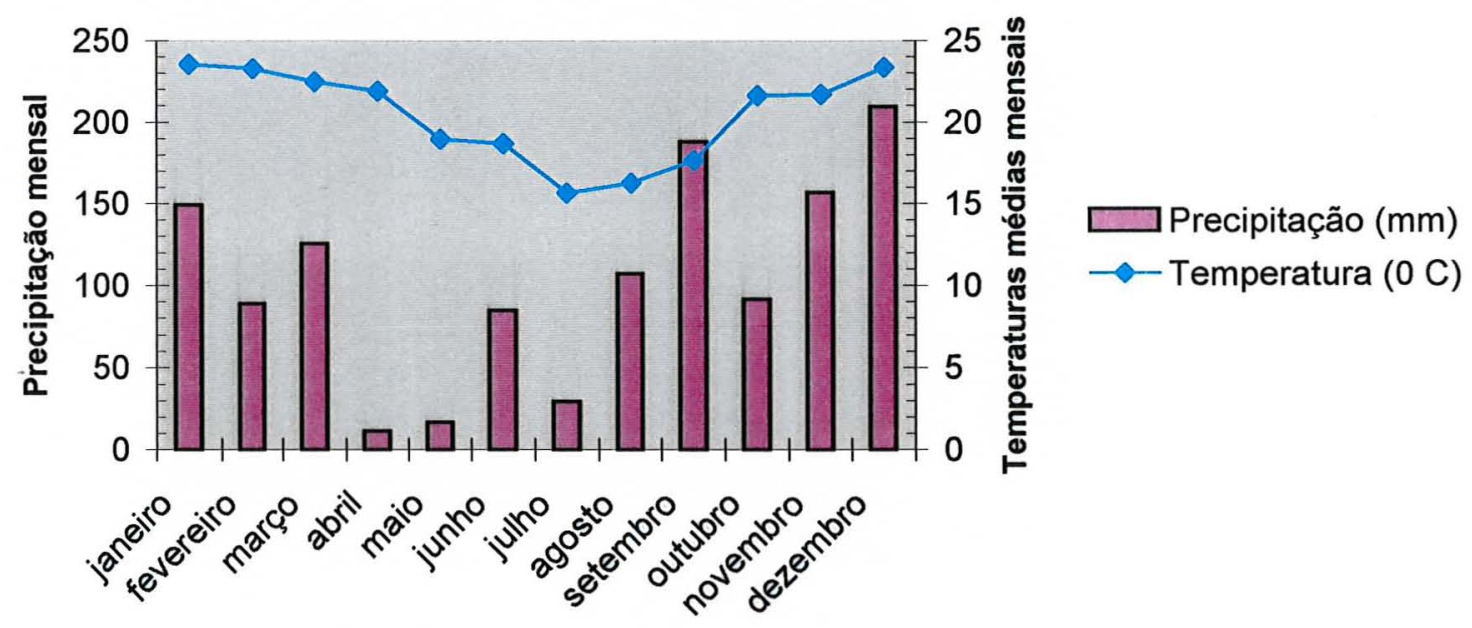

Figura 6 - Pluviosidade anual (mm: barras) e temperatura média do ar $\left({ }^{\circ} \mathrm{C}\right.$ : linha pontilhada) de janeiro a dezembro de 2000 para região de Pariquera-Açu.

Fonte: Instituto Agronômico de Campinas. 


\section{REFERÊNCIAS BIBLIOGRÁFICAS}

ALVES, S. B.; LECUONA, R. E. Epizootiologia aplicada ao controle microbiano de insetos. In: ALVES, S. B. (Ed.). Controle microbiano de insetos. Piracicaba: FEALQ, 1998. cap. 5, p. 97-169.

AMRINE, J. W.; MANSON, D. C. M. Preparation, Mounting and Descriptive Study of Eriophyoid Mites. In: LINDQUIST, E. E.; SABELIS, M. W.; BRUIN, J. (Ed.). Eriophyid mites: their biology, natural enemies and control. Amsterdan: Elsevier, 1996. p. 383-396.

ANDRÉ, H. Note sur le genre Mediolata (Actinedida: Stigmaeidae) et description d'une nouvelle èspece corticicole. Acarologia, v. 18, n. 3, p. 462-474, 1977.

AQUINO, M. L. N.; ARRUDA, G. P. O agente causal da "necrose do olho do coqueiro" em Pernambuco. Recife: Empresa Pernambucana de Pesquisas Agropecuárias, 1967. 33p. (Boletim Técnico, 27).

BORROR , J. D.; DeLONG, D. M. Introdução ao estudo dos insetos. Rio de Janeiro: Edgard Blucher, 1969. 653p.

CHAUDRI, W. M. New mites of the genus Ledermuelleria. Acarologia, v. 7, n. 3, p. 468-486, 1965. 
CHAUDRI, W. M.; AKBAR, S.; RASOOL, A. Taxonomic studies of the mites belonging to the families Tenuipalpidae, Tetranychidae, Tuckerellidae, Caligonellidae, Stigmaeidae and Phytoseiidae: (project A 17 ENT 26). Lyallpur: Pakistan University of Agriculture, 1974. 250p.

CHAZEAU, J. Predaceous insects. In: HELLE, W.; SABELIS, N. W: (Ed.) World crop pests: spider mites, their biology, natural enemies and control. Amsterdam: Elsevier, v. 1B, p. 211-246, 1985.

CHIAVEGATO, L. G. Contribuição ao estudo dos ácaros na cultura algodoeira em algumas regiões do Estado de São Paulo. Piracicaba, 1971. 135 p. Tese (Doutorado)Escola Superior de Agricultura "Luiz de Queiroz". Universidade de São Paulo.

CHIAVEGATO, L. G. Ácaros da cultura algodoeira. Campinas: Instituto Agronômico de Campinas, 1972. 28p. (IAC. Circular, 17).

COLLYER, E. Phytophagous mites and their predators in New Zeland orchards. Agriculture Research, v.7, p. 551-568, 1964.

CROFT, B. A.; MAcRAE, I. V. Biological control of apple mites: impact of Zetzellia mali (Acari: Stigmaeidae) on Typhlodromus pyri and Metaseiulus occidentalis (Acari: Phytoseiidae). Environmental Entomology, n.22, p.865-873, 1993.

DELUCCHI, V. Integrated pest management vs systems management. In: YANINEK, J. S.; HERREN, H. R.(Ed.) Biological control: a sustainable solution to crop pest problems in Africa. Ibadan: International Institute of Tropical Agriculture, 1989. cap. 6, p.51-67.

DOSSE, G. Schadmilben des lebanons und ihre pradatoren. Zeitschrift für Angewandte Entomologie, n.59, p.16-48, 1967. 
EHARA, S. Predaceous mites of the genus Agistemus in Japan (Acarina: Stigmaeidae). Annotationes Zoologicae Japonenses, v.37, n. 4, p. 226-232, 1964.

EHARA, S.; OOMEN-KALSBEEK, F. Stigmaeidae mites associated with tea plants in Indonesia (Prostigmata: Stigmaeidae). International Journal of Acarology, v. 9, n.1, p. 19-26, 1983.

EHARA, S. Two new species of the genus Agistemus Summers from Malasya (Acari, Stigmaeidae). Journal of the Acarological Society of Japan, v. 2, n. 2, p. 79-82, 1993.

EHARA, S.; WONGSIRI, T. Stigmaeidae mites associated with plants in Thailand (Acarina, Stigmaeidae). Kontyû, v. 52, n.1, p. 110-118, 1984.

EICKWORT, G. C. Potencial use of mites as biological control agents of leaf-feeding insects. In: HOYT, M. A.; CUNNINGHAM, G. L.; KNUTSON, L. Biological control of pests by mites. Berkeley: University of California, 1983. cap.6, p. 41-52.

EVANS, R. J. Systematics of Cryosophila (Palmae). Systematic Botanic Monography, v. 46, p. 1-70, 1995.

FAIN, A.; HYLAND, K. E.; AITKEN, T. H. G. Flower mites of the family Ascidae phoretic in nasal cavities of birds (Acarina: Mesostigmata). Acta Zoological et Pathologica Antwerpiensia, v. 69, p. 99-154, 1977.

FAIN, A.; NOTI, M. I.; DUFRÊNE, M. Observations on the mites (Acari) associated with carabidae (Coleoptera) in Belgium. I. Annotated list of the species. International Journal of Acarology, v. 21, n. 2, p. 107-122, 1995. 
FERES, R. J. F. Ácaros (Acari, Arachnida) associados às plantas silvestres no município de São José do Rio Preto, Estado de São Paulo. Botucatu, 1993. 151 p. Tese (Doutorado) - Faculdade "Júlio de Mesquita Filho".Universidade Estadual Paulista.

FERES, R. J. F. Levantamento e observações naturalísticas da acarofauna (Acari: Arachinida) de seringueiras cultivadas (Hevea spp., Euphorbiaceae) no Brasil. Revista Brasileira de Zoologia, v.17, n. 1, p. 157-173, 2000.

FERLA, N. J; MORAES, G. J.de. Ácaros predadores em pomares de maçã no Rio Grande do Sul. Anais da Sociedade Entomológica do Brasil, v.27, n.4, p.649-654, 1998.

FERLA, N. J. Ecología e controle de ácaros (Acari) da seringueira (Hevea brasiliensis Muell. Arg.) no Estado do Mato Grosso. Piracicaba, 2001. 141 p. Tese (Doutorado) Escola Superior de Agricultura "Luiz de Queiroz". Universidade de São Paulo.

FERNANDO, L. C. P.; WICKRAMANANDA, J. R.; ARATCHIGE, N. S. Status of coconut mite, Aceria guerreronis in Sri Lanka. In: INTERNATIONAL WORKSHOP ON COCONUT MITE (Aceria guerreronis), Lunuwilla, 2000. Lunuwilla: Coconut Research Institute, 2000. p. 6.

FERREIRA, J. M. S. Proteção fitossanitária do coqueiral: III. Controle de pragas no campo. Aracaju: Embrapa, CNPCo, 1987. 23p. (Circular Técnica, 7).

FERREIRA, L. G. S. Pupunha (Bactris gasipaes H. B. K.). In: COORDENADORIA DE ASSISTÊNCIA TÉCNICA INTEGRAL. Manual técnico das culturas. Campinas, 1997. p.317-331. 
FLECHTMANN, C. H. W. Phytoseiidae do Estado de São Paulo (Acarina: Mesostigmata). Anais da Escola Superior de Agricultura "Luiz de Queiroz", v.24, p. 247-248, 1967.

FLECHTMANN, C. H. W. Alguns gêneros de Raphignathoidea (Acari, Prostigmata) do Estado de São Paulo. Anais da Escola Superior de Agricultura "Luiz de Queiroz", v. 25, p. $173-175,1968$.

FLECHTMANN, C. H. W. Ácaros de importância agrícola. São Paulo: Livraria Nobel, 1972. 189 p.

FLECHTMANN, C. H. W. Elementos de acarologia. São Paulo: Livraria Nobel, 1975. $344 \mathrm{p}$.

FLECHTMANN, C. H. W. New records of mites from Brazil with description of two new species in the genus Oligonychus Berlese (Acari: Tetranychidae). Revista Brasileira de Biologia,v.41, n.4, p. 861-866, 1981.

FLECHTMANN, C. H. W. Eustigmaeus bryonemus, sp. n., a moss-feeding mite from Brasil (Acari, Prostigmata: Stigmaeidae). Revista Brasileira de Zoologia , v.2, n. 6, p. 387-391, 1985.

FLECHTMANN, C. H. W. Cocos weddelliana Wendl. (Palmae: Arecaceae), a new host plant for Eriophyes guerreronis (Keifer, 1965) (Acari: Eriophyidae) in Brazil. International Journal of Acarology, v. 15, p. 241, 1989.

FLECHTMANN, C. H. W. Amrineus cocofolius n.g., n.sp. (Acari: Eriophyidae) from Brazil. International Journal of Acarology, v. 20, p.57-59, 1994. 
FLECHTMANN, C. H. W. On the mite fauna of bamboo leaves in the Parque Nacional do Itatiaia, Rio de Janeiro, Brazil. International Journal of Acarology, v. 21, n.4, p. 243-252, 1995.

FLECHTMANN, C. H. W. Mite (Arthropoda: Acari) associates of palms (Arecaceae) in Brazil. II. Redescription of Amrineus cocofolius Flechtmann, 1994 (Acari: Eriophyidae). International Journal of Acarology, v.23, n.3, p. 195-197, 1997a.

FLECHTMANN, C. H. W. Mite (Arthropoda: Acari) associates of palms (Arecaceae) in Brazil.III. Eutetranychus nomurai n.sp. (Tetranychidae) from Attalea phalerata Mart. International Journal of Acarology, v.23, n.4, p. 269-273, 1997 b.

FLECHTMANN, C. H. W. Mite (Arthropoda: Acari) associates of palms (Arecaceae) in Brazil. IV. Description of two new species in the family Eriophyidae. International Journal of Acarology, v.24, n.2, p. 113-117, 1998.

FLECHTMANN, C. H. W.; FERNANDO, C. P. Dolichotetranychus cocos n.sp. from the perianth of coconuts in Sri Lanka (Acari: Tenuipalpidae). International Journal of Acarology, v. 26, n. 2, p. 145-153, 2000.

FLECHTMANN, C. H. W.; MORAES G. J. de. Biodiversidade de ácaros no Estado de São Paulo. In: BRANDÃO, R. F.; CANCELLO, E. M. (Ed.) Biodiversidade do Estado de São Paulo, Brasil: síntese do conhecimento do final do século XX, 5: invertebrados terrestres. São Paulo: FAPESP,1999. cap.6, p.58-63.

FleChtmanN, C. H. W.; MORAeS, G. J. de. Mites of São Paulo State. http:www. bdt.org.br/bdt/acarosp, (12 set. 2000). 
FLECHTMANN, C. H. W; KREITER, S.; ETIENNE, J. et al. Plant mites (Acari) of the French Antilles - 5. Stigmaeidae (Prostigmata). Acarologia, v. 40, n. 4, p. 401-406, 1999.

FLECHTMANN, C. H. W.; SANTANA, D. L. Q. Ocorrência de Notostrix attenuata Keifer (Acari: Eriophyidae) em coqueiros no Brasil. In: CONGRESSO BRASILEIRO DE ENTOMOLOGIA, 16., Salvador, 1997. Resumos. Salvador: Sociedade Entomológica Brasileira, 1997. p. 40.

FURIA, L. R. R. Características e usos de juçara (Euterpe edulis). In: ENCONTRO SOBRE PRODUÇÃO DE PALMITO, Piracicaba, 1993. Piracicaba: Calq, 1993. p.13.

GASTON, K. J. What is biodiversity? In: GASTON, K. J. (Ed.) Biodiversity: a biology of numbers and difference. Massachussetts: Blackwell Science, 1996. p. 1-9.

GERSON, U. Mites of the genus Ledermuelleria (Prostigmata: Stigmaeidae) associated with mosses in Canada. Acarologia, v. 13, n. 2, p. 319-343, 1972.

GERSON, U.; SMILEY, R. L. Acarine biocontrol agents. London: Chapman \& Hall, 1990. 174p.

GERSON, U.; MEYER, M. K. P. S. Neilstigmaeus, a new australian genus in the family Stigmaeidae (Acari: Prostigmata). Acarologia, v. 36, n. 3, p. 219-222, 1995.

GONDIM Jr., M. G. C. Ácaros de palmeiras (Arecaceae) em áreas dos Estados de São Paulo e Pernambuco. Piracicaba, 2000. 161 p. Tese (Doutorado) - Escola Superior de Agricultura "Luiz de Queiroz". Universidade de São Paulo. 
GONDIM Jr., M. G. C.; MORAES, G. J. de. Phytoseiidae mites (Acari: Phytoseiidae) associated with palm trees (Arecaceae) in Brazil. Systematic and Applied of Acarology, v. 6, p. 65-94, 2001.

GONDIM Jr., M. G. C.; FLECHTMANN, C. H. W.; MORAES, G. J. de. Mite (Arthropoda: Acari) associates of palm (Arecaceae) in Brazil. IV. Descriptions of four new species in the Eriophyoidea. Systematic and Applied of Acarology v. 5, p. 99-110, 2000.

GONSALVES, A. D. O babaçu: considerações científicas, técnicas e econômicas. Rio de Janeiro: Ministério da Agricultura, 1955. 331p. (Série Estudos e Ensaios, 8)

GONZALEZ - RODRIGUEZ, R. H. Four new mites of the genus Agistemus Summers, 1960 (Acarina: Stigmaeidae). Acarologia, v. 5, n. 3, p. 342-350, 1963.

GONZALEZ - RODRIGUEZ, R. H. A taxonomic study of the genera Mediolata, Zetzellia and Agistemus (Acarina: Stigmaeidae). University of California Publications in Entomology, v. 41, p. 1-64, 1965.

HALLIDAY, R. B. Revision of the Australian Ameroseiidae (Acarina: Mesostigmata). Invertebrate Taxonomy, v. 10, p. 179-201, 1997.

HAQ, M. A. Distribution of the coconut mite Aceria guerreronis in Peninsular India and adjacent islands. Entomon, v. 24, n. 4, p. 371-379, 1999.

HOYT, S. C. Integrated chemical control of insects and biological control of mites on apple in Washington. Journal of Economic Entomology, v. 62, p. 74-86, 1969. 
INSERRA, R. Observazion morfologiche ed appunti di biologia su Zetzellia graeciana Gonzalez (Acarina: Stigmaeidae). Bollettino di Zoologia Agrária e di Bachicoltura, n.10, p.85-119,1970.

JARDIM, M. A. G.; ANDERSON, A. B. Manejo de populações nativas de açaizeiro no estuário amazônico. Boletim de Pesquisa Florestal, v. 15, p. 1-8, 1987.

JEPPSON, L. R.; KEIFER, H. H.; BAKER, E. W. Mites injurious to economic plants. Berkeley: University of California Press, 1975. 614 p.

JOLY, A. B. Botânica: introdução à taxonomia vegetal. São Paulo: Editora Nacional, 1991. 777p.

KRANTZ, G.W. A manual of acarology. Corvalis: Oregon State University Bookstores, 1978. 509 p.

LAING, J. E.; KNOP, N. F. Potential use of predaceous mites other than Phytoseiidae for biological control of orchards pests. In: HOY, M. A; CUNNINGHAM, G. L.; KNUTSON, L. (Ed.). Biological control of pests by mites. Berkeley: Division of Agriculture and Natural Resources University of California, 1983. cap.2, p. 28-35.

LORENZI, H. Árvores brasileiras: manual de identificação e cultivo de plantas arbóreas nativas do Brasil. Nova Odessa: Editora Plantarum, 1993. 384p.

LORENZI, H. Palmeiras do Brasil: nativas e exóticas. Nova Odessa: Editora Plantarum, 1996. 303p.

MARIAU, D. Aceria (Eriophyes) guerreronis: an important pest of African and American coconut grooves. Oléagineux, v. 32, n. 3, p. 109-111, 1977. 
MARIAU, D. Comportament d' Eriophyes guerreronis Keifer à l'egard de différents variétés de cocotiers. Oléagineux, v. 41, p. 499-505, 1986.

MATIOLI, A. L. Aspectos taxonômicos e bioecológicos de ácaros Stigmaeidae (Acari) e sua potencialidade de predação sobre Brevipalpus phoenicis (Geijskes) (Acari: Tenuipalpidae) na cultura do citros. Jaboticabal, 2002. 86p. Tese (Doutorado). Faculdade de Ciências Agrárias e Veterinárias, Universidade Estadual Paulista.

MEYER, M. K. P. S. Some Stigmaeidae mites from South Africa (Acari: Trombidiformes). Acarologia, v. 11, n.2, p. 227-271, 1969.

MEYER, M. K. P.; UECKERMANN, E. A. African Raphignathoidea (Acari: Prostigmata). Pretoria: Republic of South Africa Department of Agriculture and Water Supply, 1989. 58p. (Entomology Memoir, 74).

MINEIRO, J. L. C. Ácaros edáficos do município de Piracicaba, Estado de São Paulo, com ênfase na família Ascidae (Gamasida), Jaboticabal, 2000. 120p. Dissertação (Mestrado) - Faculdade de Ciências Agrárias e Veterinárias Campus de Jaboticabal, Universidade Estadual Paulista.

MOORE, D.; HOWARD, F. W. Coconuts In: LINDQUIST, E. E.; SABELIS, M. W. BRUIN, J (Ed.) Eriophyid mites: their biology, natural enemies and control. Amsterdam: Elsevier, 1996. p. 561-570.

MORAES, G. J. de. Perspectivas para uso de predadores no controle de ácaros fitófagos no Brasil. Pesquisa Agropecuária Brasileira, v. 27, p. 263-270, 1992.

MORAES, G. J. de. Controle biológico de ácaros fitófagos com ácaros predadores. In: PARRA, J. R. P.; CORREA- FERREIRA, B. S.; BOTELHO, P. S. M. (Ed.). Controle Biológico no Brasil: parasitóides e predadores. 2002. No prelo. 
MYERS, N. The biodiversity crisis and the future of evolution. The Environmentalist, v. 16, p. 49-53, 1996.

NAIR, C. P. R.; KOSHY, P. K. Studies on coconut eriophyid mite, Aceria guerreronis Keifer in India. In: INTERNATIONAL WORKSHOP ON COCONUT MITE (Aceria guerreronis), Lunuwila, 2000. Lunuwilla: Coconut Research Institute, 2000. p.7.

NASKRECKI, P.; COLWELL, R. K. Monographs: systematics and host plant affiliations of hummingbird flower mites of the genera Tropicoseius Baker \& Yunker and Rhinoseius Baker \& Yunker (Acari: Mesostigmata: Ascidae). Maryland: Entomological Society of America, 1998. 185p.

OCHOA, R.; AGUILAR, H.; VARGAS, C. Ácaros fitófagos da America Central: guia ilustrada. Turrialba: CATIE, 1991. 251p.

OOMEN, P. A. Sudies on Population Dynamics of the Scarlet Mite, Brevipalpus phoenicis, a Pest of Tea in Indonesia. Mededelingen Landbouwhogeschool Wageningen, v. 82, n.1, p.1-88, 1982.

OSMAN, A. A.; ZAKI, A. M. Studies on the predation efficiency of Agistemus exsertus Gonzales (Acarina, Stigmaeidae) on the eriophyid mite Aculops lycopersici (Massee). Anzeiger Schadling Pflanzenschutz, v.59, p. 135-136, 1986.

ROBBS, C. F.; PERACCHI, A. L. Sobre a ocorrência de um ácaro prejudicial ao coqueiro (Cocos nucifera L.) In: REUNIÃO DE FITOSSANITARISTAS DO BRASIL, 9, Rio de Janeiro, 1965. Anais. Rio de Janeiro: Ministério da Agricultura, 1965. p.65-70. 
SANTANA, D. L. Q.; FLECHTMANN, C. H. W. Mite (Arthropoda: Acari) associates of palms (Arecaceae) in Brazil. I. Present status and new records. Revista Brasileira de Zoologia, v. 15, n.4, p. 959-963, 1998.

SANTANA, D. L. Q.; FLECHTMANN, C. H. W.; LIMA, M. F. Novos ácaros do coqueiro no Brasil. Aracaju: EMBRAPA, CNPCO, 1994. 4p.

SANTOS, M. A.; LAING, J.E. Stigmaeidae predators. In: HELLE, W.; SABELIS, M. W. Spider mites: their biology, natural enemies and control. Amsterdam: Elsevier Science, 1985. v.1B, p. 197-203.

SEPASGOSARIAN, H. I. Addendum of the world species of the superfamily Raphignathoidea (Acari). Entomological Mitteilungen Zoological Museum, v. 10, n. 139 , p. $75-84,1990$.

SIMONS, N. H. R. Una especie nueva de Stigmaeidae (Agistemus mendonzensis $\mathrm{sp} . \mathrm{n}$. Acari) y llave para las espécies del género. Revista de Investigaciones Agropecuarias. Patologia Vegetal, v. 4, n. 4, p. 55-67, 1967.

SMILEY, R. L.; KNUTSON, L. Aspects of taxonomic research and services relative to mites as biological control agents. In: HOY, M. A.; CUNNINGHAM, G.; KNUTSON, L. (Ed.) Biological control of pests by mites. Berkeley: University of California, Division of Agriculture and Natural Resources, 1983. cap.3, p. 148-164.

SOLIMAN, Z. R. Genus Ledermuelleriopsis Willmann from Lattakia, Syria (Acari: Prostigmata) with a description of two new species. Acarologia, v. 17, n. 2, p. 243$247,1975$. 
SUMMERS, F. M. Several Stigmaeidae mites formerly included in Mediolata redescribed in Zetzellia Ouds., and Agistemus, new genus. Proceedings of the Entomological Society of Washington, v. 62, n. 4, p. 233-247, 1960.

SUMMERS, F. M. The genus Stigmaeus (Acarina: Stigmaeidae). Hilgardia, v. 33, n. 10, p. 491-537, 1962.

SUMMERS, F. M. Genera of the mite family Stigmaeidae Oudemans (Acarina). Acarologia, v.8, n. 2, p. 230-249, 1966.

SUMMERS, F. M.; EHARA, S. Reevaluation of the taxonomic characteres in four species of the genus Cheylostigmaeus Willmann (Acarina). Acarologia, v. 7, n. 1, p. 49-62, 1965.

SUMMERS, F. M.; PRICE, D. W. New and redescribed species of Ledermuelleria from North America (Acarina: Stigmaeidae). Hilgardia, v. 31, n. 10, p. 369-387, 1961.

TANAKA, M. Fundamental studies on the utilization of the natural enemies in citrus grove in Japan. I. The binomics of natural enemies of the most serious pests. II Stethorus japonicus (Coccinellidae) a predator of the citrus red mite, Panonychus citri (Mcgregor). Bulletin of the Horticultural Research Station, (Japan), n. 4, v. D, p.22-42, 1966.

TSENG, Y. H. Mites of the family Stigmaeidae of Taiwan with key to genera of the world (Acarina: Prostigmata). Phytopathologist and Entomologist, NTU, v. 9, p. 1$52,1982$.

VAN DER GEEST, L. P. S.; ELLIOT, S. L.; BREEUWER, J. A. J. Diseases of mites. Experimental and Applied Acarology, v. 24, p. 497-560, 2000. 
VILA, W. M.; FLECHTMANN, C. H. W. Ácaros em essências florestais. Silvicultura em São Paulo, v. 7, p.99-102, 1970.

WALTER, D. E.; PROCTOR, H. C. Mites: ecology, evolution and behaviour. New York: CABI Publishing, 1999. 320p.

WHITE, N. D.; LAING, J. E. Field observations of Zetzellia mali (Ewing)(Acarina: Stigmaeidae) in Southern Ontario apple orchards. Proceedings of Entomological Society of Ontario, v. 108, p. 23-30, 1978.

WOOD, T. G. Mites of the Genus Ledermuelleria Oudms. (Prostigmata, Stigmaeidae) from New Zealand, with records of one species from southern pacific islands. New Zealand Journal of Science, v. 9, n. 1, p. 84-102, 1966.

WOOD, T. G. New Zealand mites of the family Stigmaeidae (Acari: Prostigmata). Transactions of the Royal Society of New Zealand, v. 9, n. 9, p. 93-139, 1967.

WOOD, T. G. Stigmaeidae (Acari: Prostigmata) from the British Solomon Islands. Acarologia, v. 13, n.1, p. 65-87, 1971.

WOOD, T. G. New and redescribed species of Ledermuelleria Oudms. and Villersia Oudms. (Acari: Stigmaeidae) from Canada. Acarologia, v. 13, n. 2, p. 301-318, $1972 \mathrm{a}$.

WOOD, T. G. Redescription of Stigmaeus youngi (Hirst): Acari, Stigmaeidae. Acarologia, v. 14, n. 2, p. 163-165, 1972 b.

WOOD, T. G. Redescription of Cheylostigmaeus longisetosus Willmann (Acari: Stigmaeidae). Acarologia, v. 16, n. 1, p. 62-67, 1974. 
WOOLHOUSE, M. E. J.; HARMSEN, R. The mite complex of the foliage of a pesticide-free apple orchard: population dynamics and habitat associations. Proceedings of the Entomological Society, v. 115, p. 1-11, 1984.

YANINEK, J. S.; HERREN, H. R.; GUTIERREZ, A. P. Dynamics of Mononychellus tanajoa (Acari: Tetranychidae) in Africa: seasonal factors affecting phenology and abundance. Environmental Entomology, v. 18, n. 4, p. 625-631, 1989.

ZAHER, M. A.; AFIFY, A. M.; GOMA, E. A. Survey and biology of Agistemus exsertus Gonzalez in U. A. R., with description of the immature stages. Angewandte Entomologie, v. 67, p. 272-279, 1971. 